\title{
ESCLAVITUD DE POR ACÁ, LA DE ÉBANO Y LA DE LOS OTROS, Y LA HISTORIA PARALELA. SEGUNDA PARTE: AÑOS 1825 D.C. - 2006 D.C.
}

\section{SLAVERY HERE, THE EBONY AND THE OTHER, AND THE PARALLEL STORY. PART II: YEARS 1825 D.C. - 2006 D.C.}

Carlos Gamero Esparza: Universidad Inca Garcilaso de la Vega (Perú) carlos.gamero@ozu.es

\section{CURRÍCULUM VITAE}

Reconocido Periodista peruano del Diario OJO de Lima. Licenciado con Diploma de Honor en la Universidad Inca Garcilaso de la Vega.

\section{RESUMEN}

Durante tres siglos y medio, 10 ó 15 millones de negros africanos fueron trasladados forzosamente a América como esclavos. Más de 12 millones de personas son víctimas del trabajo forzoso en el mundo, según un informe de la Organización Internacional del Trabajo. El término "trata" es un eufemismo conveniente que busca eliminar la dimensión ética del concepto implícito en "la trata de esclavos". Un término mucho más apropiado es el de "comercio negrero", pues la palabra "negrero" ha conservado la carga de infamia que implica rebajar al ser humano a la categoría de mercancía. En cualquier caso, ambos términos se nos presentan en el siglo XXI como lejanos, como desprovistos de verdadero significado. Y ese es precisamente el objetivo de esta dimensión gráfica: aproximar a nosotros el concepto de la 
esclavitud, procurar, en lo posible a través de la fotografía, que adquiera vida la institución de la esclavitud.

\title{
PALABRAS CLAVE
}

Esclavitud - Negros africanos - Evolución - Mercancía

\begin{abstract}
For three centuries and a half, 10 to 15 million black Africans were forcibly moved to America as slaves. Over 12 million people are victims of forced labor in the world, according to a report by the International Labour Organization. The term "trafficking" is a convenient euphemism that seeks to eliminate the ethical dimension of the concept behind "the slave trade." A more appropriate term is "slave trade" since the word "slave" has kept the load of infamy that involves human beings down to the category of goods. In any case, both terms are presented to us in the XXI century as far as devoid of real meaning. And that is precisely the aim of this size chart: to bring us the concept of slavery, seek, where possible through photography, which come alive the institution of slavery.
\end{abstract}

\section{KEY WORDS}

Slavery - African Black - Evolution - Merchandise

\section{ÍNDICE}

1. Introducción

2. La historia paralela... de una tragedia humana, provocada por homo sapiens... 
2.1. Siglo XIX

2.2. Siglo $X X$

2.3. Siglo XXI

3. Esclavitud del siglo XXI

4. Epílogo

5. Notas al margen de la segunda parte

6. Origen de las ilustraciones

\section{TEXTO:}

\section{Introducción}

"Durante tres siglos y medio, 10 ó 15 millones de negros africanos fueron trasladados forzosamente a América como esclavos (Klein 25)... ¿Cómo pudo resistir la conciencia cristiana un crimen histórico tan horrible? Lo toleró sin perder por eso el sueño. La conciencia renacentista e ilustrada era mucho menos cristiana que la conciencia medieval".

José María Iraburu. (Nota_1)

"Nos oprimen en obrajes y cañaverales, cocales, minas y cárceles en nuestros pueblos... nos recogen como brutos y ensartados nos entregan a las haciendas para laborar... a veces sin nada. Los indios rinden la vida con vómitos de sangre." José Gabriel Condorcanqui. Tupac Amaru II (Nota_2)

"...a pesar de esfuerzos aislados, el porcentaje de mortalidad en la travesía era alto (se ha calculado que en algunos años pasó del 50\%) y al llegar los cargamentos 
humanos al Callao, se producía una inspección oficial y a los que no tenía contrato, se les alineaba en la cubierta para ponerlos a disposición de los interesados; en los periódicos solían aparecer, además, avisos ofreciendo chinos". Jorge Basadre. (Nota_3)

"Más de 12 millones de personas son víctimas del trabajo forzoso en el mundo, según un informe de la Organización Internacional del Trabajo (OIT)". BBC Mundo. (Nota_4)

Les debemos el acervo cultural y una idiosincrasia única; por ellos resuena la magia de Perú Negro y la melancolía del yaraví; sus manifestaciones plásticas y coreográficas son el reflejo de un folclor que causa asombro en el mundo entero; a ellos les debemos el ingenio y la picardía criolla y un arte culinario sin cuento. Son gentes de acá y del otro lado del charco, son gentes de tantas partes y de tantos colores. A ellos, no importa si vinieron de allá o de aquicito nomás, les debemos nuestra identidad como pueblo, un pueblo multirracial y multisecular que es el resumen de todas las risas y todas las lágrimas y todos los sueños y todas las pasiones $\mathrm{y}$ todas las esperanzas y todas las desesperanzas y todos los gritos y todas las canciones y todas las heridas y todos los cielos y todas las tierras y todos los bosques y todas las montañas del Perú profundo. Son gentes de todos los orígenes a los que se sumó la presencia europea, que también dejó su cuota.

El establecimiento forzado de unos y el sometimiento del resto de los pobladores de estos reynos del Pirú, tras la Conquista, hizo que estas etnias pasaran a formar parte de un paisaje humano donde ahora no cabe ninguna objeción racista ni consideraciones exclusivistas pues aquí, en el Perú de hoy, si uno no tiene los rasgos de un tipo étnico determinado, tiene el del otro... o ambos o varios a la vez. Por eso se dice, no sin razón, que el Perú es el país de todas las sangres, pues en este viejo suelo 
conviven, juntos -y muchas veces revueltos - negros, mulatos, zambos, mestizos, blancos, andinos, orientales, selváticos, etc. No en vano ese gran maestro de nuestras letras, que fue don Ricardo Palma, acuñó en una de sus memorables Tradiciones Peruanas aquella frase indeleble que lo explica todo... en el Perú quien no tiene de inga, tiene de mandinga. De hecho, ésta, más que un recuento histórico, es un sacarse el sombrero por aquellos ingas y mandingas que crearon lo que somos ahora; hombres y mujeres que por causa de su origen y/o color de piel fueron arrebatados de sus pueblos para ser explotados o convertidos en mercadería humana, todo a cambio de poco o nada. Su cruel destino, empero, no fue óbice para que nos dejaran con sus descendientes un legado inmemorial que se escucha en las canciones criollas o se saborea en un sabroso plato típico o se disfruta en el arte pictórico o en un sinfín de manifestaciones culturales; es una herencia que mezcla el aroma de sus tierras lejanas con el misterio de civilizaciones milenarias. Ahora, a los siglos, sus creencias, su filosofía de vida, su amor por la vida, su forma de encarar lo cotidiano, su irresistible creatividad, nos enseñan a ser más humanos. A ellos, pues, sin citar a uno por no omitir a otro, les sobran motivos para el orgullo: su fortaleza espiritual les hizo soportar las pruebas más duras; el negro nunca perdió la sonrisa y el andino jamás dejó de cantarle a sus apus, los señores de sus montañas sagradas. Ellos nos han enseñado una lección de vida que debemos valorar, de una vez por todas: que la humanidad es una sola, no es de ningún color, no es patrimonio de nadie, que ni siquiera la genética puede resistirse al hecho de que el colorinche de mis poros tenga algo que ver con esos ridículos prejuicios y estereotipos tejidos alrededor de unos prójimos cuyos marrones o negros no se los pintaron ellos.

Ésta es, pues, una modesta cronología, diseñada y adaptada en base a datos encontrados en diversas fuentes, la misma que pretende mostrar su rostro humano inmenso y la dimensión histórica y trágica que alcanzó en nuestro país la esclavitud y la explotación del hombre por sus semejantes. Los angoleños del África y los 
mitayos andinos y los coolies chinos de Macao -tres pueblos y un destino casi común - nos cuentan ahora el drama que ellos no se buscaron. Ellos cuentan cómo llegaron a este país de desconciertos, cómo tuvieron que someterse a unos conquistadores, cómo lloraron y cómo rieron y cómo nacieron y cómo murieron y cómo lucharon... y cómo nos enseñaron a amar la libertad. Ellos están aquí, y nos hablan...

Nota: En la presente hemos considerado oportuno intercalar también algunos datos de acontecimientos paralelos relacionados con lo tratado en este trabajo, ocurridos en otras latitudes, para ubicarlas comparativamente en el tiempo y el espacio, que de alguna forma influyeron en nuestro devenir histórico. De modo que ésta es la historia paralela de la esclavitud en el Perú (y el mundo) desde el siglo XV hasta el XXI, con el fin de ayudar a comprender la coyuntura en la que esta se desarrolló.

\section{La historia paralela... de una tragedia humana, provocada por homo sapiens...}

\subsection{Siglo XIX}

1825

19 de septiembre. Simón Bolívar restablece la esclavitud a quienes no estén en el ejército. Las protestas no se hicieron esperar.

1826

Protestas. Estalla el primero de una serie de levantamientos de esclavos en la Hacienda San Pedro, en el valle de Lurín, al sur de Lima, lo mismo que se repite en 1833 y en 1844 . 
Intereses de por medio. Presionados por los antiesclavistas, los ingleses ocupan los islotes de Fernando Poo que estaban en poder de España.

1828

La Constitución peruana de este año, en su artículo 152, señala que: "Nadie nace esclavo en la República; tampoco entra de fuera ninguno que no quede libre". Implícitamente esta constitución decía que aquellos que son esclavos lo seguirán siendo.

El acuerdo de Guayaquil. Uno de los artículos del tratado entre Perú y Colombia, firmado en Guayaquil el 22 de septiembre, estipulaba que: Las partes contratantes se comprometen a cooperar a la abolición y extirpación del tráfico de esclavos de África...; declaraban que los que traficasen en esclavos o en buques cargados de esclavos procedentes de la costa de África con bandera de una $\mathrm{u}$ otra parte (peruana o colombiana), debían considerarse como culpables del crimen de piratería.

1830

México libre. La esclavitud queda suprimida para siempre en México.

Guillermo IV, rey del Reino Unido y duque de Clarence (n. 1735 - m. 1837), se opuso a la abolición de la esclavitud de 1807 en la Cámara de los Lores. Al final tendría que ceder a las presiones de los abolicionistas. 
No a la esclavitud... a medias. Portugal suprime la trata de negros al sur del Ecuador... pero sigue manteniéndola en Brasil.
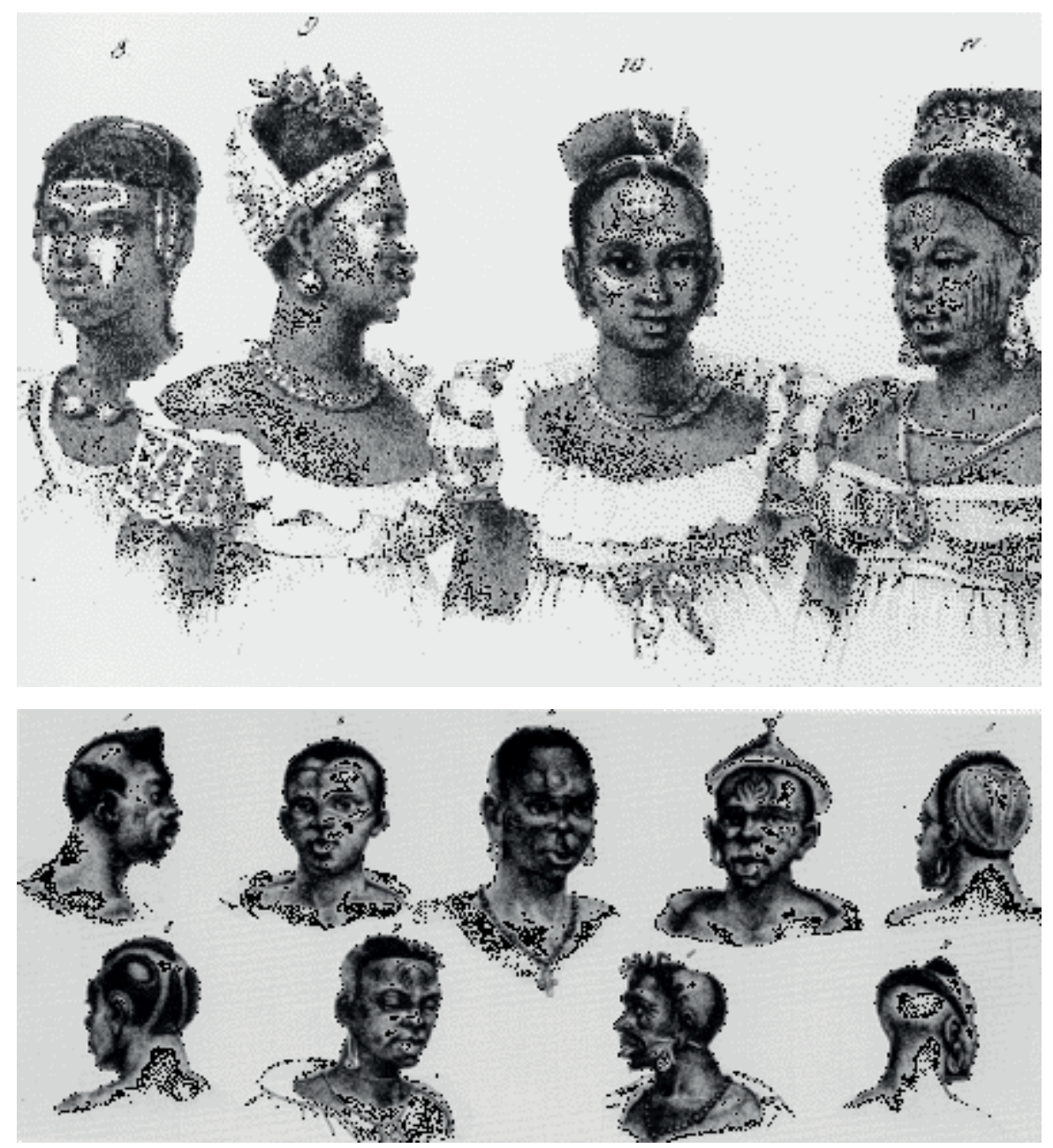

Figuras 40 (a y b). Dos litografías de diversas etnias de esclavos negros en Brasil, tomadas por Jean-Baptiste Dubret para ilustrar su obra Voyage Pittoresque et Historique au Bresil, Rio de Janeiro. Fascimil copiado en 1965 de la versión original de 1834. Ilustración tomada de African Presence 1492-1992 - Schomburg Exhibit. 
1831

Pioneros en Europa. Inglaterra y Francia acuerdan mutuamente abolir totalmente la trata de negros.

1832

Inglaterra decide aplicar su abolición de la esclavitud de 1807 al extenderla a todas las colonias inglesas.

1833

Instalación en Lima de la Convención Nacional donde los amos logran que se expongan sus "derechos" de propiedad sobre otros seres humanos, conculcados por el general San Martín. La intentona de los antiguos dueños fracasó. (Nota_54)

1835

El 10 de marzo de este año, el entonces presidente Felipe Santiago Salaverry (n. 1805 - m. 1836), presionado por los hacendados, reestablece la trata negrera.

1836

El filántropo de la ciudad brasileña de Bahía, Joaquim Pereira Marinho, también gobernador de la provincia portuguesa de Cabo Verde, es el último tratante de esclavos del Brasil. 
Disminuye la población de color. En la Lima de aquel año, la población de esclavos negros, mulatos y otros había descendido a 5.791 habitantes (el 10\% del total de la ciudad) con respecto a las cifras de 1820.

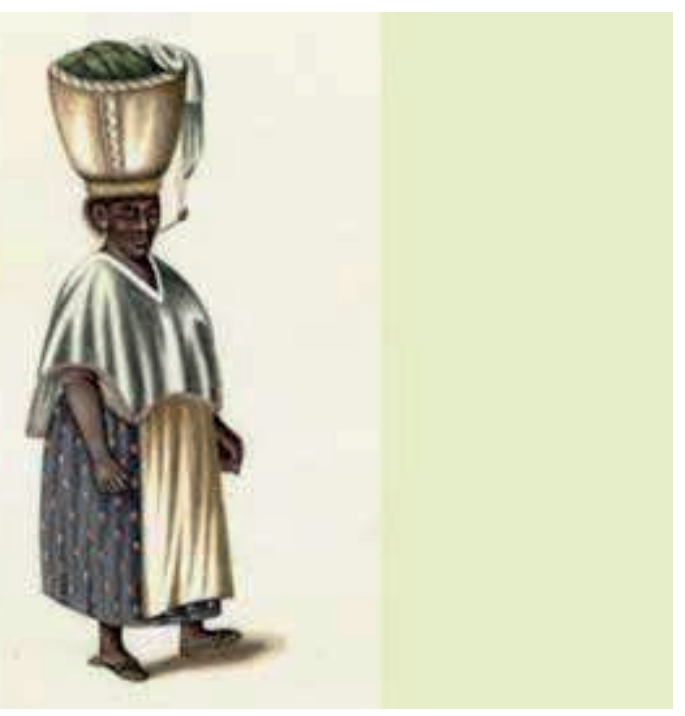

Figura 41. La sociedad a inicios de la República. Con la llegada de la independencia disminuyó la esclavitud pues el General San Martín estableció la ley de vientres libres: se establecía la libertad de los hijos de esclavos nacidos después de la declaración de independencia.

Vendedora ambulante negra en el primer tercio del siglo XIX.

Grabado de época de la Biblioteca Nacional de Francia.

Texto de Perú Republicano. El fenómeno caudilista. Educared.edu.pe.

1836-1939

Entre estos años, el general Andrés de Santa Cruz (n. 1762 - m. 1865) instaura la Confederación Peruano-Boliviana, donde nuevamente se intenta restaurar los antiguos privilegios de los amos. Santa Cruz y el Partido Nacional se opusieron a ello basados en el principio del derecho de las gentes a la libertad. 
El 5 de junio de aquel año, la Confederación Perú-Boliviana firma un tratado con Inglaterra para la abolición total de la trata de esclavos.

1838

Inglaterra decreta la abolición definitiva de los esclavos negros en las islas del caribe británico. Posteriormente, esto se hizo extensivo al resto de sus colonias.

1839

Una ley dada el 27 de noviembre extiende hasta los 50 años el patronato sobre los siervos.

Los hacendados consiguen que la Constitución de Huancayo no mencione el tráfico de esclavos, que siguió practicándose a pesar de las voces en contra.

27 de noviembre. Se deroga sorprendentemente la ley que prohibía el tráfico de esclavos y se reintenta reanudar la trata.

El brasileño Francisco Félix de Sousa es el mayor magnate negrero que domina la trata entre su país y Dahomey, colonia portuguesa en África.

1840-1841 
El infierno de las islas. Se inicia la explotación masiva y exportación del guano de las islas a Europa y Estados Unidos. Cientos de esclavos negros y mulatos son destinados a las islas de San Lorenzo, San Gallán, Chincha, Guañape, Lobos de Adentro, Lobos de Afuera, entre otras, para trabajar en las condiciones más adversas además de que éstos jamás se acostumbrarían a laborar en semejantes latitudes. Y pronto la escasez de mano de obra urgiría tomar nuevas medidas para explotar el codiciado fertilizante natural.

1840-1845

La libertad en los Andes. Abolición de la esclavitud en Colombia, Venezuela y Ecuador.

1842

Bajo el primer gobierno de Ramón Castilla (1845-1851) comienza el llamado periodo de la falaz prosperidad del guano de las islas, que duró hasta 1866 y que, al finalizar, encontró a un Perú sumido en una profunda crisis. La crisis provocada por la caída de los precios internacionales del salitre y una gran deuda externa terminaría por hundir la endeble economía nacional.

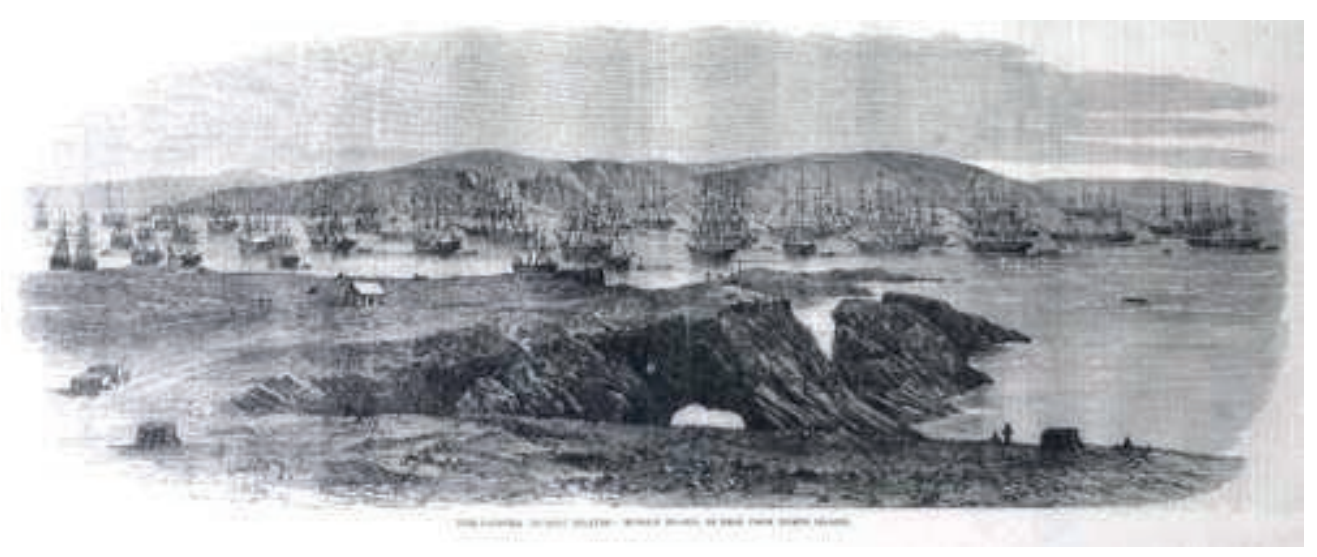


Figura 42. El guano de las islas, un abono animal resultado de la acumulación de excrementos de cientos de miles de aves marinas que pululan por las costas del Pacífico sudamericano, se convirtió en la mayor riqueza natural en el Perú de mediados del siglo XIX, pues este era exportado a Estados Unidos y Europa para ser utilizado como un poderoso fertilizante, muy requerido para una agricultura de alto rendimiento. La industria de la explotación del guano de las islas no sólo generó fortunas sino también influyó en las cotizaciones internacionales. Cuando el precio del abono bajaba, causaba profundas crisis económicas en los países que vivían de este recurso natural e incluso estallaron conflictos armados por el control comercial de la producción del guano. Hasta estas islas, como fue el caso de las Chincha, un pequeño archipiélago situado frente a la costa sur peruana, eran llevados miles de trabajadores para extraer tan ingente riqueza, aunque en las peores condiciones que se pudiera imaginar. La sobreexplotación del hombre por el hombre, para engordar los bolsillos de unos pocos privilegiados, daría pie a que se recurriera a mano de obra foránea... cuando la nativa y la de raza negra ya no daban abasto. Así, llegarían los chinos coolies, cuya actividad laboral forzada dio pie a muchas críticas y justificados reclamos, incluso desde el otro lado del Pacífico.

Foto de Manuel González Olaechea y Franco, publicada en The Illustrated London News, 1863. Tomada del artículo Guano, en el portal Vikipedia, la enciclopedia libre.

Una ley del 13 de febrero de ese año decreta la abolición del Reglamento de la esclavitud en España.

1845

En España: La ley del 2 de mayo de ese año impone penas a los que se dediquen a la trata de negros. 
El 17 de diciembre, cuando se iban a refrendar los pedidos de los hacendados para la apertura del tráfico, se formó una compañía para introducir esclavos del Chocó, los cuale,s en número de 480, ya estaban comprados y fueron introducidos 500. Desde mediados de 1830 ya existía un comercio clandestino con Nueva Granada hacia la región de Piura. Domingo Elías trajo el último cargamento de esclavos negros entre 1850 y 1854... (se sabe que este "cargamento" llegó al Perú vía el puerto de Paita, pues el Callao ya estaba cerrado a este tráfico. N. de VA). (Nota_55)

1847

El gobierno español ordena destruir todas sus factorías negreras en Sierra Leona y Liberia.

1848

Rebelión en el sólido norte. Un grupo de esclavos negros de la Hacienda Nepén (Trujillo) se subleva y se declaran libres.

La República Francesa decreta la abolición de los esclavos en el Caribe Francés. Motivado por los sucesos en las Antillas francesas, y temeroso de que las rebeliones de esclavos se propagaran por las colonias españolas, Don Juan Prim, Conde de Reus, dicta en Puerto Rico el denominado Bando Negro del 31 de mayo de 1848. En él se imponían penas drásticas contra los negros libres o esclavos de la isla ("Art. 2. Todo individuo de raza africana, sea libre o esclavo, que hiciere armas contra los blancos, justificada que sea la agresión, será, si fuese esclavo, pasado por las armas, y si fuese libre se le cortará la mano derecha por el verdugo; pero si resultase herida será pasado por las armas") (Nota_56) 
Ese mismo año, los franceses fundan Libreville, la colonia de negros libres, hoy capital de Gabón.

La ley chinesca. En enero de ese año, Lima es una ciudad sobresaltada por las movidas en el Congreso, pues se estaba debatiendo el derecho al sufragio para los indios y la defensa de los derechos de los jornaleros, muchos de los cuales vivían en estado de esclavitud en las haciendas. Por aquellos días, había una dura polémica entre Bartolomé Herrera y Pedro Gálvez (hermano de conocido héroe José Gálvez). Mientras tanto, el Convictorio de San Carlos y el Colegio Guadalupe, fundado en 1841 por Domingo Elías, a la sazón próspero productor de algodón, simbolizaban un país que, aunque progresista, sufría una seria crisis de mano de obra, sobre todo en sectores como el agrario, en la construcción de vías de comunicación -léase, los ferrocarriles - y en la explotación de los recursos del guano de las islas. Fue precisamente este empresario y un colega suyo, Juan Rodríguez, los primeros en traer trabajadores orientales al Perú. Según refiere el portal China.org.cn, al referirse a la historia de la inmigración de ese país al Perú, En octubre de 1849, nueve años después del estallido de la Guerra del Opio, el primer grupo de 75 "culís chinos bajo contrata" a bordo del barco danés Federico Guillermo llegó tras una difícil navegación de 120 días al puerto de Callao, el Perú, en la costa del Pacífico Este, levantando así el telón de la inmigración china en el país. Los 25 años subsiguientes fueron el pico de esta inmigración y vieron arribar a 100.000 trabajadores chinos a través del Pacífico.(Nota_57)

Poco después, el 17 de noviembre, el Congreso promulgaba la Ley general de inmigración, obedeciendo "al grado de postración de la agricultura del país por la 
falta de brazos", y ofreciendo una prima de treinta pesos a todo introductor de colonos extranjeros."

El mismo artículo continúa... De los primeros grupos de chinos llegados al Perú, casi todos fueron reclutados en las zonas costeras de la provincia china de Guangdong. Estos campesinos, llevados primero a Hong Kong (más tarde en esta ciudad se prohibió la transacción de trabajadores chinos) o Macao, eran obligados a vivir hacinados en habitaciones sucias, en espera de "compradores" extranjeros. Una vez que un culí fuera escogido por el "comprador", se firmaba un contrato, al principio de cinco años y después de ocho años, pero el cual muchas veces no se cumplía o se prolongaba sin justificación. Estos contratos eran como una especie de autoventa, de modo que el culí se convertía en propiedad del "comprador" y era revendido en el plazo de contrato no se sabe cuántas veces.

Los barcos partían de Macao y el viaje duraba hasta cuatro meses largos. La higiene era muy pobre, el tiempo cambiaba constantemente, y la comida se limitaba a un poco de arroz y carne salada pero sin frutas ni verduras. Mientras por la mala nutrición cundían las enfermedades contagiosas, los chinos enfermos no tenían atención médica y muchos muertos eran arrojados al mar. Agobiados por la nostalgia de su propia tierra y no pudiendo soportar la vejación de los dueños de barco, algunos se alzaron en motines que estremecieron a China y el mundo. (Nota_58) 


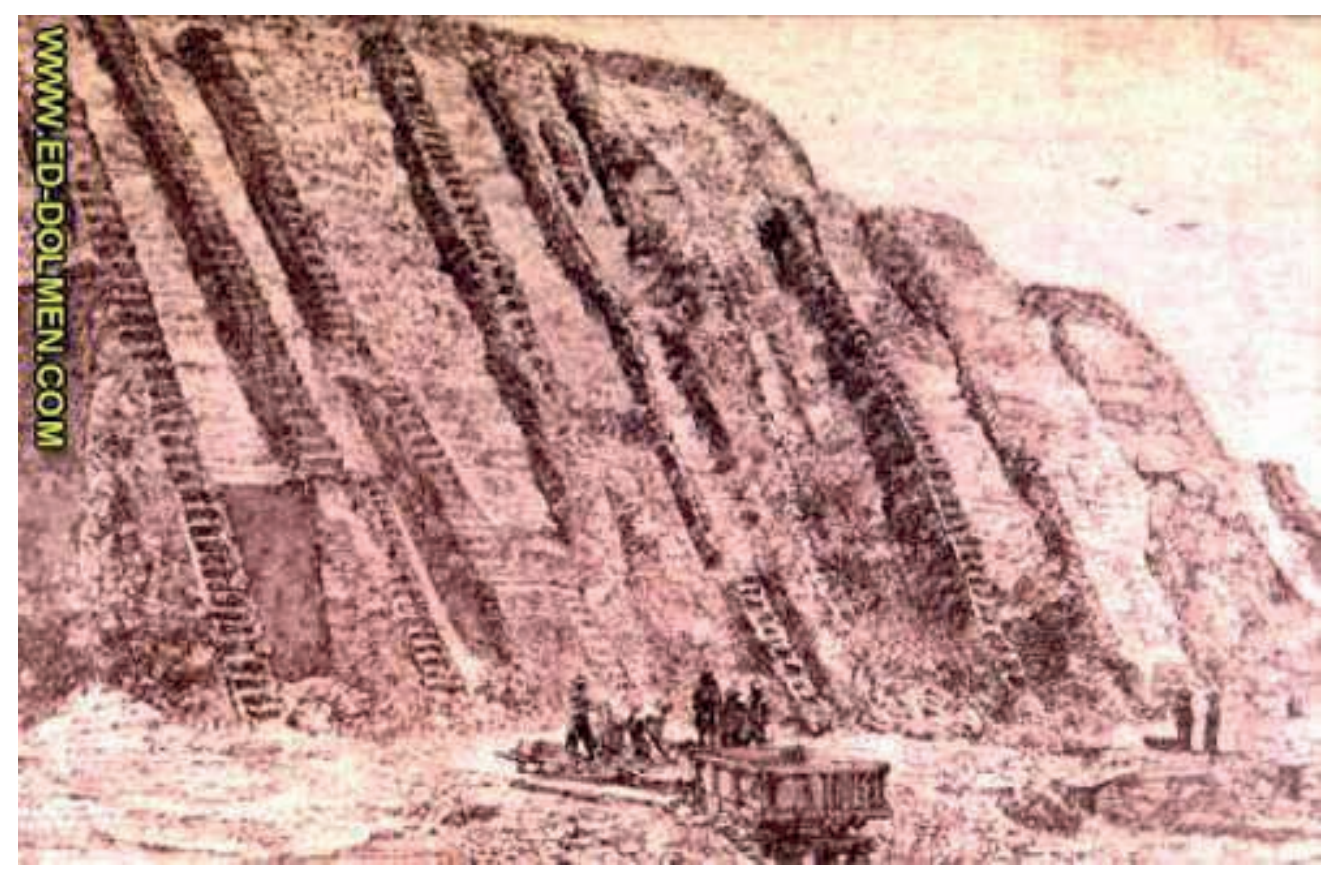

Figura 43. En la tierra de las montañas de estiércol. Los culíes chinos demostraron su capacidad de trabajo en tan insalubres latitudes, pero no aguantaron por mucho tiempo la explotación.

En la imagen, unos trabajadores extraen el pestilente pero preciado abono acumulado por centurias en las emblemáticas, islas Chincha.

Grabado de la segunda mitad del siglo XIX. Explotación del guano en Perú. Portal Antehistoria.com.

La sabiduría popular. El ingenio popular terminó llamando a esta Ley de Inmigración la ley chinesca, en vista de que con ella se daba inicio a la inmigración china al Perú. Por ello, a los pobres chinos, que ignoraban lo que les aguardaba, los bautizaron como macacos porque provenían del puerto de Macao, y como coolí muchos piensan que era por la "colita", una diminuta trenza que llevaban en la cabeza, sin entender que se trataba de una acepción hindú cuyo significado era trabajador golondrino-.

La esclavitud es definitivamente abolida en Francia y en sus dominios coloniales. 
Desde 1550, la ciudad de Río de Janeiro es el mayor puerto negrero del Brasil. Sus tratantes se volvieron millonarios por su "negocio" de traer esclavos de África. El recuerdo de esta riqueza se puede apreciar ahora en la opulencia de los barrios de la clase acomodada del siglos XVII al XIX.

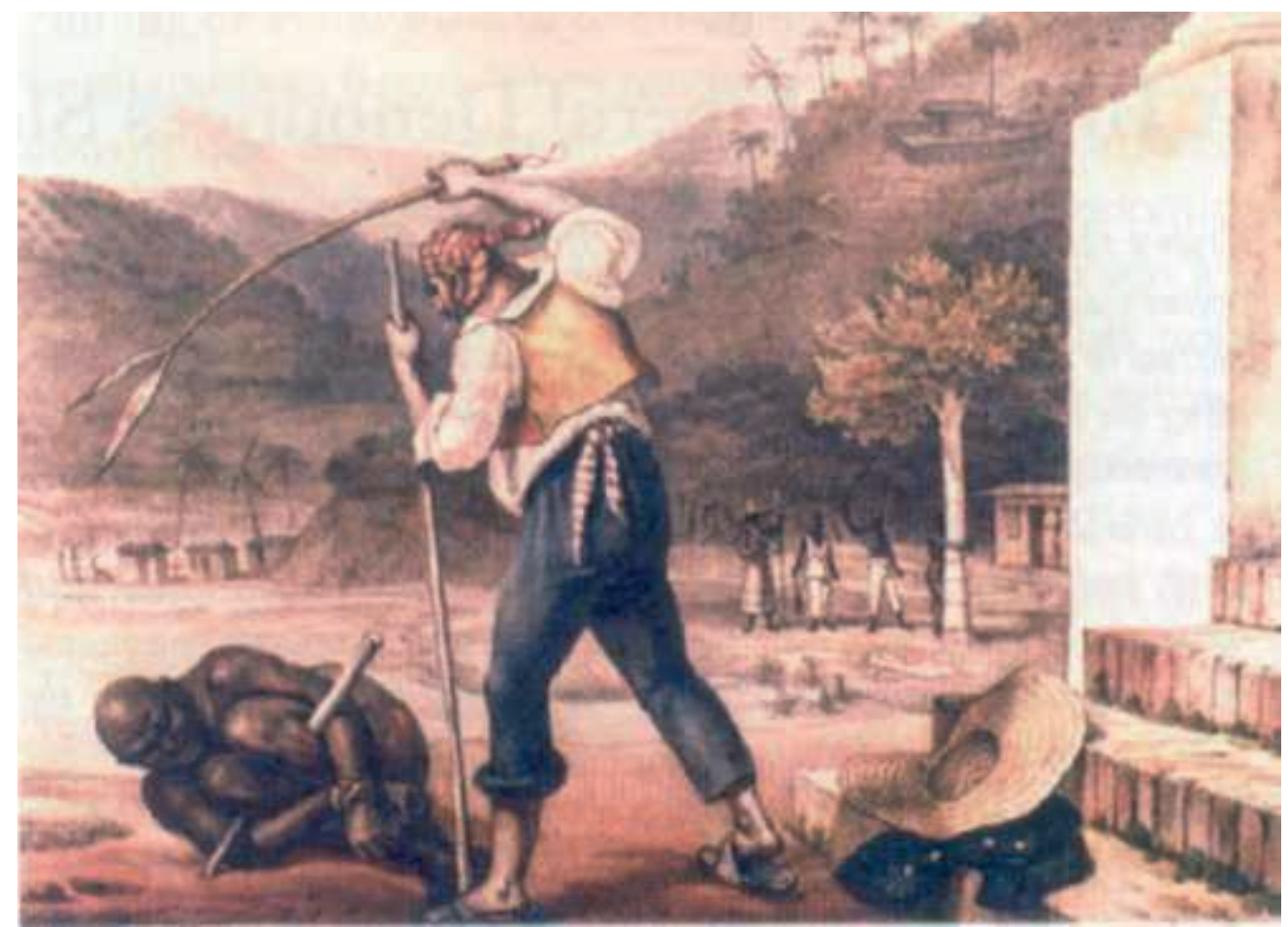

Figura 44. La vida a golpes. En Brasil, la esclavitud duró más tiempo que en ninguna otra parte de América del Sur. Los grupos antiesclavistas difundieron grabados tales como esta ilustración publicada en Francia para ilustrar la brutalidad que se vivía en este país, territorio imperial luso hasta 1880. Portugal fue tal vez el país más esclavista del mundo, a tal punto que sus gobernantes se empeñaron en mantener la trata negrera contra todas las corrientes de libertad que se respiraban a fines del siglo XIX.

Ilustración del artista francés Debret. Introduction to World History. Gallery Images for Lecture. Part IV. andrew.cmu.edu. 
¿Premio? La Ley de Inmigración peruana de 1849, la ley chinesca o de chinos, prometía dar del tesoro nacional un "premio" de 300 pesos por cada emigrante a quienquiera que introdujera de una vez 50 emigrantes de 10 a 50 años de edad. Para este año surgieron voces que ponían en tela de juicio tales "premios". Los críticos de los alcances de dicha norma veían en esta presunta "dádiva" una suerte de "gato por liebre".

Hombres "solos". Según estimaciones, por paradójico que parezca, durante los primeros 25 años de la masiva llegada de inmigrantes chinos al Perú, sólo arribaron 150 mujeres de esta nacionalidad, por lo que, consecuentemente, la mayoría de los chinos varones tuvieron que formar hogares con mujeres locales. (Nota_59)

Todavía son muchos. Se ha calculado que por aquel año viven unos 19.000 esclavos en el Perú.

1851

¡A las armas! Todos los esclavos de los valles de Chicama, Santa Catalina y la ciudad de Trujillo se sublevan, se enfrentan al ejército y toman la plaza Mayor de esta última localidad. Los levantiscos abren las cárceles e invaden los cuarteles para tomar las armas; este suceso obligó al entonces prefecto de Trujillo y a los hacendados a firmar su manumisión. Se dice que esta revuelta fue una de los principales causas que esgrimió el presidente Ramón Castilla para abolir la esclavitud tres años después. (Nota_60)

Alma llanera. "Ley declarando abolida para siempre la esclavitud en Venezuela".

Entre 1853 y 1855 
Un estudio de Towson University, Maryland (USA) hace hincapié en las revueltas que debilitaron la esclavitud en el Perú al comentar lo siguiente: En el intervalo comprendido entre las primeras declaraciones de emancipación y el momento de la abolición nacional en la década de 1850, los esclavos del Perú y del Ecuador, a menudo con la ayuda de sus contrapartes libres, contribuyeron a debilitar la esclavitud. Lo hicieron con sus esfuerzos para asegurar la liberación y un trato mejor, y mediante la rebelión abierta. Una rebelión de esclavos en el Valle de Chicama desestabilizó a la clase de amos de plantaciones en 1851. En el mismo año se abolió la esclavitud en el Ecuador con la firma del Decreto Urbina, ratificado el año siguiente por la Convención de Guayaquil. La esclavitud en el Perú fue finalmente abolida por decreto en 1855 cuando rivales políticos en guerra comenzaron a hacer, otra vez, llamados de apoyo militar a los esclavos para pelear a su lado con la libertad como recompensa. (Nota_61)

1853

Durante el gobierno de José Rufino Echenique (presidente del Perú en los periodos 1851-54 / 1854-55), se ordenó la libertad de varios esclavos negros merced a un sorteo público realizado en la plaza mayor de Lima; y se declaró libres a 116 esclavos de Nueva Granada (del Choco, Colombia) que habían sido importados por Domingo Elías, un hacendado iqueño enemigo del entonces presidente de turno, que había luchado contra Castilla. 


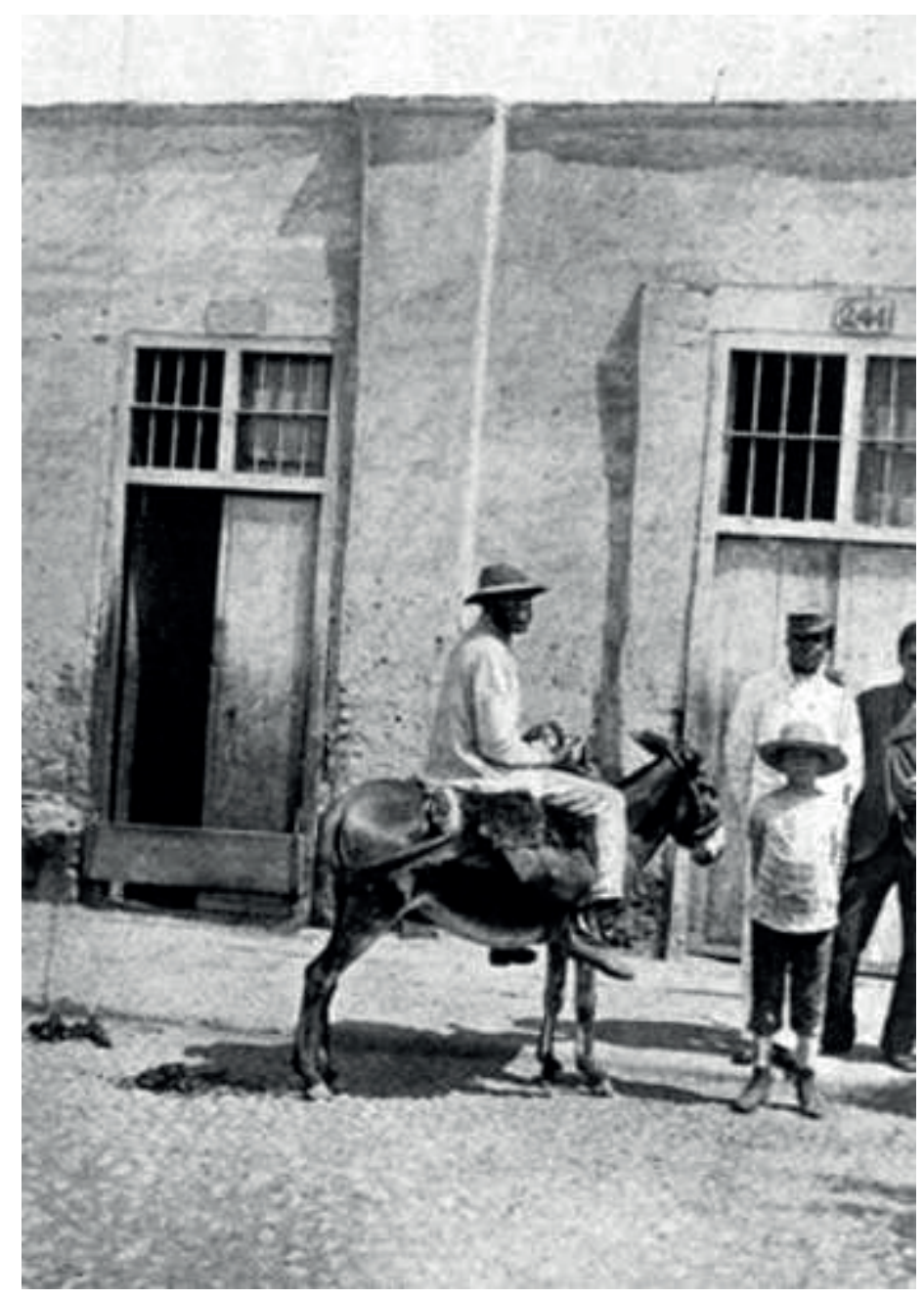

Figura 45. Esclavo sobre un burro en algún lugar de Lima.

Foto de mediados del siglo XIX. Tomado de Common Place (Lugar Común), comentario del libro Early Cities of the America. A Day in the Life. Lima, de Christine Hunefeldt, Hunefeldt, profesora de Historia Latinoamericana de la Universidad de California, San Diego.

El Artículo 15 (primera parte) de la Constitución Argentina de ese año declara la abolición de la esclavitud en el territorio argentino.(Nota_62) 
El diario El Comercio de Lima se hace eco de los numerosos casos de maltratos a que son sometidos muchos esclavos sobre todo negros, como se puede apreciar en esta recopilación de Humberto "Tito" Rodríguez en las notas al margen. (Nota_63)

No era cuento chino. La historia dice que, después de la aprobación de la llamada Ley chinesca, aumentó el flujo de inmigrantes procedentes del extranjero, sobre todo de orientales. Por aquellas fechas, según datos del ministro de Gobierno, José Manuel Tirado, desde febrero de 1850 hasta julio de 1853, fueron introducidos en el Perú 3.932 colonos, de los cuales, 2.516 fueron chinos. (Nota_64)

Los primeros chinos llegados al Perú eran enviados a las islas cercanas a la costa para explotar los recursos de guano. El guano, fertilizante orgánico de alta calidad, era entonces el principal producto del Perú para la exportación y la principal fuente generadora de divisas. En esas islas subtropicales, calientes y húmedas, las condiciones de trabajo y vida eran pésimas y el mal olor del guano provocaba náuseas. Los chinos cavaban guano con palas de hierro y lo cargaba a los barcos. El trabajo era agobiante. (Nota_65)

No se escapen... todavía. Cuenta Humberto "Tito" Rodríguez en el Boletín de Cimarrones que Los esclavos que se escapaban de sus amos, debían conseguir un medio de vida; entre las formas de sobrevivir, una actividad en la que se les encuentra es como miembros de las montoneras. Con este término eran conocidos los grupos de asaltantes que vivían por los caminos que conducían a las ciudades o pueblos, preferentemente los que se dirigían a Lima. Iban montados a caballo y se les tenía temor por sus fechorías y asesinatos. Esas montoneras estaban compuestas no sólo por esclavos cimarrones; y en algunos casos en ellas había mucha gente y 
siempre había un jefe que las dirigía. En algunas oportunidades hubo el uso político de estas bandas. Ver casos de antes y después de la abolición; al parecer, algunos prójimos de color no se enteraron que ya eran libres o qué sabemos...(Nota_66)

¡Ah, Rufino! Si bien es cierto, como señala el CEDET, no existió en el Perú un contexto ideológico que sustente la abolición decretada por Castilla, la verdad es que, aún así, los hechos se precipitaron, como se verá, debido a una polémica norma previa dictada por el entonces presidente, José Rufino Echenique, contra quien había estallado la rebelión de Arequipa (enero de aquel año), liderada por Ramón Castilla, que lo consideraba un dictador. La citada fuente habla aquí del avance de las fuerzas revolucionarias de Ramón Castilla de carácter liberal, (que) buscaban derrocar al gobierno corrupto de José Rufino Echenique. El 18 de noviembre de 1854 el presidente Echenique, buscando atraer el apoyo de los esclavos, decreta la abolición de la esclavitud enunciando la necesidad de asegurar el triunfo de las instituciones y del orden social, por lo cual todo esclavo domestico o de hacienda que se presentase al servicio del ejercito obtendría la libertad, la cual se extendería a su mujer legitima. El servicio era de dos años como mínimo en el ejercito, además de la indemnización para el amo. Vale decir, se trataba de una liberación de la esclavitud bajo condiciones.

Algo más sobre mercancía humana. A mediados de aquel siglo, la esclavitud estaba institucionalizada en el Perú desde hacía más de trescientos años. Prueba de ello es este artículo de Humberto "Tito" Rodríguez -en las notas al margen - que recoge el texto de algunos anuncios de oferta y demanda de esclavos en Lima, e incluso el movimiento comercial que había en torno a este tráfico humano, lo que revela la magnitud que alcanzó la explotación del hombre por el hombre en Lima y otras ciudades peruanas. (Nota_67) 
También era frecuente que un esclavo se fugara, y lo que les pasaba a continuación, es decir, era un verdadero escándalo en la sociedad de entonces. Estas son noticias de ese año. (Nota_68)

El 3 de diciembre, en la ciudad de Huancayo, Ramón Castilla firma la célebre ley que decreta la libertad de todos los esclavos, sean negros o de otras etnias, en el Perú. Fue en respuesta a la ya mencionada ley de José Rufino Echenique, dada el 18 de noviembre de aquel año, según la cual se ofrecía libertad a los esclavos si estos se enrolaban en su ejército. Dicho decreto fue calificado de prostitución de la filantropía. (Nota_69)

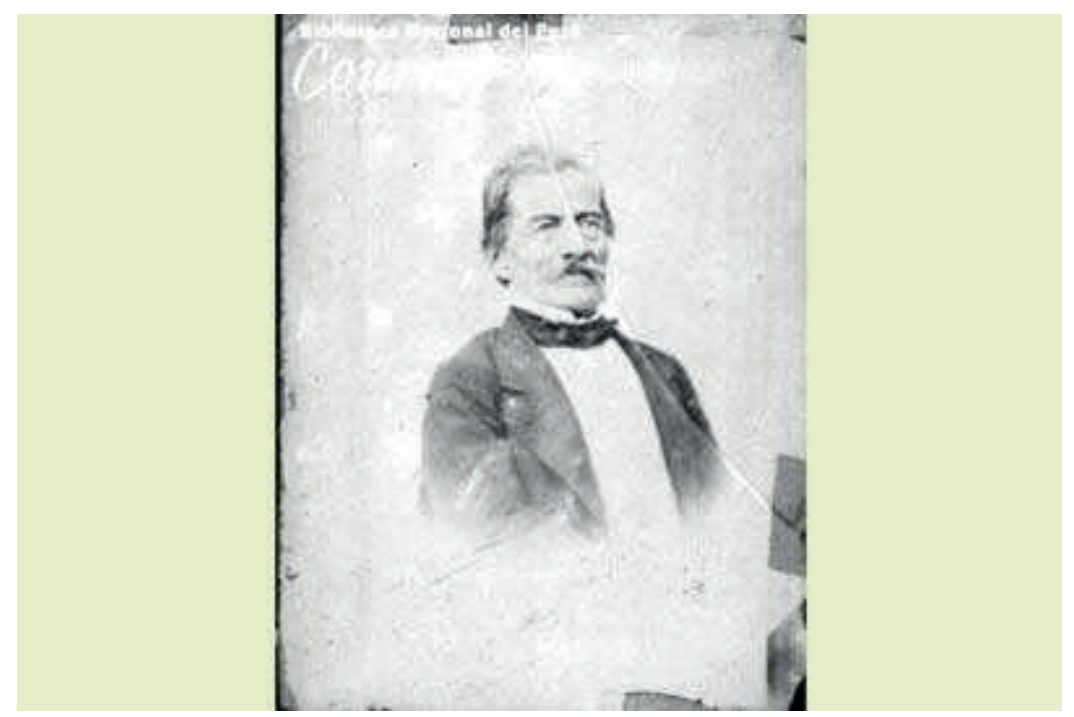

Figura 46. Don Ramón Castilla (n. 1797 - m. 1867), dos veces presidente del Perú, quien abolió la esclavitud del Perú mediante el histórico decreto de Huancayo. Foto del Archivo Courret que le fue tomada en sus últimos años. Perú Republicano. La prosperidad falaz. 
El 23 de enero se publica por diversos medios el texto del decreto del 3 de diciembre de 1854, no en su versión inicial hecho en campaña, sino otra muy amplia, por eso es más que un decreto, incluye indicaciones de cómo debería hacerse el proceso para la puesta en marcha de la manumisión de la esclavitud. Según las precisiones añadidas se debían crear juntas de inscripción en distritos donde hubiera habido esclavos y siervos; en cada uno de ellos el gobernador, el cura y un vecino notable debían formarlas. De esta manera se harían los registros en los que se debían consignar datos tales como: nombre, edad (años y meses), estado civil, oficio, hacienda o casa de procedencia y nombre del dueño, constitución física (robusta o débil), estado de salud. Luego se hacían los envíos al gobierno. Texto de Humberto "Tito" Rodríguez. (Nota_70)

Se ponen en boga los Pagos por la Manumisión de los Esclavos liberados por el decreto de Ramón Castilla. Era una suerte de indemnización que recibían los antiguos amos por desprenderse de sus criados sometidos a su mandato. (Nota_71)

1856

El decreto de Ramón Castilla trajo mucha cola por las arduas discusiones entre los que no se resignaban a perder su condición de amos, los comerciantes de mercadería humana, y los partidarios de la libertad de los esclavos, como podemos apreciar en las notas al margen. (Nota_72)

Según documentos históricos, en este año llegó a la costa brasileña el último barco negrero luso de esclavos negros procedente de África. Ahora los cautivos seguirían llegando procedentes del Caribe o vía tratantes de otros países ajenos a Portugal. 
1859

El velero Wanderer, del que se decía que más que navegar parecía volar... fue el último barco que transportó esclavos a Norteamérica.

Por 30 soles. Cuenta el historiador Jorge Basadre (n. 1903 - m. 1980) en su obra Historia de la República del Perú que, en aquel año, cuando el gobierno peruano nombró a la casa Gibas -una de las más antiguas y poderosas firmas británicas en la West Coast, esto es, la costa pacífica sudamericana - consignataria exclusiva de la producción del guano de las islas en el Perú, se tuvo que reemplazar la mano de obra local y negra, que ya no daba abasto para tan ingente trabajo de explotación de los recursos naturales, con otra proveniente del Lejano Oriente. Es así que aprovecharon la ley de inmigración de 1849, que otorgaba un subsidio de 30 soles por cada colono traído al país -se hizo esto, por ejemplo, con los alemanes del Pozuzo y los italianos del Chanchamayo - , se adoptó esta política con los cariamarillos, es decir, los coolies o culíes chinos, para suministrar la tan requerida mano de obra tanto en las islas como en las haciendas azucareras y algodoneras, además de trabajadores para las obras de la infraestructura ferroviaria, entre otros.

1860 y ss.

Figura 47

Población negra en América entre 1860 y 1872

Región esclavos libres total

Cuba (1861) $\quad 370.553$

Estados Unidos (1860) $\quad 3.953 .696 \quad * 488.134 \quad 4.441 .830$

$\begin{array}{llll}\text { Brasil (1872) } & 1.510 .806 & 4.245 .428 & 5.756 .234\end{array}$ 
Caribe hispano

Cuba (1861)

370.553

232.493

603.046

Puerto Rico (1860)

41.738

241.037

282.775

Totales

5.876 .793

5.207 .092

11.083 .885

${ }^{*}$ De estos negros libertos, 261.918 residían en los estados esclavistas del sur. Y en esos años (1860), los Estados Unidos tenían 31 millones de habitantes (+C. Pereyra, La obra... 269).

Estos cuadros estadísticos de la esclavitud negra en América explican no poco algunas cuestiones comparativas, pues las enormes diferencias cuantitativas que se aprecian de unas a otras regiones proceden y, al mismo tiempo, causan ciertas diferencias cualitativas.

Fuente: Algunas notas sobre la esclavitud en América.

Revista Arbil, anotaciones de pensamiento y critica. \# 42 (Nota_73)

1863

La Corona holandesa decreta la abolición de la esclavitud en sus territorios de ultramar de Surinam y en las Antillas holandesas. También en aquel año se proclama la emancipación de los esclavos en Estados Unidos.

Decreto del entonces presidente Abraham Lincoln, con el que Estados Unidos proclama la abolición de la esclavitud y la hace efectiva a través de una enmienda a su constitución (Enmienda XIII). Dos años después, Julio Vizcarrondo, hacendado puertorriqueño que había dado libertad a sus esclavos, crea la Sociedad Abolicionista Española. En este mismo año de 1865 se funda el periódico El abolicionista. (Nota_74) 


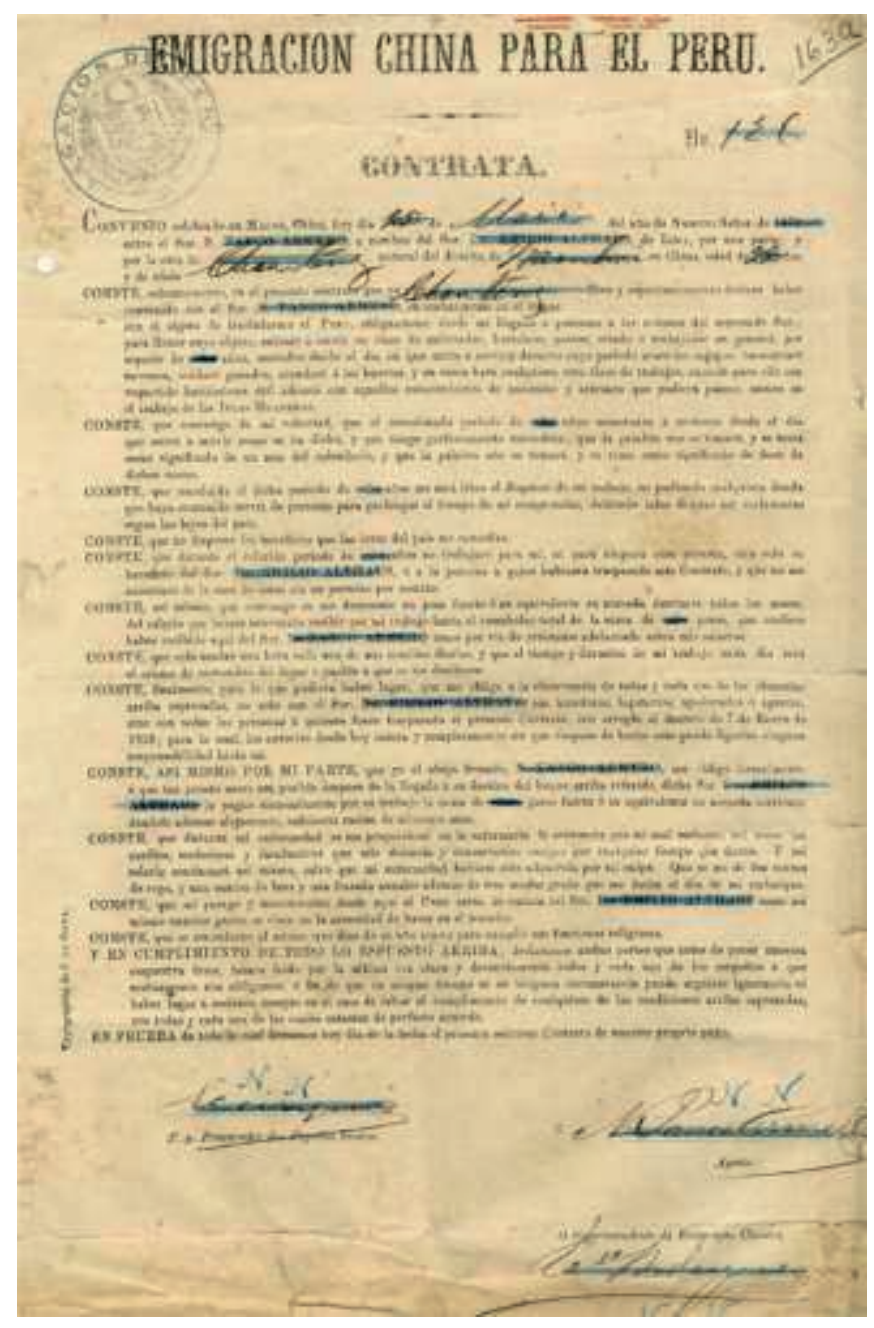

Figura 48a. (lado a) Modelo de contrato suscrito en Macao, entre el ciudadano chino Chan Teng y el representante Tanco Armero, en nombre de Emilio Althaus, donde se establece la permanencia del contratado por ocho años en el Perú para realizar labores de cultivador, hortelano, pastor, criado, exceptuando el trabajo en las Islas Guaneras. Macao, 25 de mayo de 1872. Tal parece que en ese entonces los súbitos del celeste imperio ya le habían agarrado ojeriza a la idea de trabajar en alguna isla exótica.

De la Exposición: Las Migraciones y el Perú. Inmigración china. Ministerio de Relaciones Exteriores del Perú. 


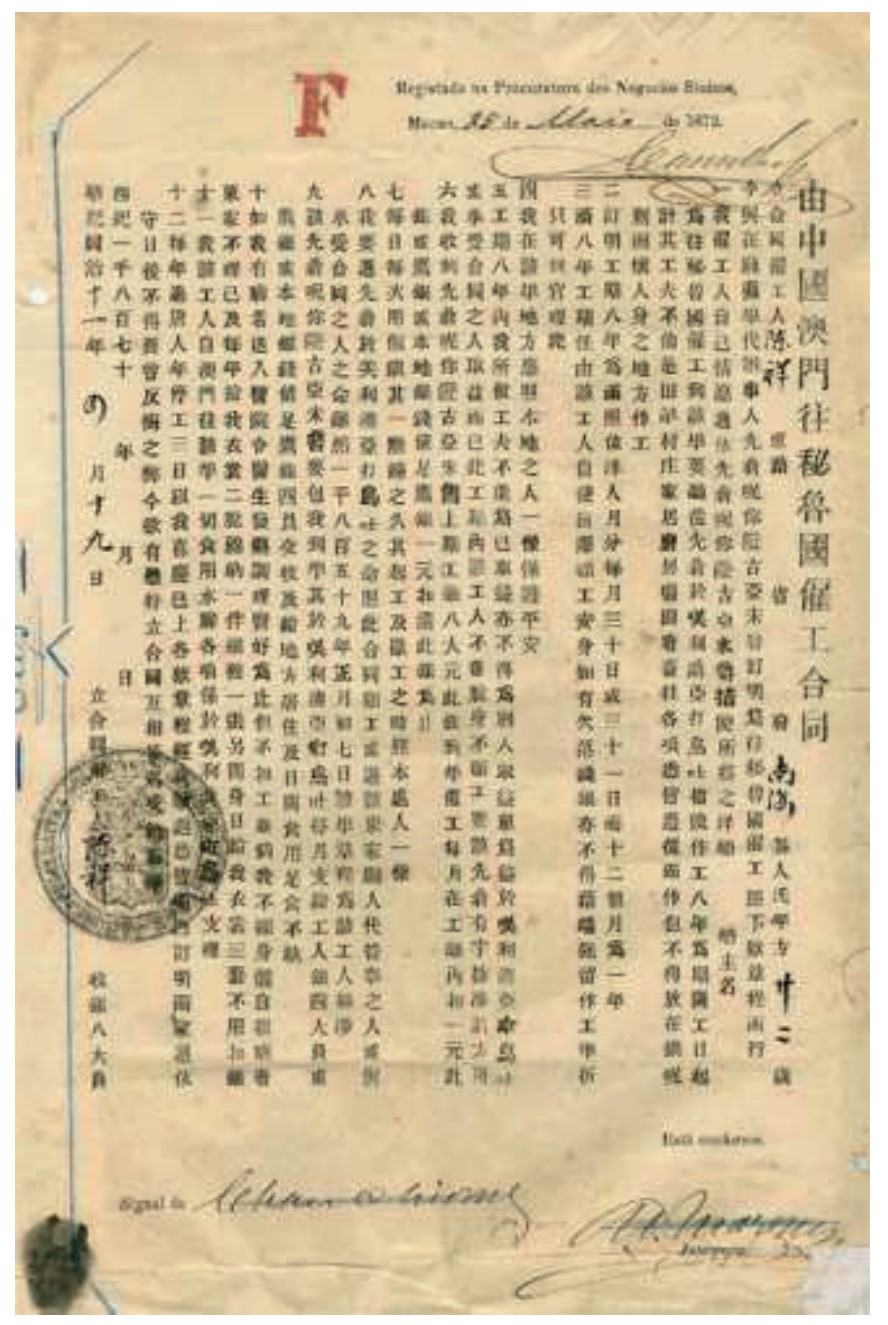

Figura 48b. (lado b) El mismo documento en su versión en chino.

De la Exposición: Las Migraciones y el Perú. Inmigración china. Ministerio de Relaciones Exteriores del Perú.

En ese año, el Perú abre un consulado en Macao, el cual se encargaba de informar a Lima acerca de la contratación de trabajadores chinos con destino al Perú. 
Llega a Cuba el último barco de esclavos negros procedente de África. Se promulga en esta colonia la Ley del 17 de mayo de ese año que "establece normas para la represión y castigo del tráfico de negros. Quedan configurados como delitos de trata:

* El armamento de buques y cualquier operación que se haga en ellos para destinarlos al tráfico de negros, así como el viaje de los mismos a la costa africana, cualquiera sea su bandera;

* La adquisición de negros fuera de la isla de Cuba, Puerto Rico o adyacentes, y su transporte a estas islas o cualquiera otro punto;

* La introducción de ellos en las islas referidas o la presencia en sus aguas jurisdiccionales de buques con cargamento de negros bozales." (Mesa 141-142) (Nota_75)

El largo camino a la libertad. El ya mencionado estudio publicado por la Towson University, Maryland, USA, estima que entre 1519 y 186711.569 .000 de africanos fueron llevados a América: 38,5\% al Brasil, 17,5\% a la América Hispana, 28,1\% a la América Británica (incluyendo 6,45\% a Norte América Británica, más tarde los Estados Unidos), y el 15,9\% restante a la América Francesa, Danesa y Holandesa. En América los africanos y sus descendientes realizaban labores domésticas, de plantación y calificadas bajo la amenaza constante de violencia: azotes, marcas, violación, encadenamiento, mutilación de apéndices, negación de alimentos, agua, sueño y albergue. (Nota_76) 
Cuba libre. Decreto sobre la esclavitud, del 27 de diciembre, de Carlos Manuel de Céspedes, capitán general del Ejército Libertador de Cuba y encargado de su gobierno provisional.

La revolución que tuvo lugar en España en septiembre de 1868, denuncia también la esclavitud e inicia el camino para su abolición, aun cuando su propuesta sea todavía tímida:

La Junta Superior Revolucionaria, Considerando que la esclavitud de los negros es un ultraje a la naturaleza humana y una afrenta para la nación, que única ya en el mundo civilizado, la conserva ya en todo su integridad.

[...] la esclavitud es una de esas instituciones repugnantes, cuya desaparición no debe hacerse esperar [...]

La Junta Superior Revolucionaria propone al gobierno provisional como medida de urgencia y salvadora:

Quedan declarados libres todos los nacidos de mujer esclava, a partir del 17 de septiembre próximo" (Mesa 71). (Nota_77)

1868

Decreto de extinción de la esclavitud, promulgado en Camagüey (Puerto Rico N. de VA) el 26 de febrero. Los independentistas cubanos publican la Constitución de Guáimaro, cuyo artículo 24 declara que "Todos los habitantes de la República son enteramente libres." (Nota_78)

1869

En España se aprueba la "Ley Moret". Su propulsor, Emilio Castelar, pretendía defender una enmienda propuesta por él mismo al artículo 21 de dicha ley para dar inicio a una política abolicionista en este país. (Nota_79) 
España da una ley que decreta la abolición de la esclavitud en la isla de Puerto Rico.

1870

El 4 de septiembre de ese año estalla al norte de Lima la llamada Rebelión de los cariamarillos: miles de chinos que trabajaban en el campo se manifestaron violentamente contra los abusos que se venían cometiendo contra ellos. Fue una verdadera clarinada de alerta contra el gobierno peruano que estaba tolerando los excesos que se cometían, sin que nadie le pusiera un párale. (Nota_80)

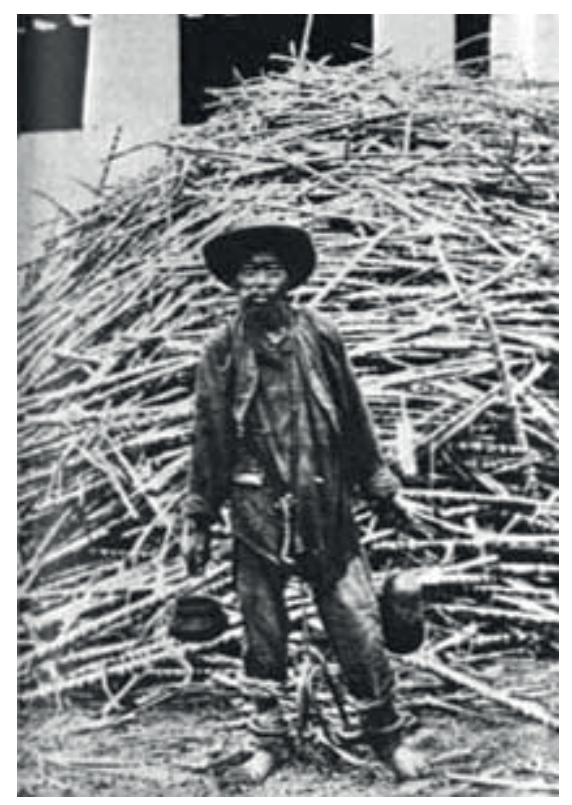

Figura 49. Cariamarillo. Trabajador chino coolie en una plantación de caña de azúcar. Chicamita, Perú, entre los años 1860s y 1870s.

Foto cortesía de N. Jacobsen. History 228 Race, Class and Gender in Latin America, 1520-2000 


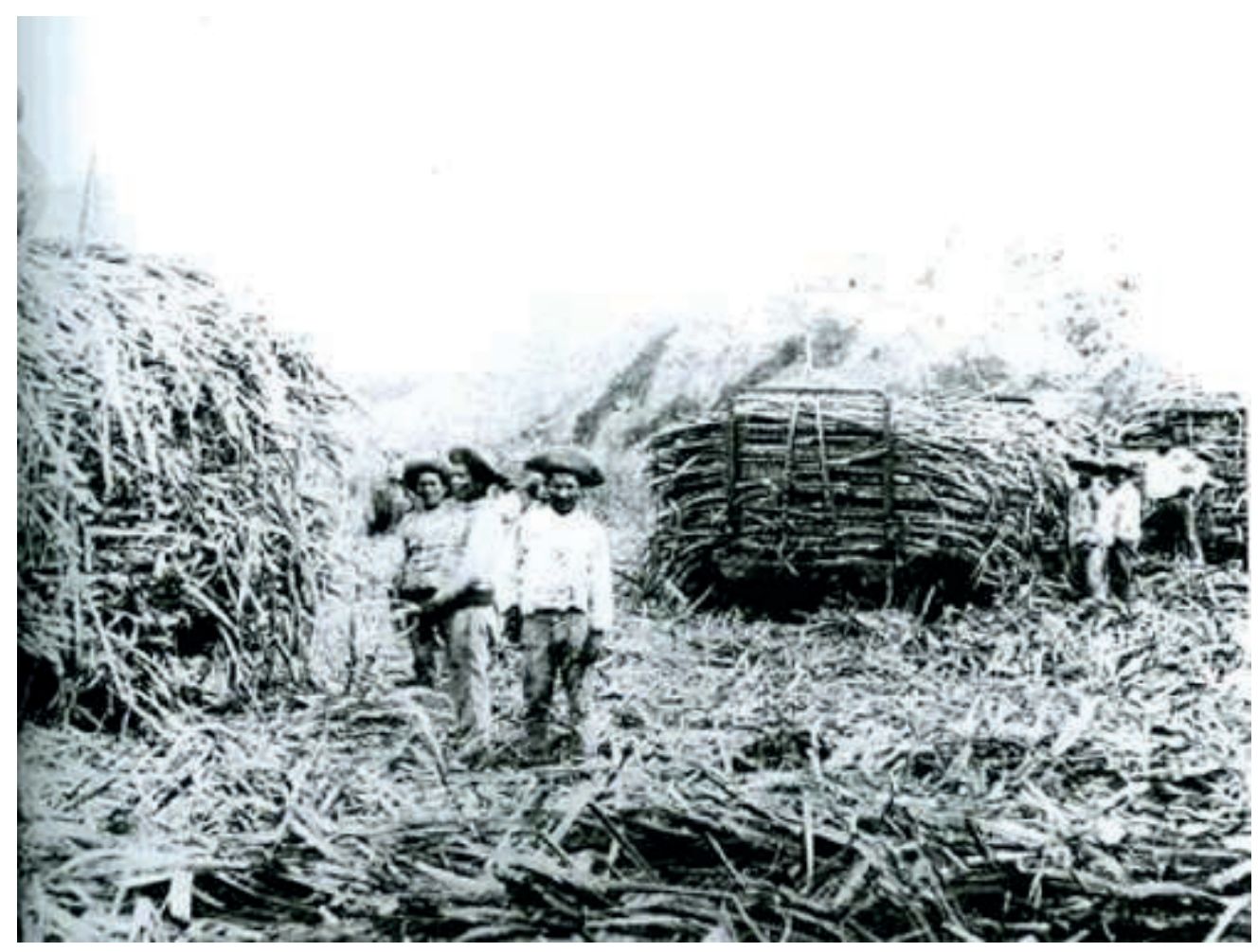

Figura 50. Inmigrantes chinos cortando caña. Fines del siglo XIX. El establecimiento de inmigrantes chinos en el Perú se realizó mediante contratos de trabajo, cerrados en Macao, para el desarrollo de labores en haciendas, posteriormente estos se dedicarían a diversas actividades, incursionando en diversos oficios:

peluqueros, bodegueros, cocineros y empresarios.

De la Exposición: Las Migraciones y el Perú. Inmigración china. Ministerio de Relaciones Exteriores del Perú.

1873

Pese a la explotación y a los maltratos, los chinos supieron sobreponerse a su lamentable condición, situación que en aquel año un periódico de Lima tuvo que admitir que:" en la actualidad, eran los chinos los que estaban roturando y cultivando grandes extensiones de fincas, sobre todo en las zonas del litoral. El poeta Juan de 
Arona escribió que en el Perú no había lugar donde no hubiera chinos y que no había trabajo que ellos pudieran cumplir." (Nota_81)

Fin de la esclavitud en Puerto Rico. La isla todavía estaba en poder de España.

1874

El baile de los que llegaron. Se ha calculado que, entre 1848 y este año, llegaron al Perú unos 100.000 chinos, en su mayoría Coolies, para que trabajaran en las haciendas de algodón y caña de azúcar en la costa, en la construcción de ferrocarriles y como peones en las islas guaneras. A los emigrantes los traían con el cuento de que el Perú era el país del oro, ya que estaba en la misma costa que California, donde por esos años se había desatado la fiebre del oro. Pero, cuando llegaban, descubrían que en lugar de oro había inmensos desiertos y estrechos valles, donde sólo les esperaba una vida miserable y cruel, bajo la tutela de unos patrones inhumanos. Cual cruel engaño, la "tierra de promisión" se convirtió en la cárcel inmensa donde estos seres humanos fueron tratados como cosas o como animales de carga. Al término de sus contratos, muy pocos regresaron a casa y muchos murieron víctimas de la explotación, los maltratos, la malnutrición, la insalubridad, las enfermedades, el clima hostil. El Perú no era California.

Tardío. El Ministro peruano del Exterior, José de la Riva Agüero, reconoció, en un memorando entregado al Parlamento, que "el comercio de culís entre Macao y Callao era salvaje y era una afrenta a China." Para ese entonces, ya habían muerto miles de chinos coolis explotados en las islas guaneras frente a la costa peruana. (Nota_82)

Lima envió a China al capitán de fragata García, en calidad de enviado especial, con el propósito de firmar un tratado de comercio con la Corte Qing. Pero el 
representante omnipotenciario chino Li Hongzhang rehusaba recibir a García al enterarse del maltratamiento que sufrían los chinos en el Perú. Sólo fue después de los buenos oficios de los diplomáticos americanos y británicos acreditados en China y tras la entrega del documento aprobado por el Gobierno peruano para mejorar el status de los trabajadores chinos, que se entrevistaron los representantes. El 26 de junio del mismo año se firmó oficialmente el primer convenio bilateral: Tratado Chino-Peruano de Amistad, Comercio y Navegación. Hoy día sigue colgando en el vestíbulo de la sede de la Beneficencia Central de China en Lima el rótulo con caracteres dorados obsequiado por el omnipotenciario imperial de la Corte Qing. (Nota_83)

1876

Según el censo nacional de ese año, en el Perú había 40.664 habitantes de raza negra. El empadronamiento incluyó Lima y Callao. (Nota_84)

1878

El 22 de agosto de ese año muere en el puerto del Havre, Francia, María Cristina de Borbón-Dos Sicilias, Reina consorte (1829 - 1833) y Regente (1833 - 1840) de España. Durante años apoyó la esclavitud en Cuba, debido a que tenía muchos intereses en esta isla caribeña, una de las últimas colonias españolas de América.

Zanzíbar, de la mano del sultán omaní Hamoud bin Mohammed (n. 1853 - m. 1902), firma un tratado con Inglaterra para abolir la trata negrera y la exportación de esclavos. Este territorio había sido el centro del tráfico de esclavos en el Este de África entre los siglos XVII y XIX. 
La esclavitud queda abolida en todos los territorios del África portuguesa.

1879-83

Guerra del Pacífico. Debido al asunto de los nitratos, fertilizante que había reemplazado al guano de las islas, Chile le declara la guerra a Perú y Bolivia. Esta infausto conflicto armado, también conocido como Guerra del salitre, motivó la ocupación de Lima por las tropas chilenas y la pérdida de las provincias de Tacna (hasta 1929), Arica y Tarapacá, mientras que Bolivia perdió su litoral costero (provincia de Antofagasta).

1879

23 de diciembre. A poco de estallar la Guerra del Pacífico (entre Perú y Chile) y a pesar de que la esclavitud ya estaba abolida, estalla una revuelta de 300 campesinos negros, que tomaron y asesinaron a los administradores de las haciendas San José, Hoja Redonda y Larán. Al grito de ja matar! y ¡viva Piérola!, los negros se habían levantado porque los hacendados atacados estaban colaborando con los invasores chilenos. El 25 de diciembre, temiendo que la rebelión llegara hasta Pisco, los hacendados y sus familias se refugiaron en barcos anclados en la bahía. Poco después, los rebeldes intentaron tomar la ciudad de Chincha pero fueron sofocados en los cañaverales de San José por efectivos del ejército llegados de Pisco y Chincha.

1880

13 de febrero. Otra ley determina la abolición definitiva de la esclavitud en España y crea el sistema de patronato que permitía, entre comillas, la imposición de la esclavitud. 
España decide abolir la esclavitud en Cuba pero, a contrapartida, crea el polémico sistema de transición de Patronato.

1881

Ahora en el sur chico. En febrero de ese año, cuando los invasores chilenos ya estaban en Lima, hubo una revuelta de campesinos negros en Cañete, el emporio de la caña de azúcar del departamento de Lima; todo ardió. Años después, en 1891, documentos diversos señalan que para ese entonces, todo estaba en ruinas.

1888

Corrigiendo el error de 1880, María Cristina de Habsburgo-Lorena, Reina consorte (1879 - 1885) y Regente (1885 - 1902) de España, emite una Real Orden que elimina el sistema de Patronato, aboliendo para siempre la esclavitud en la isla Cuba.

Más vale tarde... Brasil es el último país americano en prohibir la esclavitud en todas sus formas y modalidades. 


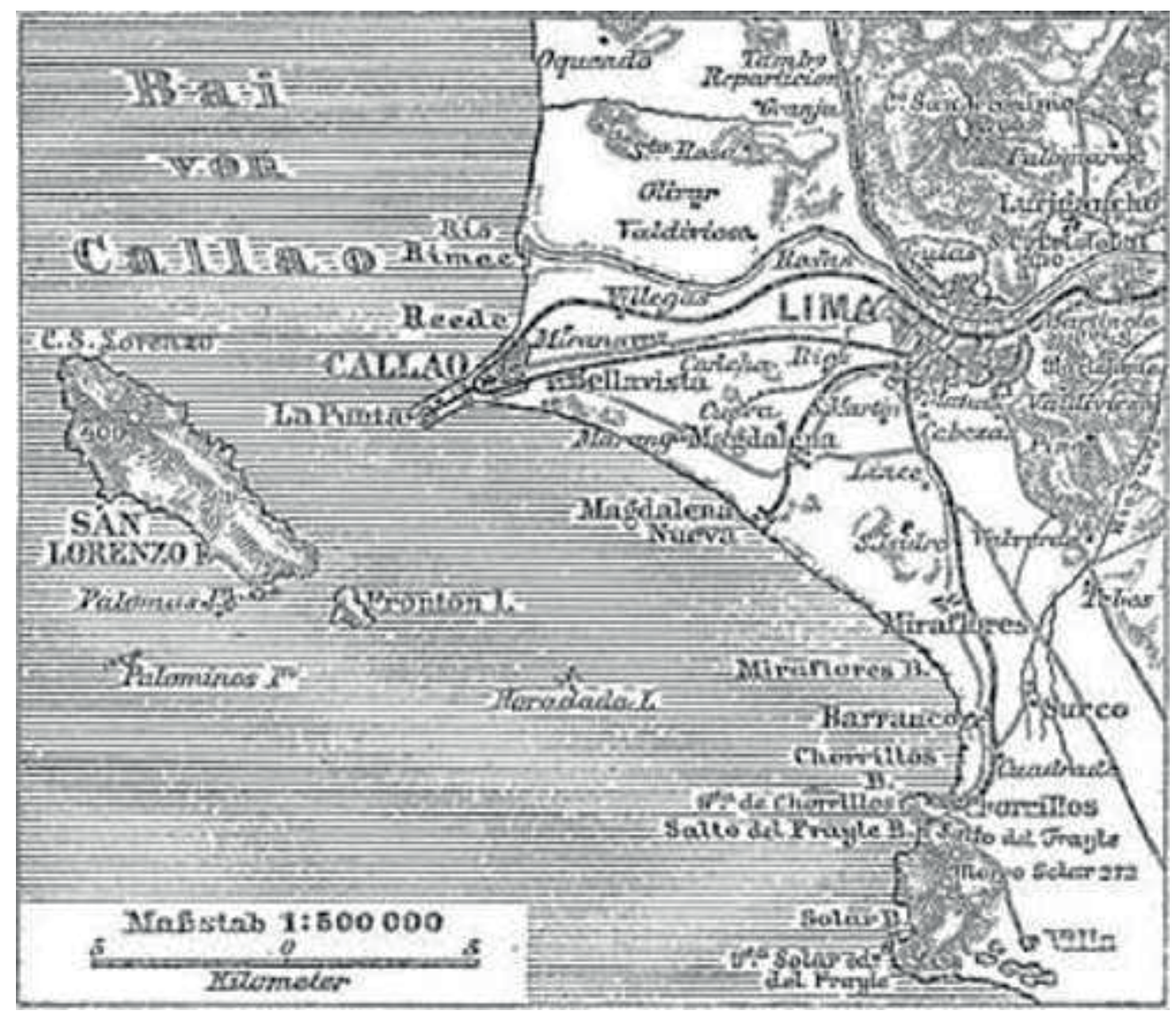

Figura 51. Mapa de Lima y Callao en 1888. Este mapa forma parte de la 4th edition of Meyers Konversations lexikon (1885-90). Lima. Vikipedia, la enciclopedia libre.

\subsection{Siglo $X X$}

1905

Un movimiento negro en Niágara, Canadá, sienta en este país las bases de una nueva legislación acorde con la situación social de los afrodescendientes canadienses.

$1914-1918$

Primera Guerra Mundial. 
1918

En Estados Unidos. Marcus Garvey (n. 1887 - m. 1940) lanza la asociación universal para la mejora de la calidad de vida de las etnias de origen africano en ese país.

$1920-21$

Rebeldes con causa. Huelgas con derramamiento de sangre en Perú por parte de sindicatos organizados. El presidente Augusto B. Leguía (n. 1863 - m. 1932) viene liderando una dictadura populista -el Oncenio - en la que se da el reconocimiento legal de las comunidades indígenas (1919).

1919 a 1930

Harlem. Surge en Nueva York un nuevo Movimiento Negro en Estados Unidos por los derechos civiles, el llamado Renacimiento de Harlem. Se trató de un movimiento popular que buscaba revalorar el arte y la cultura de la población afrodescenciente en este país, el mismo que dejaría profunda huella.

1929

El "crack" de la bolsa neoyorquina de Wall Street provoca una gran depresión mundial de la economía que empobreció a millones de personas en todo el mundo.

1930-33

Perú. Ante el cansancio social por el Oncenio de Leguía, el general Luís M. Sánchez Cerro (n. 1889 - m. 1933) se levanta en armas en la ciudad de Arequipa y toma el 
poder; en 1932, sofoca a sangre y fuego un movimiento social del Partido Aprista Peruano (APRA), en la ciudad de Trujillo, que casi provoca una guerra civil. Sánchez Cerro sería asesinado al año siguiente durante una velada hípica en Lima.

1932

Perú. Durante la dictadura de Sánchez Cerro estalló la rebelión del movimiento obrero y sindical peruano (CGTP) en Lima, donde trabajadores de la industria manufacturera y textil se manifestaron contra los abusos cometidos por sus empleadores, a quienes acusan de explotarlos y tenerlos en condición de semiesclavitud.

$1936-39$

Guerra Civil española. Los republicanos son derrotados por las tropas de Francisco Franco y se instaura un largo régimen franquista en las tierras de Cervantes.

$1939-45$

Segunda Guerra Mundial. En este mismo periodo, Egipto, Etiopía, Liberia y Sudáfrica logran su independencia.

1948

El artículo $4^{\circ}$ de la Declaración Universal de los Derechos Humanos involucra a todas las naciones del mundo. Uno de sus artículos estipula la total eliminación de toda forma de esclavitud, y de toda forma de explotación del hombre por el hombre. (Nota_85) 
2 de diciembre. La Organización de las Naciones Unidas instituye el día en que se conmemora el Convenio para la Represión de la Trata de Personas y de la Explotación de la Prostitución Ajena, suscrito por la Asamblea General (los países integrantes de la ONU) ese año. Posteriormente, en 1998, la Asamblea General decidió que el 2 de diciembre fuera el Día Internacional para la Abolición de la Esclavitud.

$1955-75$

Guerra de Vietnam, que, finalmente, pierde Estados Unidos.

1955

En la Unión. Con el boicot contra el servicio de autobuses de Montgomery (Ohio), comienza la lucha por los derechos civiles en EEUU.

1957

Independencia de Ghana (la ex colonia portuguesa de Costa de Oro). Empieza a nacer un África libre.

1958

La Guinea Francesa se declara independiente a pesar de la oposición de su antigua metrópoli. 
1960

Independencia de Nigeria, ex colonia de Portugal e Inglaterra.

La isla de Madagascar se independiza de Francia.

Níger, una parte del África Occidental Francesa se declara independiente.

La República Democrática del Congo, un inmenso territorio del centro de África, colonizado por portugueses y belgas, declara su independencia el 30 de junio de aquel año. Por su parte, en agosto de ese año, el Congo Brazzaville, una ex colonia de la tierra de Napoleón, se separa del África Ecuatorial Francesa y se declara independiente.

Nace la República de Gabón, tras una cruenta lucha contra la dominación francesa.

Senegal se independiza de Inglaterra y Camerún hace lo mismo de Alemania; por su parte, Malí se rebela contra sus colonos franceses y los obligan a reconocer su independencia.

1961

Sin disparar un tiro, Sierra Leona, ex colonia de portugueses e ingleses, se declara independiente. Inglaterra fue la primera potencia europea en llevar esclavos libertos de regreso a su país. 
1962

Jamaica y Trinidad \& Tobago proclaman su independencia.

Edward G. Dwight es el primer negro candidato a ser astronauta en la NASA.

Argelia, entonces colonia francesa, declara su independencia.

1963

Movimiento por los derechos civiles. Se produce en la capital de Estados Unidos la más grande demostración en pro de los derechos civiles en la historia de este país. La Marcha en Washington por el Trabajo y la Libertad congregó a millones de afroamericanos e integrantes de otras comunidades étnicas en el monumento a Lincoln, donde Martin Luther King pronunció uno de sus discursos más memorables.

En Estados Unidos. Martin Luther King Jr. recibe el premio Nóbel de la Paz por sus acciones en pro del respeto a los derechos civiles.

22 de noviembre. El presidente John F. Kennedy (n. 1917 - m. 1963) es asesinado en Dallas.

Malcolm X (n. 19 de mayo de 1925 - m. 1965) era un ex pandillero de Boston que llegó a ser uno de los activistas de los derechos humanos y defensor de las comunidades negras más importantes de Estados Unidos. En ese año fundó la primera organización para la unidad Afroamericana en Nueva York. Dos años después sería asesinado casualmente en esta ciudad. 


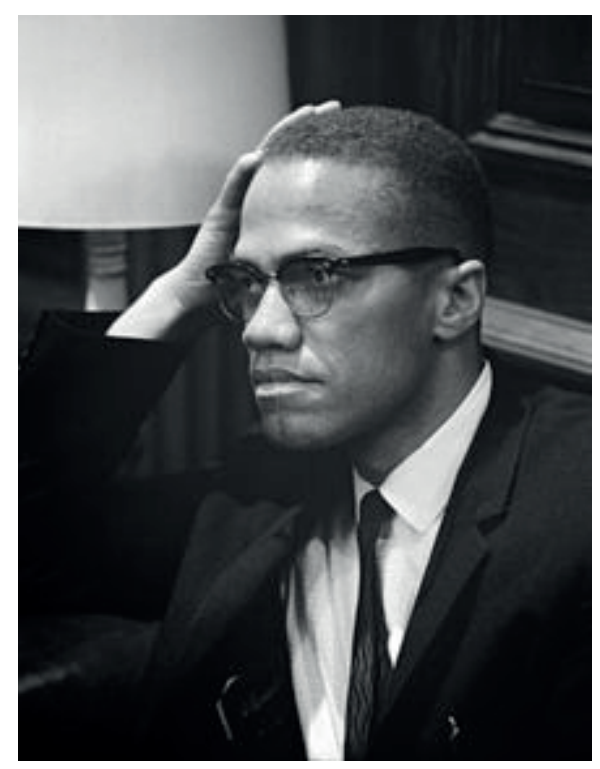

Figura 52. Malcolm X.

Foto de Marion S. Trikosko - U.S. News \& World Report Magazine Collection. Vikipedia, la encyclopedia libre.

1965

África libre. Para ese año ya se habían independizado casi todos los países africanos.

1966

Barbados proclama su independencia.

Primer gobierno americano africano en una comunidad predominantemente blanca en EEUU.

1968

El gran líder de la no violencia y la lucha por los derechos civiles, el ministro bautista Martin Luther King Jr. (n. 1929 - m. 1968), es ultimado a tiros en Memphis por un asesino a sueldo contratado por activistas blancos que lo odiaban. Fue declarado 
héroe nacional y el tercer lunes de enero de cada año pasó a llamarse "Martin Lutner King Day" fue convertido en feriado nacional en 50 estados de la unión.

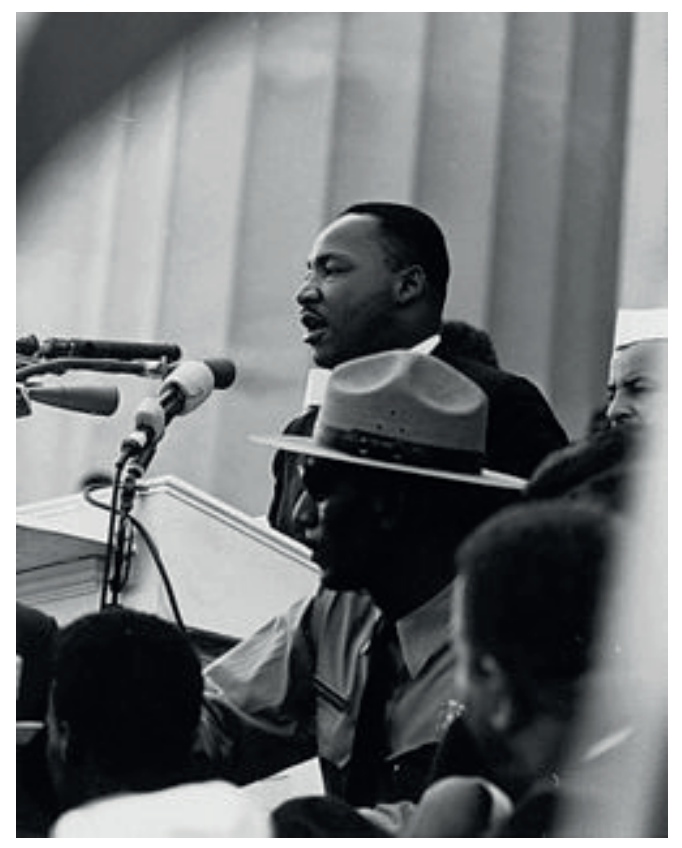

Figura 53. King hablando en la famosa marcha por los Derechos Civiles en el monumento a Lincoln en 1963.

Foto del National Archives and Records Administration. Vikipedia, la enciclopedia libre.

Carl B. Stokes es el primer alcalde negro de una ciudad importante: Cleveland, Ohio.

Guinea Ecuatorial, antiguo protectorado español, se independiza de la otrora metrópoli hispana.

Los atletas negros estadounidenses John Charles y Tommie Smith hacen su polémica demostración de "poder negro" en los Juegos Olímpicos de México.

$1968-80$

El 3 de octubre de 1968, un alzamiento armado del general Juan Velasco Alvarado (n. 1909 - m. 1977) depone al entonces presidente Fernando Belaunde Terry (n. 1912 - m. 2002). Se inicia una dictadura militar -el llamado "Gobierno Revolucionario de las 
Fuerzas Armadas -" en la que se pretende dar mayor protagonismo a las comunidades indígenas. La "Junta Militar" de Velasco instaura un gobierno autoritario de izquierda, no marxista, reconocido por Estados Unidos. Se confiscan los intereses petroleros estadounidenses y se nacionalizan los yacimientos y la producción de petróleo. En 1969 se inició una reforma agraria que fracasó y se confiscaron los periódicos y canales de televisión para entregarlos a los gremios de trabajadores. En 1975 Velasco fue depuesto por su colega, el general Francisco Morales Bermúdez (n. 1921), quien finalmente, en 1978, convocó a elecciones para entregar el poder en 1980 al mismo presidente que Velasco había derrocado: Belaunde.

1973

Uno de los mayores exportadores de esclavos africanos al Nuevo Mundo durante tres siglos, Guinea Bissau se independiza de Portugal en septiembre de aquel año.

1974

El caso Watergate hunde al presidente republicano de Estados Unidos, Richard M. Nixon (n. 1913 - m. 1994), quien finalmente presentó su renuncia.

1975

25 de julio. Mozambique era una provincia portuguesa de ultramar cuando decidió optar por su independencia.

Guinea y Cabo Verde, ex colonias portuguesas, se independizan. 
En noviembre de ese año, tras una sangrienta guerra de independencia y luchas intestinas, Angola se declara independiente de Portugal.

1977

El productor Alex Haley filma para la televisión la serie histórica: Raíces, que narra la historia de unos esclavos africanos que son arrebatados de su pueblo nativo y llevados al sur de Estados Unidos.

1978

Negros en el cosmos. Por vez primera, la NASA elige para sus misiones a tres astronautas negros.

1983

S. Bluford Jr. es el primer astronauta negro en ser lanzado al espacio.

1989

Douglas Wilder es el primer negro que se convierte en gobernador de Virginia (USA).

1990

Haití celebra las primeras elecciones democráticas de su historia, y elige un Parlamento con representantes de raza negra. 
En Sudáfrica, Nelson Mandela deja la prisión, luego de 27 años de encierro.

1999

De fiesta. Al cumplirse los 150 años de la llamada ley chinesca y la Inmigración china al Perú, se estimó que unos 600.000 chinos viven en la capital peruana -residen principalmente en los distritos limeños de San Borja, Pueblo Libre, La Victoria (Balconcillo y Santa Catalina), Jesús María, Lince, Barrios Altos (Barrio Chino), San Martín de Porres y Los Olivos -, mientras que, a nivel nacional, sumando Lima, hay más de un millón de tusanes hasta la quinta generación, que dominan el español, cantonés, mandarín e inglés. Se trata de una población en crecimiento, pues en los últimos diez años (1996-2006) han llegado al Perú unos quince mil chinos. (Nota_86)

\subsection{Siglo XXI}

2001

Lima, 3 de mayo. Los niños no deben hacer trabajos forzados. En un pormenorizado informe, la revista limeña Caretas denuncia que la mano de obra infantil es La fuerza laboral más barata e injustamente tratada del Perú. Dos millones de niños atrapados en jornadas de trabajo inhumanas. (Nota_87) 

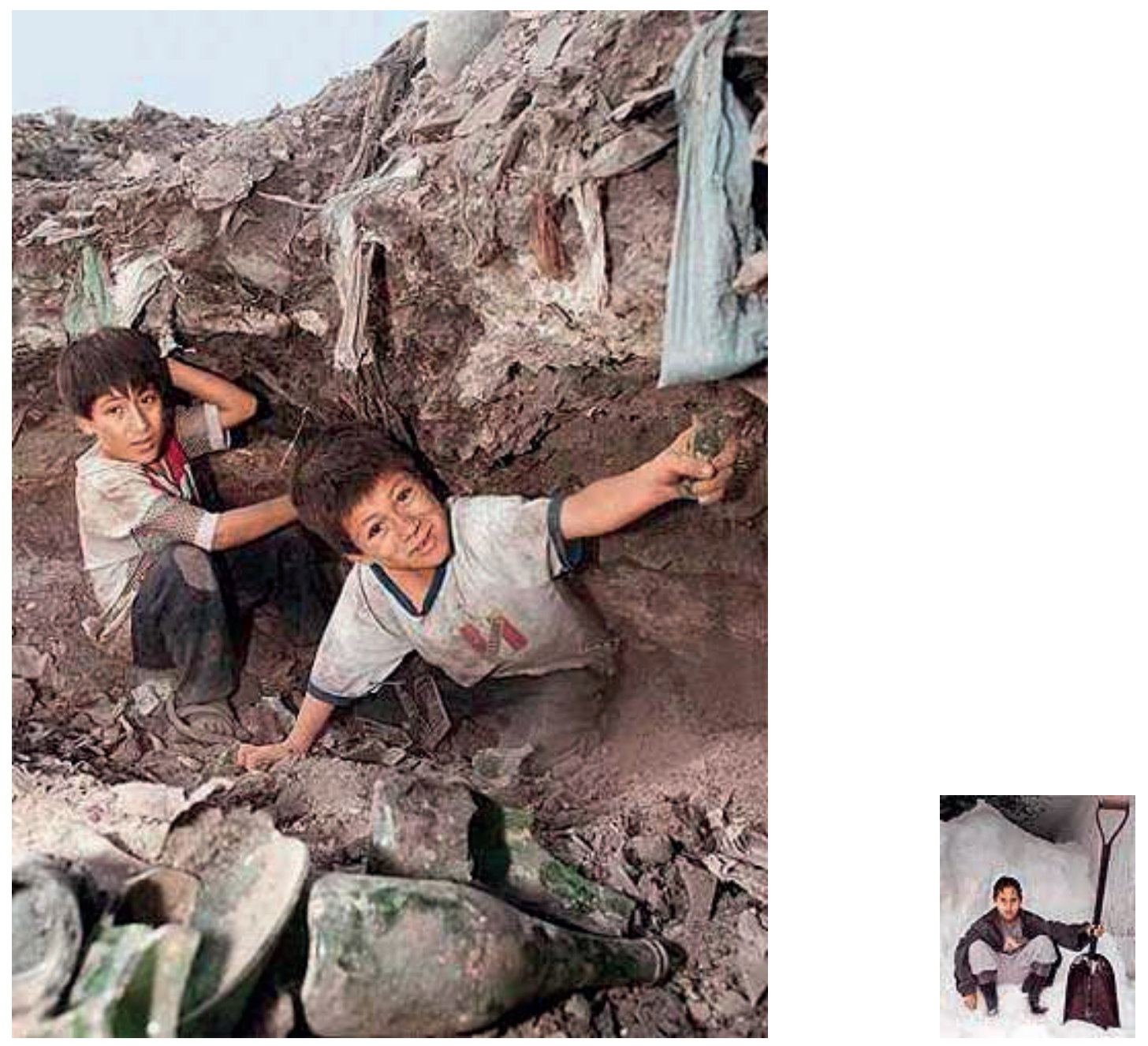

Figuras 54a. y 54b. Polo (9) y Benigno (8) buscan desperdicios en un basural de Carabayllo. El kilo de vidrio cuesta diez céntimos. Derecha: Francisco (10) trabaja seis horas diarias picando hielo en el terminal pesquero de Ventanilla.

Leyenda texto de Gastón Agurto. Fotos de la revista Caretas. 


\begin{tabular}{|c|c|c|c|c|}
\hline \multicolumn{5}{|c|}{$\begin{array}{l}\text { Al Perú en Alnérica Latina: } \\
\text { Ratificación de convenios sobre Trabajo Infantil }\end{array}$} \\
\hline PAISES & $\begin{array}{l}\text { Edad de } \\
\text { educación } \\
\text { obligatoia }\end{array}$ & $\begin{array}{c}\text { Eojad legal } \\
\text { mirima del } \\
\text { ingreso al trakajo }\end{array}$ & $\begin{array}{l}\text { Convenio } \\
138-01 T^{*}\end{array}$ & $\begin{array}{l}\text { Converio } \\
182 \text {-OlTth }\end{array}$ \\
\hline Argentina & 6.14 & 14 & $\checkmark$ & $\checkmark$ \\
\hline Bolivia & 613 & 14 & $\checkmark$ & -- \\
\hline Brasil & $7-14$ & 16 & $\checkmark$ & $\checkmark$ \\
\hline Chile & 6.13 & 15 & $\checkmark$ & $\checkmark$ \\
\hline Colombia & 612 & 14 & $\checkmark$ & en táainite \\
\hline Costa Rica & 6.15 & 15 & $\checkmark$ & $v$ \\
\hline Ecuador & 6.14 & 14 & $\checkmark$ & $\checkmark$ \\
\hline El Salvador & $7-15$ & 14 & $\checkmark$ & $\checkmark$ \\
\hline Honduras & 7.13 & 14 & $\checkmark$ & $\checkmark$ \\
\hline Guatemala & $7-14$ & 14 & $\checkmark$ & $\checkmark$ \\
\hline Nicaragua & $7-12$ & 14 & $\checkmark$ & $\checkmark$ \\
\hline Panamá & 615 & $14-15$ & $\checkmark$ & $\checkmark$ \\
\hline Paraguay & 7.12 & 15 & apromugarse por Ejecutwo & $\checkmark$ \\
\hline Perú & $6=16$ & 12 & renitidoal Congreso & -- \\
\hline Rep Dominicana & $7-14$ & 14 & $\checkmark$ & $\checkmark$ \\
\hline Uruguay & 6.14 & 15 & $\checkmark$ & $\checkmark$ \\
\hline Venezuela & 515 & 14 & $\checkmark$ & -- \\
\hline \multicolumn{5}{|c|}{$\begin{array}{l}\text { * Conyenio sobre la ecad minima de admisión al trroleo. } \\
\text { * Convenio sobre la prokikición de las peores formas del tabajo infantil y la acción inme } \\
\text { dlata para su elminación. }\end{array}$} \\
\hline
\end{tabular}




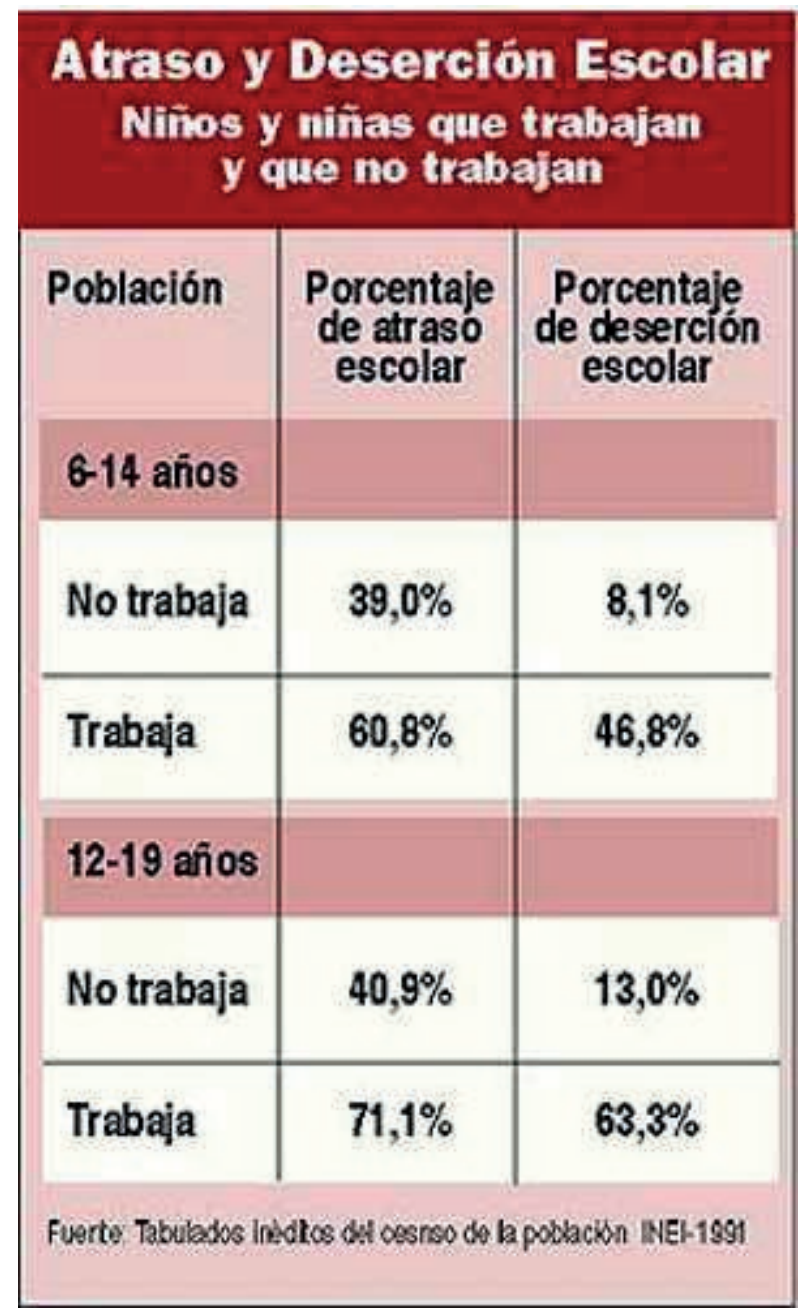

Figuras 54c. y 54d. El empleo se contradice con la educación. Derecha: el Perú es el país de latinoamérica que permite la menor edad para trabajar.

Leyenda texto de Gastón Agurto. Fotos de la revista Caretas.

31 de agosto al 1 de septiembre. Se realiza en Durbán, Sudáfrica, la III Conferencia Mundial contra el Racismo, Discriminación Racial, Xenofobia e Intolerancia, evento ha incluido a la esclavitud como parte de su agenda.

No quieren. Estados Unidos envió a Durbán una comitiva de bajo nivel a la conferencia contra el racismo, pero persistieron con su política de no intervención, llegando incluso a amenazar con un boicot, si los organizadores del evento tocaban 
puntos que incomodaban a la administración Bush, tales como cuestionar a Israel, país de quien es aliado. Estados Unidos, país que en su momento fue uno de los mercados negreros más activos, no acudió a las conferencias anteriores (1978 y 1983) por no estar de acuerdo con la agenda.

Monstruo de mil cabezas. En un especial de BBC MUNDO publicado con ocasión de la conferencia mundial contra el racismo, destaca el tema de la esclavitud con las siguientes palabras: La esclavitud alteró millones de vidas en el pasado. Organizaciones africanas y afroamericanas de derechos humanos reclaman el pago de una compensación por parte de los países europeos.

Pero la esclavitud no ha desaparecido. Grupos de derechos humanos aseguran que en Sudán se la ejerce. Los bajos salarios de campesinos brasileños serían, en la práctica, una forma de esclavización. (Nota_88)

Ser negro es pasaporte al paro. Dentro del marco de la conferencia de Durbán, se informó que los prejuicios raciales todavía sobreviven en Sudáfrica, el país anfitrión del evento, con una población mayoritariamente negra. Según datos oficiales de 1999, el 36\% de los hombres y el 51\% de las mujeres negras están desempleados, mientras que entre la población blanca, este índice apenas supera el 7\%.

Cifras de la esclavitud. Información de BBC Mundo del 5 de septiembre. La conferencia contra el racismo también sirvió para sacar "cuentas" sobre las dimensiones numéricas de la esclavitud en los últimos 500 años de historia. 
Figura 55

\section{Cifras de la esclavitud}

-Afectados por la comercialización de Esclavos (África-América) Siglos XV y XIX Entre 10 y 28 millones de personas.

-Hombres, mujeres y niños fallecidos antes de llegar a las distintas colonias europeas: Un 20\% (aproximado)

-Esclavos africanos que cruzaron el Atlántico desde sus países de origen a las colonias de Norte América, Sudamérica y el Caribe (1450-1850)

12 millones

\section{Comercio de esclavos desde África}

-Vendidos en las costas del Océano Índico, Medio Oriente y norte de África 17.000.000

-Trasladados a América

12.000 .000

-Viajaron a través del Sahara y África del Este 5.000 .000

-Primer país europeo en iniciar la esclavitud en el Atlántico Portugal (S. XV) 
-Primer país europeo en formar una sociedad de indias orientales para la trata Holanda (1602)

-Primer país europeo en formar una sociedad antiesclavista Inglaterra (1787)

-Primera potencia europea en abolir la esclavitud Dinamarca (1803)

-Primer país no hispano en abolir la esclavitud en América Haití (1801)

-Primer país de habla hispana en abolir la trata en América República Dominicana (1801)

-Primera potencia europea en votar la abolición de la esclavitud en América Francia (1794)

-Último país en prohibir la esclavitud en el mundo Brasil (1888)

Fuente: BBC Mundo - III Conferencia Mundial contra el Racismo, Discriminación Racial, Xenofobia e Intolerancia. Durbán, Sudáfrica, 2001 (Nota_89)

Europa pide perdón por la esclavitud (a medias). Referencia: BBC Mundo del 7 de septiembre. En la conferencia de Durbán, se dio un gesto atípico para un "primer mundo" que no contempla la humanidad desde una perspectiva humana y que rechaza a los inmigrantes africanos, asiáticos y latinoamericanos que buscan el viejo 
continente para salir de la miseria: los delegados de los países europeos que recibieron beneficios con la esclavitud acordaron disculparse por el tráfico de esclavos desde una perspectiva moral. Esto, desde luego, no implica un compromiso de compensación económica por parte de los países del viejo continente para con los descendientes de las víctimas de la trata. Muchas comunidades aborígenes africanas y organizaciones de derechos humanos, además de organizaciones representativas de las comunidades negras de América, chinas y demás, expresaron su disconformidad por una solicitud de disculpas tan poco "sincera".

La explotación infantil en el Perú y el mundo. ADITAL, 11 de abril. Existen más de 400 millones de niñas esclavas en el mundo, menores de 15 años. -Niñas de 6 años trabajan en minas de oro y mercurio en Perú-. 70 millones de esclavas adolescentes fabrican en China. Cifras alarmantes que muestran la desprotección y el abandono de las niñas y los niños del mundo, una realidad que se da no sólo en el Perú; estas cifras, proporcionadas por ADITAL, dan escalofríos. Esta organización defensora de los derechos humanos, en una apretada síntesis publicada en un boletín, agrega también que en España existe una suerte de impunidad solapada en cuanto a la situación de miles de menores de edad, lo que no otorga a este país una situación tan envidiable que digamos; así, denuncia la existencia de más de 20.000 niños y niños y niñas sometidos a la explotación en la comunidad de Madrid. Además, también denunció que en la capital española hay unas 5.000 niñas y niños inmigrantes que no van a la escuela y viven en condiciones miserables. Volviendo al ámbito mundial, ADITAL agrega también que más de 200.000 niños son comprados como esclavos en África Occidental.

-Las familias afganas están vendiendo a sus hijas para poder sobrevivir. 
-Medio millón de niñas son utilizadas como esclavas en más de 87 países.

-Miles de niñas son explotadas en las cadenas del narcotráfico.

-Existen en el mundo 300.000 niños soldados a los que se les entrena para matar.

-Un millón de niñas son explotadas sexualmente en el mundo, más de la mitad en Asia.

-300.000 niños y niñas sufren explotación laboral en España (agricultura e industria textil).

-Uno de cada 6 niños de los países enriquecidos vive sumido en la pobreza (OCDE).

-Hay más de 2 millones de niñas explotadas en las calles de Paraguay.

-En Pakistán, hay 3,5 millones de niñas esclavizadas, unas 7.000 vinculadas a la industria del balón.

-50.000 esclavas vendidas a EE.UU. al año entre mujeres y niñas para prostitución y servicio doméstico.

-En África Occidental 200.000 menores son vendidos a las plantaciones de cacao o café.

-Niñas entre 12 y 18 años del Este de Europa, las más codiciadas por las mafias para la explotación sexual infantil (entre 200.000 y 400.000 sólo en Alemania). 
-En España se venden niños para trasplante de órganos.

-Hay 13 millones de niños huérfanos por el SIDA.

-Hay 14 millones de niños refugiados por las guerras.

-Más de 15 millones de niñas asesinadas en China desde 1975, por la política del hijo único.

-500.000 menores entre 12 y 14 años, explotadas en México. (Nota_90)

¿Tapar el sol con un dedo? El entonces Consultor de la Organización del Trabajo en Brasil (OIT), Eduardo Bedoya, denunció que en Ibero América vivían unos 1,3 millones de personas sometidas a condiciones de esclavitud. Entre ellas se cuenta un gran número de indígenas forzados a trabajar en la industria maderera en Perú, o como cortadores de caña en Bolivia, y en grandes ranchos de Paraguay. Bedoya también indicó que en Bolivia los indígenas son obligados a trabajar en haciendas de caña de azúcar en jornadas de hasta 12 horas diarias y sujetos a castigos físicos si comenten algún error. Ante esta situación, muchos gobiernos, en especial algunos sudamericanos como es el caso del Perú, han adoptado la postura del avestruz o se han "lavado las manos" -pues parece que el tema "les quema", por un lado, mientras que por el otro habría intereses creados entre algunos malos cargos y funcionarios públicos, amén de ciertas autoridades civiles y policiales que se alían con empresarios sin escrúpulos, y el accionar criminal de las bandas de traficantes de personas (internacionales y locales), a las que se suman los explotadores de trabajadores forzados - , sin que les entre el más mínimo remordimiento. (Nota_91) 
4 y 5 de octubre. Se lleva a cabo en Montevideo la Conferencia contra el Racismo en América Latina y el Caribe, donde participaron 17 países.

Porcentajes étnicos. En aquella reunión de Uruguay, Naciones Unidas informó que los descendientes de Africanos son el 30\% de la población actual de América Latina y el Caribe, mientras que en el caso de los indígenas está entre el 8 y el 15\%.

2004

11 de enero. La ONU declara a ese año como "Año mundial contra la esclavitud" como parte de la conmemoración de la Lucha contra la esclavitud y su abolición. Esto se realizó en una ceremonia organizada en Cape Coast, en Ghana, uno de los centros históricos de la trata negrera que ha sido declarado como patrimonio cultural de la humanidad por la UNESCO.

Nadie "la ve"... pero está allí. Noticia de BBC Mundo del 3 de diciembre. Ya no zarpan los barcos de África con esclavos para ser vendidos en América, no se comercia con los seres humanos en público, donde los terratenientes revisan los dientes y la capacidad física de los esclavos, pero el tráfico continúa. Esta fue la desoladora conclusión a la que se llegó en el Año Internacional de Conmemoración de la Lucha contra la Esclavitud y de su Abolición, propiciado por las Naciones Unidas. "Desafortunadamente, nuestros cálculos indican que la esclavitud moderna está en aumento", dijo a la BBC Angélica Berndt del Grupo Internacional Contra la Esclavitud (Anti-Slavery International).

Esta organización sostiene que la esclavitud contemporánea "adopta diversas formas y afecta a personas de todas las edades, géneros y razas", pese a que a que "está prohibida en la mayoría de los países donde se practica". 
Además, según el grupo, "el trabajo en condiciones de servidumbre afecta a por lo menos 20 millones de personas en todo el mundo".

El director de la UNESCO para Centroamérica, Arvelio García, dice que para encarar el actual problema de la esclavitud es preciso mantener en mente los errores del pasado:

"Nosotros hemos partido del reconocimiento mundial del problema. La esclavitud fue una tragedia sin precedentes de la humanidad que hoy en día se ha transformado".

La prostitución, la explotación doméstica y el trabajo infantil son los ejemplos más evidentes de la esclavitud moderna.

García describe varios motivos por los que las personas se convierten en víctimas de la esclavitud:

"En muchos casos se hace por la necesidad de trabajo; en otros, porque el menor aporta una fuerza de trabajo inagotable y puede ser mal pagado, y algunas veces porque los niños son de familias pobres". (Nota_92)

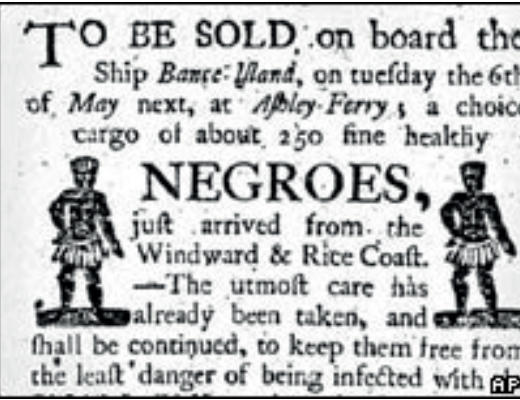

Figura 56. La esclavitud permanece camuflada.

Aviso de época publicitando la venta de esclavos en el sur de Estados Unidos (S. XIX). 
Perú Negro. Coincidiendo con el año de la conmemoración de los 150 años de la abolición de la esclavitud en el Perú, según cálculos y proyecciones basados en censos generales anteriores al de 2005 en Perú, en el Perú viven actualmente unos 2.500.000 afrodescendientes, aproximadamente. (Nota_93)

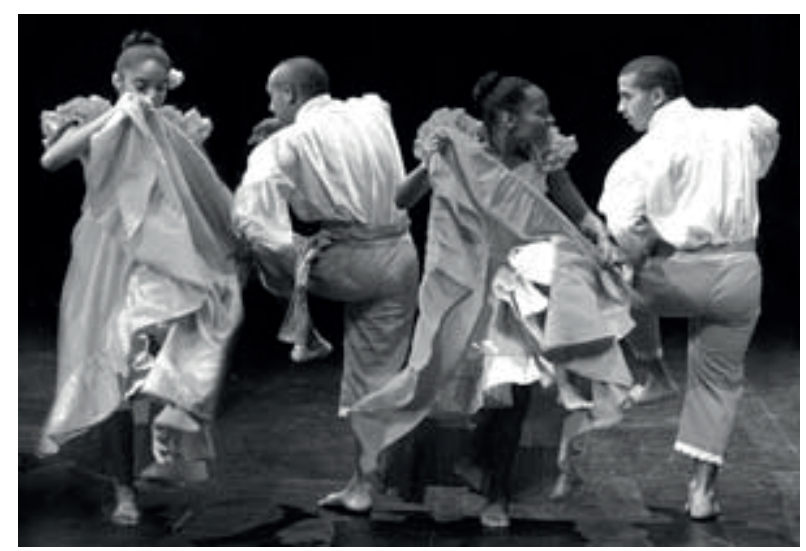

Figura 57. Perú Negro pa' todo el mundo. Uno de los ritmos afrolatinos más emblemáticos es esta trepidante danza peruana que resume toda la magia y la fuerza de este pueblo venido de lejos que supo preservar sus tradiciones. En la imagen, vemos en acción a uno de los tantos grupos de "Perú Negro" que se han difundido fuera de nuestras fronteras. Foto de Victoria Lord Public Relations Inc. Roy Thomsom Hall. Toronto, Canadá.

La vergüenza (ajena) de Brasil. Noticia de BBC Mundo del 20 de julio. Un informe de la Organización Internacional del Trabajo (OIT) denunció que en Brasil hay unas 25.000 personas que trabajan en condiciones de esclavitud en apartados fundios amazónicos. Estas personas, aparentemente, fueron contratadas para hacer labores de campo y pastoreo. Sin embargo, según testimonios, están siendo sometidas a condiciones totalmente insalubres, además de la explotación: "Viven en tiendas rústicas bajo láminas plásticas, en el medio de la selva, sin sanidad ni agua potable. Ingieren a veces comida podrida, restos de vacas que murieron de enfermedades. No 
tienen platos, comen en latas; a veces, latas que fueron envases de pesticidas", indicó Jan Rocha, autor del citado informe. (Nota_94)

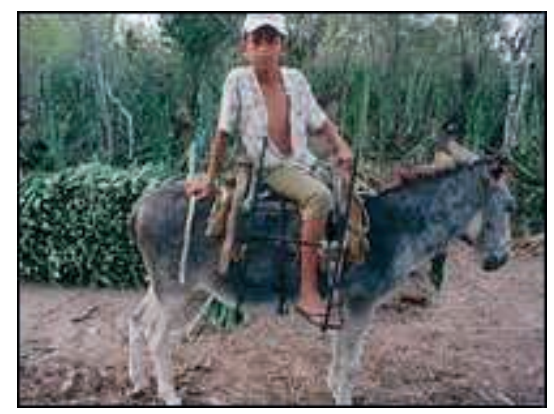

Figura 58. En Brasil la esclavitud fue abolida en el siglo XIX, pero del dicho al hecho..., se puede constatar las lamentables condiciones de insalubridad y trabajos forzados en las que vive esta gente. Foto de BBC MUNDO. Artículo Brasil: "25.000 esclavos". 20 de julio de 2004.

El estudio mencionado arriba de estas líneas señala también que se han detectado que cientos de bolivianos que llegan al Brasil son explotados en la ciudad de San Pablo, aprovechándose de sus necesidades de subsistencia.

Se ha estimado que el cruento genocidio en América provocado por los europeos tuvo como saldo unos 90 millones de indígenas diezmados, sino a sangre y fuego para quitarles sus tierras y someterlos a servidumbre, con las enfermedades que los colonizadores trajeron consigo. A estos se suman, por supuesto, muchos otros millones más de negros esclavizados importados del África en condición de mercancía. Se habla, por ello de unos 66 millones de esclavos africanos, los que desde el siglo XV hasta fines del siglo XIX fueron arrebatados de su tierra. De ellos, unos quince millones de negros -según algunos autores - dieron con sus huesos en suelo americano.

En el Perú la esclavitud está abolida, pero... En septiembre de este año una legisladora peruana, Dora Núñez, denunció que en su país hay unos 2.000.000 de 
niños viviendo en las peores condiciones de esclavitud y señaló como uno de los responsables de que no se haga nada al respecto al propio gobierno del entonces presidente Alejandro Toledo. También se denunció que los niños son explotados sobre todo como cargadores de cosechas en la sierra, asimismo, exponen sus vidas en lavaderos de oro informales, ubicados en la zona de selva alta y baja en el centro y sur del país, amén de hacer duras tareas en la industria. "Es una canallada llamar trabajo lo que es explotación y esclavitud actualmente en Perú durante un promedio de 45 horas a la semana, señala un informe presentado en el Congreso peruano. Nuñez indicó que el promedio de horas semanales de "trabajo de los menores es apenas menor en tres horas al de los adultos" Por otro lado, se reveló que el 70 por ciento de los menores explotados pertenecen a zonas rurales, y un 30 por ciento a las áreas urbanas. En aquella oportunidad, la legisladora presentó un proyecto de ley para modificar el Código del Niño y Adolescente y erradicar el "trabajo forzado" infantil. Pero en los últimos años, la esclavitud infantil ha aumentado. El citado proyecto, hasta ahora, duerme el sueño de los justos. (Nota_95)

Los datos más conservadores del UNICEF indican que en todo el mundo hay unos 240 millones de niñas y niños víctimas del trabajo infantil; sin embargo, los datos más reales hablan de 400 millones de niños esclavos que trabajan de sol a sol sin recibir ninguna atención. La región de Asia y el Pacífico alberga el mayor número de niños y niñas explotados en el grupo de edad de 5 a 14 años, 127,3 millones en total según UNICEF (19\% de los niños y niñas que trabajan en la región); en África subsahariana hay alrededor de 48 millones de niños que trabajan. Casi uno de cada tres menores de 15 años (29\%) es activo económicamente. Por otro lado, en lo que respecta a América Latina y el Caribe, el estudio señala que hay aproximadamente 17,4 millones de niños y niñas trabajadores (un 16\% de los niños y niñas de la región trabajan); un 15\% de los niños y niñas de Oriente Medio y África del Norte trabajan; 
aproximadamente entre 2,5 millones y 2,4 millones de niños y niñas trabajan en las economías desarrolladas y en transición respectivamente. (Nota_96)

29 de marzo. Se inaugura en la ciudad de Zaña, localidad ubicada a 46 kilómetros al sur de Chiclayo, capital de la Región Lambayeque, el primer Museo Afroperuano del Perú, uno de los tres de este tipo que hay en América, con el objeto de perpetuar la memoria de cinco siglos de historia de la comunidad de afrodescendientes peruanos. El museo conserva recuerdos de los tiempos de la esclavitud. Zaña, cuyos habitantes son mayormente gente de color, fue fundada en 1563 y es famosa por sus bellas casonas y por las ruinas de sus conventos e iglesias, que datan de los siglos XVII y XVIII, y por su música típica. La sede del museo es una vieja construcción colonial, en cuya Sala de Castigos y Tortura se castigaba a los negros esclavos que cometían alguna falta por leve que fuera. Aquí se conservan instrumentos que servían para torturar a quienes caían en desgracia, tales como el cepo, los grilletes y la carimba que servía para "marcar" a los esclavos como si de ganado se tratara-, además de un potro, un garrote, entre otras "lindezas".

La organización ecologista WRM (Movimiento Mundial por los Bosque Tropicales) advirtió, en noviembre de este año, que la esclavitud del siglo XXI se llama ahora "trabajo forzado". La organización, además, denunció el madereo ilegal en la Amazonía peruana y brasileña donde se emplean trabajadores sin pago para realizar los trabajos más pesados. En la Reserva Nacional Pacaya Samiria, ubicada en el triángulo formado por la confluencia de los ríos Marañón y Ucayali, se ha identificado que trabajan un promedio de 20 hombres por campamento, y anualmente funcionan unos 50 de ellos.

Es justamente en este sector del madereo ilegal donde abunda un sistema laboral asociado al no pago, a la remuneración en especies, a la prostitución de mujeres en 
los campamentos madereros y a condiciones de trabajo infrahumanas -finalizó WRM. (Nota_97)

2006

11 de marzo. En un informe presentado en Sao Paulo, Brasil, la Organización Mundial del Trabajo (OIT) reveló que en Latinoamérica hay más de un millón de esclavos y que la población indígena es la más vulnerable a ser sometida a condiciones de esclavitud. Esta información se dio durante un seminario de la Conferencia sobre Reforma Agraria y Desarrollo Rural (Ciradr), realizada por la FAO en Porto Alegre, sur de Brasil. La misma fuente indicó también que las estadísticas de la OIT citadas en el debate señalan que de los 12,3 millones de esclavos que hay en todo el mundo, 1.3 millones viven en países de Latinoamérica y el Caribe. En países como Bolivia, Paraguay y Perú, la población indígena es la más sometida a condiciones de esclavitud, afirmó el organismo internacional.

La explotación sexual en el Perú. Noticia publicada el 29 de marzo. Según el portal cimacnoticias.com, la pobreza, el flujo turístico y la actividad minera son algunas de las causas que estarían generando la trata de mujeres, niñas y niños en el Perú, donde existen mafias que captan a sus víctimas con fines de prostitución, trabajo y matrimonios forzados o mendicidad, entre otros.

El artículo, basado en el estudio "Diagnóstico sobre trata de mujeres, niños y niñas en ocho ciudades del Perú", elaborado por el Centro de la Mujer Peruana "Flora Tristán", agrega también que esta problemática involucra mecanismos de captación o coacción que se desarrollan en la informalidad y la ilegalidad, amparados en un gran sistema de corrupción, en la tolerancia y la indiferencia social (...). El informe señala que en la ciudad del Cusco, por ejemplo, operan redes a nivel local y nacional que 
utilizan este famoso destino turístico como lugar de paso para mujeres y niñas con el propósito de brindar "servicio sexual" a ocasionales clientes. La investigación, además, denuncia que en esta ciudad existen dos redes, cuyas conexiones están en Arequipa y Juliaca, área cercana a la extracción de gas de Camisea, donde ha aumentado la demanda de prostitutas adolescentes.

De otro lado, el mismo estudio indica que este problema se ha extendido a nivel nacional, como lo indica el hecho de que en otras ciudades y regiones también se practica esta "esclavitud" solapada, como ocurre por ejemplo en la ciudad de Cajamarca, en la sierra norte de Perú, donde sus autoridades municipales informaron haber detectado la existencia de, al menos, 1.000 mujeres que estarían sometidas a explotación sexual, lo cual parece responder a la presencia de la minera Yanacocha en esta región, empresa que, por cierto, da trabajo a personal extranjero y peruano con buenos ingresos económicos. Por otra parte, la investigación recuerda que en febrero de 2004, la policía desarticuló, en la localidad de San Antonio de Putina (Puno), la red de prostitución infantil más grande del país. Otro caso es el de las ciudades de la selva peruana. El estudio indica que en la ciudad de Iquitos, así como en Puerto Maldonado y Tarapoto (en Madre de Dios y San Martín, respectivamente), existen operadores turísticos que ofrecen paquetes que incluyen servicios sexuales. El estudio advierte que existe una relación entre la trata, el tráfico y la explotación doméstica. El diagnóstico da cuenta que el 90\% de empleadas del hogar vienen a Lima y otras ciudades grandes peruanas de las zonas rurales y empobrecidas del país, principalmente de Puno, Cusco, Arequipa y Huancavelica. "La trata es un problema social y debe ser abordado, desde un enfoque de derechos humanos, como un atentado contra la vida, la seguridad y la integridad de las personas", señala Liz Meléndez, socióloga del Programa de Derechos Humanos de las Mujeres, del Centro Flora Tristán. La misma estudiosa agrega que la mayoría de las víctimas de esta explotación no denuncian los atropellos que sufren por carecer de documentos y por 
el temor que les inspiran quienes las explotan. Cuando se supone que la Constitución Política del Perú prohíbe estas prácticas, tales abusos se cometen a vista y paciencia de las autoridades responsables, y del congreso peruano, que tiene en el limbo proyectos de ley a favor de las víctimas de esta trata y explotación totalmente indignantes. (Nota_98)

\section{Esclavitud del siglo XXI}

La Organización Mundial del Trabajo (OIT) ha identificado ocho modalidades actuales de trabajo forzado, como se puede apreciar en el siguiente cuadro:

Figura 59. Definiciones de trabajo forzado según la OIT y los países donde se ha reportado que la práctica de la esclavitud todavía existe.

Modalidad: Esclavitud

Definición: Secuestro físico seguido de la imposición de trabajo forzoso.

Países: Congo, Liberia, Mauritania, Sierra Leona, Sudán

Modalidad: En la agricultura y en zonas rurales remotas

Definición: Trabajadores destinan todo su sueldo para el pago de transporte, comida y habitación ya que se encuentran "endeudados" con reclutadores sin escrúpulos y con los propietarios de las tierras; no pueden dejar el lugar porque son mantenidos a la fuerza, con amenazas o por encontrarse en lugares remotos.

Países: Benín, Bolivia, Brasil, Costa de Marfil, República Dominicana, Guatemala, Haití, México, Paraguay, Perú, Togo

Modalidad: Servidumbre por deudas 
Definición: Otra forma de servidumbre por deudas se presenta cuando un trabajador acuerda trabajar a cambio de un préstamo, pero éste rápidamente se convierte en servilismo puesto que el empleador le incrementa más y más "adeudo" a la negociación.

Países: Bangladesh, India, Nepal, Pakistan, Sri Lanka

Modalidad: Tráfico de personas

Definición: Individuos son obligados o engañados por alguien para ir a algún lugar, quien los venderá u obligará a trabajar en contra de su voluntad, comúnmente en prácticas sexuales. Muchos países son ambos "origen" y "destino" de las víctimas. Países: Albania, Bielorrusia, Bosnia, Herzegovina, Brasil, China, Colombia, Costa de Marfil, República Checa, República Dominicana, Francia, Ghana, Haití, Honduras, Hungría, Israel, Italia, República de Corea, Laos, Latvia, Malasia, Moldavia, Myanmar, Países Bajos, Nepal, Nigeria, Filipinas, Polonia, Rumania, Rusia, Tailandia, Ucrania, Reino Unido, EUA, Vietnam, Yugoslavia

Modalidad: Abuso de trabajadores domésticos

Definición: Amas de llave o empleadas domésticas son vendidas a sus empleadores o dadas en servidumbre a causa de deudas.

Países: Benín, Costa de Marfil, Francia, Haití, el Medio Este

Modalidad: Algunos aspectos de trabajo en la penitenciaría

Definición: Contratar el trabajo penitenciario o forzar a los prisioneros a trabajar para empresas lucrativas.

Países: Australia, Austria, China, Costa de Marfil, Francia, Alemania, Nueva Zelanda, Madagascar, Malasia, EUA

Modalidad: Participación obligatoria en Obras Públicas 
Definición: Obligación legal impuesta a un individuo para trabajar en proyectos públicos de construcción como calles y puentes.

Países: Camboya, República Centroafricana, Kenia, Burma (también Myanmar), Sierra Leona, Swazilandia, Tanzania, Vietnam

Modalidad: Trabajo forzoso impuesto por militares

Definición: Civiles son obligados a trabajar para las autoridades gubernamentales o militares.

Países: Burma (también Myanmar)

Fuente: Guía de Estado: La Esclavitud y el Trabajo Forzoso. USA Today - hrea.net. (Nota_98)

La explotación de la infancia en el Perú. En el rubro correspondiente a Tráfico de Personas, del cuadro de arriba, se omite el nombre del Perú, toda vez que se ha denunciado reiteradas veces que niños son arrebatados a sus familias en las zonas más empobrecidas de Lima y otras ciudades del país para ser vendidos a parejas extranjeras o a organizaciones criminales de pedofília y prostitución infantil. Se ha denunciado también que, actualmente, cientos de menores de edad laboran de sol a sol y en las peores condiciones en minas clandestinas de Lima, Cajamarca, Ayacucho, Pasco, Apurímac, y Huancavelica, o en lavaderos de oro informales de las zonas selváticas de Cusco, Madre de Dios y Puno, mientras las autoridades peruanas no hacen nada.

Sigue. Fuentes del Congreso de Estados Unidos consideran que más de 700.000 personas son vendidas todos los años, 50.000 de ellas son muchachas o mujeres traficadas en Estados Unidos. El tráfico de seres humanos, según la Organización Internacional para las Migraciones, constituye un negocio que gira entre los $5.000 \mathrm{y}$ 
los 7.000 millones de dólares. Fragmento La Esclavitud del Siglo XXI, de un editorial del portal católico Mensajero de San Antonio. (Nota_99)

\section{Epílogo}

\section{Figura 77}

La tragedia de la esclavitud negra no sólo estuvo en el Perú y América: el dolor de un continente. (Nota_100)

Consecuencias del tráfico (de esclavos) para África.

¡Qué de barcos, qué de barcos!

¡Qué de negros, qué de negros!

¡Que largo fulgor de cañas!

¡Qué látigo el del negrero!

Fragmento de Balada de los abuelos, de Nicolás Guillén.
Ah, pueblo de todas partes
ah, pueblo, contigo iré
pie con pie, que pie con mano,
iremos que pie con pie.

Nota: Enciclopedia Universal en español (Nota_101).

Cuando se habla de la esclavitud y sus secuelas en las latitudes donde este tráfico prosperó, muy pocos se detienen a pensar en las terribles consecuencias que este comercio humano trajo consigo en el continente negro, víctima principal de la expoliación de personas más grande jamás vista en la historia de la humanidad. El 
recuerdo y la memoria racial de los pueblos de las costas atlánticas e índicas del África no olvidan y aún lloran a sus antepasados que fueron arrebatados de sus tierras para ser llevados muy lejos y a quienes no volvieron a ver. Ellos también eran de carne y hueso, tenían un alma, y soñaban con ver crecer a sus hijos.

Efectos demograficos:

El tráfico de esclavos provocó estragos en Africa, los cuales aún hoy en día se hacen sentir. Durante cuatro siglos este continente fue escenario de guerras y razzias por la captura de esclavos. Millones de africanos fueron exportados para tierras lejanas, otros tantos millones murieron en largas marchas hasta la costa y en los almacenes a la espera de ser embarcados. Este éxodo forzado de millones de personas provoco la disminución del crecimiento vegetativo de la población africana, ya que los hombres y mujeres en edad de procreación eran vendidos. Algunos investigadores llegan a decir que entre los siglos XV y XIX el continente perdió más de cien millones de hombre y mujeres jóvenes. Varias regiones africanas quedaron casi totalmente despobladas. El investigador André Gunder Frank en su libro La Acumulación Mundial 1492-1789 señala la cifra de 13.750 .000 esclavos traídos a América entre los siglos XVI y XIX, a lo que el investigador Enrique Peregalli añade un 25\% por muertes en el trayecto y un $25 \%$ más por muertes en Africa con motivo de las guerras de captura, lo que da un total de 20.625.000 africanos perdidos para el continente en ese período(). Igualmente, se calcula que en ese período sólo desde la costa de Angola a los puertos de São Tomé y América fueron transportados tres millones de esclavos. Así se explica que las zonas más pobladas en el Siglo XV como el Congo, Ndongo y Quissana, en el Siglo XVII estuviesen ya despobladas. Además, muchas poblaciones, ante el peligro de la esclavitud, abandonaron sus zonas originales, refugiándose en las regiones interiores, ayudando a la despoblación.

Efectos políticos: 
El comercio de esclavos era el más lucrativo y los europeos se encargaron de persuadir a los jefes locales y a los mercaderes africanos para participar en él. De este modo se produjo una reacción en cadena. La aristocracia, los jefes y los comerciantes africanos querían aumentar su riqueza, autoridad y poder, queriendo también defender su independencia. Para ello, necesitaban de armas de fuego y mercancías de Europa. En este contexto, la fabricación de armas de fuego se transformó en un gran negocio de exportación. Con ellas se organizaban extensas cazas de hombres, ataques a otros pueblos, tribus y aldeas, con el fin de someterlos y venderlos como esclavos. De este modo, se deterioraron las relaciones entre los diversos estados y pueblos. Los pueblos del litoral y del interior más próximo se encontraban en guerra continua. Así, a partir del Siglo XVI los reinos de Benín, Congo y Angola en Africa Occidental, tal como el Imperio Mutapa en Africa Oriental, se desmoronaron. En los siglos XVII, XVIII y XIX, en las selvas del Golfo de Guinea y en el valle del río Zambeze se desarrollaron estados militares con base en el comercio de esclavos. Tenían una rígida organización militar, poseían grandes ejércitos permanentes y se enriquecían con la venta de sus propios hermanos, haciendo la guerra a los pueblos vecinos.

Efectos económicos:

Además de la captura de hombres y mujeres, el tráfico promovió el saqueo sistemático de los bienes producidos. Ya sea a través de tributos o de pillaje, los traficantes saqueaban el producto de las cosechas, ganado, marfil, pieles, cera, maderas preciosas. Las actividades económicas como la agricultura, minería, artesanía, alfarería y el comercio local fueron abandonados y se orientaron a una actividad económicamente más productiva: la esclavitud. El tráfico de esclavos trajo al continente africano un estancamiento, por no decir un retroceso económico. La agricultura, los tejidos, la fundición y la forja de metales se fueron reduciendo. En contrapartida, se desarrollo la exportación de seres humanos. En lugar de poner a la venta productos, ahora el único producto de fácil venta en el mercado eran los propios productores. Las pequeñas industrias locales no pudieron sobrevivir. Por lo 
tanto, el tráfico de esclavos retardó el desarrollo y creó condiciones para el actual estado de subdesarrollo(). (Marco Antonio Barticevic)

Fuente: Historia / Canarias / Navegación.

http://www.mgar.net/var/por_escl.htm

\section{Notas al margen de la segunda parte}

(Advertencia al amable lector: Los hipervínculos que siguen a continuación estaban operativos en la fecha de cierre de este trabajo: 1 de octubre de 2006)

Las notas 1 a 4 se corresponden, exactamente, con las de igual numeración de la primera parte

(Nota 1) Algunas notas sobre la esclavitud en América. Revista Arbil, anotaciones de pensamiento y critica. \# 42

http:/ / www.arbil.org/ (42)irab.htm

(Nota 2) Tupaj Amaru, un indomable guerrero que se pasea en los Andes.

http://www.pusinsuyu.com/html/tupaj_amaru.html

(Nota 3) Historia de la República del Perú. La falaz prosperidad del guano (18421866) Tomo 6. Empresa Editora El Comercio. Lima, 2005.

Párrafo de esta obra citado en el artículo: La inmigración china al Perú. Portal de la Asociación Peruano China (APCH) http:/ / apchjovenes.com/blog/?p=11

(Nota 4) Fuente: Trabajo forzoso en América Latina.

Artículo publicado el 13 de mayo de 2005.

http://news.bbc.co.uk/hi/spanish/specials/newsid_4537000/4537895.stm 
(Notas correlativas -5 a 53- en la primera parte)

Siguen...

(Nota 54) Quienes poseían grandes extensiones de tierras y muchos intereses creados de por medio, al sentirse "dueños" de las personas que trabajaban para ellos nunca se resignaron a perder a sus "sirvientes". Ellos justificaban su posición basándose en la Declaración de los vulnerados derechos de los hacendados, un singular documento del erudito José María de Pando, que señaló los siguientes puntos respecto a su derecho de propiedad:

* era sagrado el derecho de propiedad (de seres humanos) en la conveniencia pública;

* históricamente era comprobada esta legalidad en todos los tiempos y en todas las naciones;

* en esos años ya se sentían en la economía nacional las consecuencias de la libertad por vientre.

* Se añadía que en realidad no había ocurrido una auténtica libertad de los esclavos, pues sólo muy pocos habían salido realmente de los galpones (lugar de encierro nocturno de los esclavos en las haciendas que después heredaron los culíes chinos) y justamente los que salieron quedaron tendidos en el campo de batalla. (Cimarrones)

El Código Civil y el de Enjuiciamiento vigentes en este año, reconocían, con carácter expreso, la esclavitud y las instituciones que de ella se derivaban. Para este Código eran esclavos los que lo fueron antes de jurada la independencia y consideraba como 
libertos a los hijos de madre esclava nacidos después de esta fecha época. Los libertos no estaban sujetos a servidumbre perpetua sino temporal. En la legislación civil vigente hasta esos momentos, el esclavo no era propiamente "cosa", se le reconocía la capacidad para ejercer determinados derechos, aunque tampoco entraba en la categoría de personas ya que estaba sujeto a claras determinaciones.

Fuente: Esclavitud en el Perú -Parte 7 - Liberación de la Esclavitud: Reseñas y . AIPEUC-PS, Washington.

http:/ / www.aipeucps.org/index.php?name=News\&file=article\&sid=247

(Nota 55) Fuente: Los Afroperuanos. Historia y situación actual. Centro de Desarrollo Étnico. (CEDET)

http:/ / afrolatino.org/forum/viewtopic.php?p=5611\&sid=47960a9f6b8d22df2d4b6eb $57 \mathrm{c} 44 \mathrm{bb} 5$

(Nota 56) Fuente: Cronología: Esclavitud y trata del negro en América.

Proyecto Ensayo Hispánico - Emilio Castelar.

http://www.ensayistas.org/antologia/XIXE/castelar/esclavitud/c-esclavitud.htm 


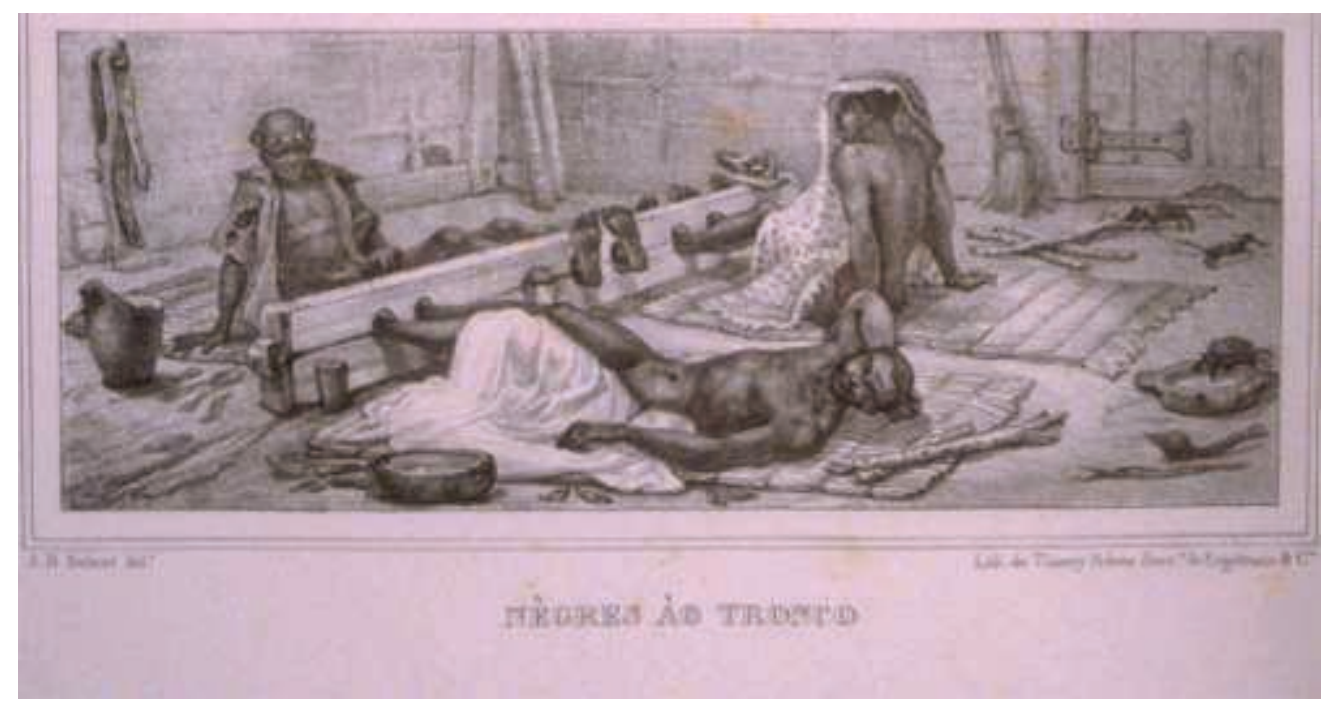

Figura 72. En la primera mitad del siglo XIX, vanos fueron los intentos por acabar con la esclavitud en Latinoamérica, esto pese a las fuertes presiones antiesclavistas. Por lo que en países como Perú o Brasil, seguía la trata. En la ilustración, una litografía de Jean Baptiste Debret en su obra Voyage Pittoresque et Historique au Bresil (Paris,1834-39), vol. 2, plate 45 (bottom), p. 139. (Copy in the John Carter Brown Library at Brown University). Portal From Africa To Slavery. Slavery in Latin America.

(Nota 57) Fuente: Compra de culíes chinos, comercio por "la ruta de la muerte", publicado en el portal Chinos Residentes en Latino América http:/ / www.china.org.cn/xi-xinwen/peru1-2.htm

(Nota 58) Un artículo publicado por la Asociación Peruano China (APCH) rememora las causas y las consecuencias de lo que vendría a llamarse la gran inmigración china al Perú, en estos términos: Esta primera experiencia trajo consecuencias inmediatas: según datos del ministro de Gobierno, José Manuel Tirado, desde febrero de 1850 hasta julio de 1853, fueron introducidos en el Perú 3.932 colonos, de los cuales, 2.516 fueron chinos. 
El gobierno peruano puso atención en el fenómeno de la inmigración ya que había realizado el primer contrato de conversión y de consolidación de la deuda externa, basado en el guano de las islas como hipoteca. Hacia allá fueron a parar las primeras hornadas de trabajadores chinos.

Los coolíes venían al Perú traídos por contrato. Primero tenía una vigencia de cinco años y luego se extendió hasta ocho. Ganaban mensualmente cuatro pesos fuertes o soles y podían ser vendidos a otro dueño a un precio promedio entre 300 y 400 pesos por cada uno. Cuando concluía su contrato la policía les confería un "Boleto de asiático libre" que debía ser refrendado por el intendente de turno.

Pero el maltrato, malas condiciones de vida y tráfico ilegal de coolíes tuvo que ser reprimido por el Congreso y, el 6 de marzo de 1856, se prohibió la importación de chinos. Pero no duró mucho, cinco años después, el 14 de marzo de 1861, se volvió a permitir, a pesar que el gobierno de Ramón Castilla vetó la norma. Sin embargo, durante el período 1853 - 1861 se continuaron expediendo permisos especiales para seguir trayendo coolíes.

Cuenta Jorge Basadre que "...a pesar de esfuerzos aislados, el porcentaje de mortalidad en la travesía era alto (se ha calculado que en algunos años pasó del 50\%) y al llegar los cargamentos humanos al Callao, se producía una inspección oficial y a los que no tenían contrato, se les alineaba en la cubierta para ponerlos a disposición de los interesados; en los periódicos solían aparecer, además, avisos ofreciendo chinos".

Mientras tanto, el gobierno de Manuel Balta, aceptaba, el 20 de abril de 1868, la propuesta del norteamericano Enrique Meiggs para construir los ferrocarriles de Callao - La Oroya y Arequipa - Puno. Reiniciado el tráfico en gran escala los coolíes 
tuvieron pronto un nuevo destino; se estima que Meiggs empleó de inmediato más de cinco mil chinos en forma simultánea en las líneas férreas.

Luego de varios incidentes sobre maltratos sucedidos en aguas internacionales y que comprometió la diplomacia peruana, el gobierno de Manuel Pardo dictó tres normas en 1873 que otorgaban el descanso dominical a los coolíes, la jornada de trabajo con la posibilidad del beneficio de las horas extras y se establecía el registro de asiáticos en la prefectura del Callao, con amplias funciones de tutela y supervigilancia, inclusive estaba obligada a repatriar a los chinos que, una vez terminados sus contratos, querían regresar a sus tierras. Lamentablemente, no se estableció un registro riguroso de entrada y salida.

Fuente: La inmigración china al Perú. Portal de la Asociación Peruano China. (APCH)

http://apchjovenes.com/blog/?p=11

(Nota 59) Al comienzo, debido a las diferencias de raza, religión y costumbres y a la no comunicación por la lengua, los chinos encontraban difícil formar familia con mujeres locales. Algunos simplemente convivían con hembras indígenas o negras y pocos pudieron tener matrimonio formal. Así, sus hijos nacieron peruanos.

Muchos matrimonios eran formados por la necesidad y no por el afecto. Pongamos un caso registrado en un libro de historia: Un contratante chino fue a una montaña y trajo de regreso a un grupo de mujeres indígenas para un igual número de trabajadores compatriotas que le habían pedido el favor y le habían prometido un buen pago. Estas mujeres, que preferían tener maridos chinos, eran llevadas a una habitación y se ponían de pie cara a una pared. Después, el contratante llamó adentro a los trabajadores y les exigió estar de pie cara a otra pared. Ahora, batió las manos y 
ambos grupos dieron media vuelta. Los que estaban frente a frente, serían cónyuges. Su matrimonio se decidió por la "suerte" y no se permitía contradecir. Después, las parejas tuvieron que estar juntas y llevar una vida difícil, ayudándose una a la otra.

Fuente: Compra de culíes chinos, comercio por "la ruta de la muerte", publicado en el portal Chinos Residentes en Latino América -

http://www.china.org.cn/xi-xinwen/ peru1-2.htm

(Nota 60) Sobre las líneas finales del párrafo arriba citado, don Ramón Castilla no sólo se basó en este causal para tomar tan trascendental decisión, sino que además recurrió a otros considerandos, tales como el se puede constatar en un reciente estudio del CEDET titulado: Los Afroperuanos Historia y Situación Actual, el mismo que menciona un artículo publicado en 1899 por el gran tradicionalista peruano don Ricardo Palma (1833-1919), donde señala que cuando el Libertador decretó la abolición de la esclavitud, se apoyó en el siguiente cálculo para poder determinar los pagos por el concepto de manumisión:

De los nacidos antes de 1821 .4 .000

De los nacidos de 1821-1839 .6 .000

De los nacidos de 1839-1854 .7 .000

Sobre este particular, el CEDET explica lo siguiente: Según el mismo autor (Ricardo Palma, n. de VA) los gastos que demandaría la abolición se podrían cubrir con el gasto fiscal, pero no se contó con la falsificación de partidas bautismales y que se elaborarían expedientes con esclavos muertos, estimándose en 9.500 "la cifra de estos resucitados". La cifra final de esclavos manumitidos fue de 25.505 y hacia 1872, 
durante el gobierno de Balta, se terminaron de pagar los vales. En este caso, la primera beneficiaria fue la iglesia como principal poseedora de esclavos $\mathrm{y}$, ante la protesta por el proceso fraudulento de reconocimiento de la deuda, no se hizo nada. En el entorno de Castilla se encontraba Domingo Elias, rico hacendado de la zona de Ica, al sur del Perú quien importó -pese a la prohibición- esclavos de la zona del Chocó Colombiano, comprándolos a bajo precio, para hacerlos pasar como suyos y cobrarle al Estado la "perdida" de su fuerza de trabajo, a este personaje nuevamente lo encontramos en la "contratación" de culies chinos para sus haciendas, en otro de los procesos de tráfico humano hacia nuestros territorios.

El decreto del 3 de diciembre (de 1854, n. de VA) fue complementado con otro del 23 de enero de 1855 que permitía disponer del trabajo de los esclavos hasta terminar las cosechas y estipulaba la expulsión de los no productivos. Se encomendó un reglamento del trabajo rural a los hacendados y la Junta preparó el decreto publicado el 7 de abril de 1855, que, según denuncias de la época, configuraron un régimen laboral peor que el abolido.

El 9 de marzo de 1855 se dictó el Decreto que reglamentaba la indemnización a los propietarios, estableciéndose el pago de 300 pesos sin distinción de edad ni sexo. Como señalamos, en la practica, se cobró incluso por los muertos y libertos antes del decreto. El 16 de marzo de 1855, se nombran en Chorrillos las comisiones que se encargaron de repartir las papeletas de libertad a los esclavos. Entre 1854 y 1860 se "manumitieron" 25.505 esclavos, cuando, en realidad, en 1854 existían alrededor de 17.000 . El Estado indemnizó a los amos por un monto de 7.651.500 pesos; se cometió un fraude de más de dos millones de pesos.

Fuente: Los Afroperuanos. Historia y situación actual. Centro de Desarrollo Étnico. (CEDET) 
http:/ / afrolatino.org/forum/viewtopic.php?p=5611\&sid=47960a9f6b68d22df2d4b6e b57c44bb5

(Nota 61) Fuente: Abolicionismo en América: Hacia un Estudio Comparativo de Historia Mundial, Omar H. Ali, Ph.D. Departamento de Historia. http://pages.towson.edu/oali/CASO.htm

(Nota 62) Referencia: Cronología: Esclavitud y trata del negro en América. Antología del Ensayo - Emilio Castelar http://www.ensayistas.org/antologia/XIXE/castelar/esclavitud/c-esclavitud.htm

(Nota 63) Maltratos, maltratos, maltratos...

* "El 15 de junio último se ha flagelado cruelmente a Esteban Ita, esclavo de la panadería de Siete Jeringas (nombre de una de las calles de Lima, HRP) cuyo propietario es Francisco Ramírez. El estado del esclavo es tan delicado que se teme por su vida". (EC, 18 de junio de 1853).

El maltrato físico y psicológico ha sido una constante en las relaciones patróntrabajador y el castigo físico ha sido lo más llamativo y lo que más ha trascendido en cuanto al trato a los esclavos, tanto que a la esclavitud se la asocia, parcialmente cierto, con las cadenas, el cepo, el látigo, la cárcel dentro de la propiedad del amo. De ello se podría decir mucho. Por el momento sólo deseamos presentar lo que hemos encontrado en los avisos y en información del diario El Comercio, antes y después de la liberación de los esclavos el 3 de diciembre de 1854. Es conveniente señalar que los maltratos a los esclavos afroperuanos continuaron de manera muy similar con los semiesclavos culíes chinos que fueron importados desde el año 1849 hasta 1874. 
Sorprende que la manumisión de Castilla no haya representado algún cambio en cuanto al ensañamiento de los patrones con los trabajadores negros o chinos.

* El 30 de marzo de 1854 el teniente coronel Manuel Arias, comisario de policía, encontró en la hacienda Retes, valle de Chancay, cuya arrendataria era Manuela Pardo de Martínez, a dos mujeres jóvenes y a un criado que estaban encerrados en unos calabozos totalmente oscuros de la misma hacienda; estos prisioneros sólo recibían, por un agujero hecho exprofesamente, sus alimentos: pan y agua. Como la noticia escandalizó en esos momentos hubo un juicio y cartas a El Comercio que son muy ilustrativas.

La primera de las noticias de este diario la ofreció en los siguientes términos:

* "La policía tuvo noticias que Dña. Manuela Pando tenía encerrados y privados de toda comunicación a dos esclavos que alimentaba casualmente cada veinticuatro horas. Tal aviso dio por resultado que la Intendencia (prefectura, HRP) autorizase al comisario de policía del cuartel $\mathrm{N}^{\mathrm{a}} 1$, teniente coronel Manuel Arias, para que allanara la casa, extrajese de ella a las dos siervas. La orden se cumplió y fueron conducidos al local de su despacho a Juana Ramírez, menor como de 14 a 15 años y Peta de 8 a 9 años. La primera no sabe el tiempo que ha permanecido privada de toda libertad, y por los datos que posteriormente se han obtenido, en el año de 1850 ya existía así; la segunda llevaba de incomunicación más de cinco meses; ambas dicen ignorar la causa de tamaña crueldad.

Se presentó también a ese tiempo implorando la protección de las leyes un moreno nombrado José de los Santos de más de 30 años, esclavo de dicha señora, manifestando haber sufrido igual suerte que las anteriores, por espacio de dos años sin saber el motivo. Lo admirable en esto ha sido que las tres víctimas, estando 
reunidas en una misma casa tanto tiempo, se han venido a conocer en la Intendencia, pues en la casa no se llegaron a ver ni los días festivos a la hora de la misa, habiendo oratorio, porque no se les permitía llenar este deber religioso".

(EC, 31 de marzo de 1854)

La carta que sigue fue editada en El Comercio, la escribe un oficial de la policía, Juan Bustamante, desde la Intendencia (prefectura) y está dirigida a Francisco de Paula Romero, juez de 1era Instancia.

* "Con motivo del incendio que tuvo lugar esta mañana en la panadería de la Pescadería (calle al costado del Palacio de Gobierno, HRP) a la que tuvo que concurrir de auxilio la policía, se supo que, en el interior del amasijo, se mantenían cargados de prisiones a cinco individuos. Desde luego di orden para que se extrajesen aquellos y fueron conducidos a la Intendencia. Esta diligencia debió practicarse sin estrépito, pero el dueño de este establecimiento, José Manuel Ayulo faltó los respetos que se debe a la Policía, intentó desobedecer, y me vi precisado a hacer uso de la fuerza. De esto ha resultado haber sacado del interior de dicha casa a Juan del Carmen Muro, Pedro Monteblanco, Manuel Barreda y dos asiáticos (chinos, HRP) Asu y Asan; de estos cinco los tres primeros permanecían en calidad de esclavos sufriendo toda clase de penalidades a la vista de la policía y no obstante el decreto de 3 de diciembre de 1854 dictado en Huancayo por Su Excelencia el Libertador.

Tal monstruosidad me ha precisado a poner en libertad a los cinco individuos mencionados, y a Ayulo por un corto rato una de las prisiones quitadas a esos desgraciados, sin perjuicio de que se le juzgue por usted por la barbaridad y por el desprecio con que se ha mirado al supremo decreto que ya he citado. Ayulo permanece en la policía". 
(EC, sábado 3 de marzo de 1855)

* Dos días después El Comercio informaba que José Manuel Ayulo había sido multado en cien pesos por haber mantenido hombres con prisiones en el interior del amasijo de la panadería de la calle de la Pescadería como si fueran esclavos, con desprecio del decreto del 3 de diciembre de 1854, dictado por su excelencia el Libertador en la ciudad de Huancayo.

Fuente: Recopilación de noticias sobre casos de maltratos a esclavos en Lima. Boletín de Cimarrones.

http://www.concytec.gob.pe/foroafroperuano/tito5.htm

(Nota 64) Información citada en La Inmigración China al Perú. Portal de la Asociación Peruano China (APCH) http://apchjovenes.com/blog/?p=11

(Nota 65) La citada fuente relata también que, en 1853, más de 600 chinos, 50 esclavos y 200 reos y soldados desertores peruanos y chilenos cavaban guano para el finquero Elías. Debían cavar al menos cuatro toneladas al día. Calculado al precio de exportación, cada trabajador aportaba seis pesos por día al patrón, pero recibía solamente una octava de peso, y de esta ínfima cantidad dos tercios eran empleados para pagar la comida. Algunos chinos murieron de enfermedad o trabajo y otros, desesperados, se suicidaron saltando de los barrancos cuando los vigilantes estaban menos alertas.

La construcción de ferrocarriles era otro trabajo pesado de los primeros grupos de chinos, quienes participaron en el tendido de varios ferrocarriles en el centro y el sur del país y asumieron las tareas más arduas y más peligrosas. 
Aparte de ello, un buen número de chinos eran instalados en las fincas del litoral, unos para cultivar caña de azúcar o algodón y otros para cultivar arroz o verduras. Cada finca tenía de decenas a mil trabajadores chinos, y la jornada duraba más de 12 horas.

Con su laboriosidad, los chinos contribuyeron enormemente al desarrollo agrícola del Perú.

Fuente: Los chinos trabajaban como esclavos, excavando guano, construyendo ferrocarriles y cultivando caña de azúcar. Jóvenes Residentes en Latino América. http://www.china.org.cn/xi-xinwen/peru1-3.htm

(Nota 66) En vísperas de la abolición, la libertad les quedó chica; y después... muy grande. El diario El Comercio grafica de esta forma el panorama social previo al decreto de Ramón Castilla de diciembre de 1854.

Desórdenes y Montoneras...

* El Comercio del 22 de mayo de 1854, publica una carta en la que el autor, un oficial de la policía, informa desde Chorrillos que "una partida de (15) malhechores compuesta toda de negros de la hacienda San Juan, Villa y La Molina" había creado pánico en el camino a Surco hacía pocos días. Tanto era el temor, que las familias que estaban allí en Chorrillos tomando baños se preparaban para abandonar el pueblo y regresar a la capital. Por mucho que se les habló, el terror continuaba. Y otras familias de Lima que estaban por ir a los baños, desistieron de hacerlo.

* "El salteador de caminos Fermín Bernardo, comandante de la pandilla de ladrones que han asaltado estos días las chacras del Inquisidor, Barbadillo, La Menacho y 
Quiroz, ha sido muerto ayer en el valle de Ate, por la partida de campo que estaba a órdenes del teniente Andrés Carmona, a causa de que fugaba y lo obligó a hacerle disparar algunos tiros de cuyos resultado murió".

(El Comercio, 31 de mayo de 1854).

* En otra ocasión en fecha cercana a la anterior, en uno de los refugios de otro grupo de malhechores, se encontraron las siguientes prendas que habían sido robadas por otro grupo de montoneros: un reloj de plata de dos tapas, cuatro pesos en plata sellada, un freno corriente con sus respectivas piezas de plata, un par de riendas y una cabezada de esterillas nuevas, un par de espuelas grandes de plata, un bocado de freno nuevo con rosario de Jerusalén con cruz y misterio de plata y dos perlitas, una correa con dos piezas de plata, dos canutillos de plata, un freno usado con sus bisagras de plata, una cincha nueva, un tapaojo con cuatro piezas de plata, un par de espuelas de cobre con piezas de plata, cincuenta y cuatro piezas de plata para diferentes cosas, dos pares de candados de oro quebrados, seis reales en cuartillos....la lista sigue.

(El Comercio, 27 de junio de 1854)

* Una carta que es escrita desde Chorrillos en tono muy acongojado, dice lo siguiente: "Hemos pasado la noche en vela, los montoneros en número de 30 entraron al pueblo a las 8 de la noche, tomaron preso al Intendente de la Policía, y lo obligaron a que hiciese abrir las puertas del Sr. Tejada, la del hotel de Pedro y las de la panadería; lograron sacar un poco de dinero que aseguraron será cosa como de cien pesos, estuvieron en casa del capitán de matrícula rompiéndole las puertas del rancho que le incendiaron, y después se han retirado dejándonos en la mayor consternación.

Luego que la Prefectura tuvo conocimiento de estos hechos ha enviado una fuerza considerable de infantería y caballería". 
(El Comercio, 13 de julio de 1854).

Luego de la ley de la liberación (o manumisión) de la esclavitud, este fenómeno delincuencial tuvo un crecimiento mayor. Parece que algunos de los exesclavos no sólo ingresaron a los grupos montoneros de los caminos, sino que también lo hicieron en la ciudad de Lima donde, por igual, la delincuencia tuvo un aumento notable. Leamos el caso que sigue:

* "Los ladrones tienen los caminos en estado que no se pueden transitar por ellos, porque al más encopetado caballero le hacen entregar todo lo que lleva consigo así sólo tenga el valor de dos reales (8 reales hacían un peso, HRP). Sin duda, señor Intendente, usted no sale de portadas afuera, ni le ha sucedido a ninguno de los de su casa el chasco de verse robado y estropeado por los ciudadanos negros de África". Esta carta la firma "Un Chorrillano".

(El Comercio, 11 de junio de 1855).

Fuente: Recopilación de noticias sobre casos de desórdenes y montoneros provocados por esclavos fugados o libertos.

http:/ / www.concytec.gob.pe/foroafroperuano/tito6.htm

(Nota 67) Esclavos como mercancía: Compra-venta, permutas, traspasos.

Hasta fines de 1854 la situación de los esclavos era similar a cualquier mercancía inanimada. Debe tenerse en cuenta que ya en este año no llegaban más, a los puertos peruano, los denominados "bozales", esclavos que venía directamente desde África y que eran traídos en barcos por tratantes, los que inmediatamente al arribo de las naves, los ofrecían a los interesados. 
Todo este negocio tenía reconocimiento público y por eso estaba convenientemente reglamentado. La llegada de esclavos desde África ocurrió de esta manera hasta el año 1818.

$\mathrm{Al}$ respecto copiamos la información que nos ofrece Fernando Romero, un notable historiador: "A comienzos de 1818 la fragata Rita salió de Santander (España), con rumbo al Callao pero haciendo una escala en la costa africana. Su destino se cumplió... su momentánea detención en dicho continente tuvo por objeto embarcar, como lo hizo, un total de 341 negros, de uno y otro sexo. Su viaje prosiguió sin contratiempos, llegando al Callao el 18 de marzo. Como la noticia de la próxima prohibición de la trata ya era conocida, los esclavos fueron vendidos de inmediato, a 600 pesos cada uno, lo que resultó un buen negocio."

Luego de este tipo de adquisiciones, el propietario de un esclavo podía venderlo, traspasarlo o permutarlo; y por el contrario, quien requiriera de un esclavo podía conseguirlo en el mercado. Con tal fin, además de otras modalidades, los amos utilizaron los diarios de Lima y provincias para ofertar "su mercadería". Como se leerá, colocaban en los anuncios periodísticos las características del esclavo que ofrecían, así como informaban todo lo que conviniera con tal de lograr una transacción económica satisfactoria.

La compra-venta de esclavos es bastante evidente: un amo ofrecía al esclavo y daba la dirección donde ponía realizarse el negocio. Ocurría también lo contrario, es decir, la demanda: una persona que requería de un esclavo, ponía su requerimiento en un aviso en los diarios.

La permuta era cambiar un esclavo de algunas características o con cierta especialidad por otro de otras características o especialidad. 
Debe tenerse en cuenta que, por entonces, no era lo mismo ser amo que ser patrón; de la primera manera se designaba al dueño de un esclavo; y de la segunda a los que recibían los servicios de un exesclavo (llamados libertos) a los que se les compensaba dándoles un pago semanal (1 peso) y/o educación)

En las líneas que siguen haremos notar qué tipo de transacción se buscaba y copiaremos textualmente los avisos del diario El Comercio (EC, en lo sucesivo)..

\section{VENTA:}

* "Una negra propia para chacra" (EC, 6 de noviembre de 1854)

* "Una negra muchacha lavandera y de todos quehaceres y sin vicios" (EC, 2 nov. 1854)

* "Se venden o se traspasan un negro de 13 años y 2 chinos..." (EC, 2 noviembre de 1854)

* "Un esclavo de todo servicio, sano y robusto..." (EC, 30 octubre 1954)

* "Un esclavo de edad regular en un precio cómodo" (EC, 22 de abril de 1854)

* "Por causa de viaje (se vende) un esclavo edad de 25 años, fuerte y robusto, su valor \$ 417. Se dará razón carpintería café antiguo de San Agustín" (EC, 2 de agosto de 1854)

* "Un matrimonio con una hija de seis años..." (EC, 17 de julio de 1854) 


\section{TRASPASO}

* "Se traspasa el patronato de una liberta, joven y sin vicios" (EC, 13 de julio de 1854)

* "Se vende una esclava sin vicios y de todos (los) quehaceres; y se traspasa el dominio de un liberto hijo suyo de cuatro años de edad..." (EC 13 de junio de 1854)

\section{PETICIONES}

* "Se necesita un esclavo cocinero" (EC, 21 de setiembre de 1854)

* "Se necesita una negrita de ocho a diez años y un cocinero libre o esclavo..." (EC, 6 de setiembre de 1854)

* Se necesitan dos cocineros buenos, bien sean esclavos o libres" (EC, 1 setiembre 1854)

* "\$60 de gratificación para la persona que proporcione una esclava para el servicio de mano" (EC, 6 octubre 1854)

* "Se compran esclavos sanos y sin vicios, uno que sea hombre y otra mujer, de doce años para arriba, en esta imprenta se dará razón de la persona que los necesita" (EC, 20 de abril de 1854)

"LIBERTAD DE ESCLAVO". Se necesita con urgencia dos hombres fuertes, inteligentes, activos y honrados a quienes, sin perjuicio de una gratificación semanal, se les dará la libertad a los cuatro años. Se solicita también dos personas libres con las cualidades anteriores y si alguna conoce algo de destilación será preferida, ocúrrase 
(concurrir a...) esquina del Tigre casa $\mathrm{N}^{\mathrm{a}} 117$, frente al cuartel del Colegio Real (muy cerca del actual Congreso de la República, HRP" (EC, 16 de setiembre de 1854).

\section{PERMUTA}

* "Dos negras se cambian por dos muchachos o muchachas de 10 años para arriba y se advierte que dichas negras no son para servicio doméstico sino para chacra y no se truecan sin esta condición..." (EC, 21 de marzo de 1854)

* "Se cambia un esclavo joven de todos haceres en el servicio de mano, por otro de mayor edad que entienda algo de cocina sea hombre o mujer o sino por un muchacho de 12 a 16 años" (EC, 7 de agosto de 1854)

* Se cambia un negrito cocinero de 14 años, por un zambito o zambita de 10 a 12 años para que sirva de paje de mano" (EC, 12 de setiembre de 1854)

Fuente: Recopilación de Humberto "Tito" Rodríguez. Boletín de Cimarrones. Noticias sobre casos de compra, venta, permuta, etc., de esclavos en Lima. http://www.concytec.gob.pe/foroafroperuano/tito3.htm

(Nota 68) Fugas, fugas, fugas...

Los avisos de la fuga de esclavos era algo muy frecuente en las páginas del diario El Comercio durante el año 1854.

De ello se observa que había mucha experiencia de parte de los patrones acerca de lo que correspondía indicar en los avisos: mencionaban incentivos o gratificaciones (25 pesos) para quienes entregaran a los esclavos fugados; se decía sus nombres y 
apellidos, se daba la filiación de los huidos; es decir, se precisaban sus características o defectos físicos, a veces características de personalidad, así como la manera como estaban vestidos y también sus especializaciones.

Llama la atención la cantidad de niños que se fugaban, a los que a veces se les consideraba como extraviados para no alterar mucho la sensibilidad de los lectores de El Comercio. Es conclusión nuestra que antes y ahora los niños huyen de las casas en que se encuentran, sea la de sus padres o las de sus "patrones" o amos, cuando no son bien tratados.

Otra de las observaciones inmediatas es que huían esclavos de muy diferentes edades y de muy desiguales características; la fuga se hacía casi a solas o en pequeños grupos, muy rara vez la realizaba un grupo familiar. De la información de los avisos no se puede saber las razones de las frecuentes deserciones de esa gente sometida a servidumbre.

De manera general se puede asegurar que casi todos esos avisos corresponden a esclavos de Lima, tanto de la ciudad como de las haciendas próximas. Son raros los casos de negros esclavos cimarroneados que no eran de la capital. En un caso hay la mención a un palenque -ese lugar de refugio y concentración de negros cimarronesque transcribimos. De igual manera copiamos algunos de los casos de estas fugas para mayor percepción de los lectores de esta columna.

Uno de los tantísimos casos.

"25\$ (25 pesos) de gratificación se dan a la persona que entregue o dé noticia cierta del paradero de un zambo llamado Francisco de Paula que se fugó de casa de sus amos el viernes 18 del corriente. Sus señales son: estatura proporcional, color zambo un poco claro, tiene una cicatriz en una ceja y una señal de quemadura en el 
pescuezo bajo la oreja. Al andar deja un poco el pie derecho por tener el tobillo derecho descompuesto; su voz es hueca y presenta un carácter humilde o hipócrita; su edad es de 25 a 28 años, viste con una chamarra (casaca) blanca de paño pastor, un pantalón de lanilla del mismo color y camisa también blanca. Es buen cocinero y acostumbra presentarse en las casas particulares, fondas de Lima y Callao y en los buques a pedir este trabajo, diciendo ser libre. Así mismo acostumbra presentarse a cualquier cuerpo del ejército exponiendo ser licenciado. Sus amos suplican a los señores jefes y oficiales, tengan la bondad de no admitirlo, y si lo tienen, tengan a bien retenerlo. También se advierte que en esta fecha se ha dado parte a la Intendencia (prefectura), para que, si llega el caso, se aplique la pena impuesta en los artículos Reglamento de Policía, sobre ocultación y jornales. En esta imprenta se dará razón de sus amos y también se tomarán algunos criados a jornal".

El Comercio, Lima, viernes 20 de octubre de 1854.

\section{Esclava con sus hijos huye}

"En la noche del 23 del presente (marzo) se ha fugado de casa de sus amos una zamba llamada Lorenza con dos hijos, hombre y mujer. El hombre se llama Felipe, tiene tres años y la mujer Jesús de once meses. Las señales de la zamba son: alta, borrada (picada de viruela) y de 21 a 22 años de edad. La persona que diera razón de su paradero en la calle de Mariquitas casa № 95 tendrá una gratificación y quien la oculte sufrirá las penas por la policía, a la que se le ha participado de su fuga".

EL COMERCIO, lunes 27 de marzo de 1854

\section{Fuga y robo}

En otro caso se precisa que la esclava Melchora huyó llevándose de su patrona, María Pino, veinticinco onzas de oro. La Intendencia persiguió a la sierva, la puso en prisión y se recogieron 367 pesos medio real, los mismos que fueron devueltos a la patrona. 
EL COMERCIO, Lima, jueves 10 de agosto de 1854.

\section{Niños fugados}

Un caso de niño que se ha escapado. De los tantísimos que se podría mostrar, es el siguiente:

"Ha fugado el lunes once del presente a las siete y media de la mañana de la casa $\mathrm{N}^{\circ}$ 44 de la calle de San José un muchacho nombrado Juan Pro, de casta zambo-chino, edad de diez años, y el pallar pegado al oído... "

El Comercio, viernes 15 de diciembre de 1854

\section{Un palenque cerca de Lima}

"Policía. Ocurrencias.

Una de las partidas de seguridad destinadas a perseguir malhechores encontró ayer en la hacienda de la Nievería el palenque donde se refugiaban esos, y logró recoger las bestias y especies que a continuación se expresan sin haber podido aprehender ninguno. Momentos antes de caerles fugaron precipitadamente sin descubrirse, por lo montuoso del lugar. Las personas a quienes pertenecen los caballos y demás especies pueden ocurrir por ellos. Tengan seguridad que les será entregados los que reclamen, si antes prueban su derecho de la manera debida. 29 caballos y una mula, una jáquima de plata, una cabezada de idem, un freno de copas, tres pellones forrados nuevos, once monturas, dos con hebillas de traceras de plata, siete pellones viejos, siete lazos, un freno con cuatro piezas de plata, ocho frenos, un par de polainas, ocho sombreros, dos jáquimas, 24 sobrepelos, trece cinchos, una alforja, once pares de estribos, un par de espuelas de cobre, una alforja de pellejo, dos fusiles, 9 carabinas, dos bocones, una escopeta, ocho pistolas y tres descompuestas y una daga".

El Comercio, Lima, miércoles, 9 de agosto de 1854. 
Fuente: Recopilación de noticias sobre casos esclavos fugados de Humberto "Tito" Rodríguez. Boletín de Cimarrones.

http://www.concytec.gob.pe/foroafroperuano/tito2.htm

(Nota 69) Ramón Castilla (Tarapacá, 1797 - Tiviliche, 1867), quien tuvo dos mandatos presidenciales (1845-1851 y 1855-1862), fue llamado "El Libertador" por haber promulgado la llamada "LEY DE MANUTENCIÓN" -que declara la abolición definitiva de la esclavitud en el Perú-, la misma que fue firmada en la Plaza Constitución de la Ciudad de Huancayo, donde, actualmente, existe una placa conmemorativa cuyo texto resume la norma original:

Figura 73

\section{ABOLICIÓN DE LA ESCLAVITUD}

El Libertador Ramón Castilla,

Presidente Provisorio de la República,

decreta:

Los varones y las mujeres tenidos hasta ahora, en el Perú, por esclavos o por siervos libertos, sea que su condición provenga de haber sido enagenado como tales o de haber nacido de vientres esclavos, sea que de cualquier modo se hallen, sujetos a servidumbre perpetua o temporal: todos, sin distinción de edad, son desde hoy para siempre eternamente libres.

Dado en la casa del Supremo Gobierno en Huancayo a 3 de diciembre de 1854. 
Ramón Castilla

Fuente: Boletín de Cimarrones.

http://www.concytec.gob.pe/foroafroperuano/placa_castilla.htm

(Nota 70)

Figura 74

Texto de la publicación reglamentada del Decreto de la abolición de la esclavitud.

DECRETO DE LA ABOLICIÓN DE LA ESCLAVITUD

EL LIBERTADOR RAMÓN CASTILLA PRESIDENTE Provisorio DE LA REPÚBLICA, s. s.

CONSIDERANDO:

Que es un deber de justicia restituir al hombre su libertad.

Que la Revolución de 1854 tiene por uno de sus objetivos principales reconocer y garantizar los derechos de la humanidad oprimida, explotada y encarnecida con el tributo del indio y con la esclavitud del negro.

Que satisfecha en parte esta obligación con el Decreto del 5 de Julio que redimió al indígena del peso del tributo, queda todavía por cumplirse la de restituir en libertad personal a los esclavos y a los siervos libertos. 
Que si el Gobierno Provisorio reservara decretar la libertad de los esclavos para después que el Ejercito Libertador hubiese destruido la tiranía, era porque no zozobrase a la desconfianza la indemnización debida a los amos, ni se manchase aquel acto de justicia a la humanidad con inducir al esclavo dar por rescate su vida en una guerra civil que no puede comprender, supuesto que no le dejaron ideas políticas durante su servidumbre.

Que habiendo el ex Presidente Echenique, en un decreto de 10 de Noviembre último, exigido por 2 años de sangre de los esclavos y conmovido el derecho de propiedad con la vaga indemnización que alude, sólo por los que se le vendan para combatir en su agonía contra los pueblos; se mancillaría el nombre del Perú si el Gobierno Provisorio no declarase inmediatamente los principios nacionales y no condenase aquel abuso y horrible tráfico de carne humana.

\section{DECRETA:}

Art. Único. Los varones y las mujeres tenidas hasta ahora en el Perú por esclavos o por siervos libertos, sean que su condición provenga de haber sido enajenados como tales o de haber nacido de vientres esclavos, sea que de cualquier modo se hallen sujetos a servidumbre perpetua o temporal; todos, sin distinción de edad, son desde hoy para siempre enteramente libres.

\section{DECLARA:}

$1^{\circ}$.-Que el Gobierno Provisorio creado por los Pueblos, restituye sin condición alguna la libertad a los esclavos y a los siervos libertos, cumpliendo solemnemente un deber de la justicia Nacional proclamada por la Revolución de 1854. 
$2^{\circ}$.-Que los ancianos, inválidos e impedidos de trabajar por cualquier causa básica, al tiempo de recobrar su libertad encontrarán sus alimentos en un Hospicio dispuesto por la caridad social que debe ejercitar el Gobierno.

$3^{\circ}$.-Que serán indignos de la Libertad, únicamente, los esclavos o siervos que tomen las armas y sostengan la tiranía del Ex Presidente don José Rufino Echenique que hace la guerra a la libertad de los pueblos; $y$

\section{GARANTIZA LA PROPIEDAD,}

Asegurando el justo precio que se debe a los amos de los esclavos y a los patrones de los siervos libertos, sobre la base siguiente:

$1^{\circ}$.-Quedará pagado su crédito en 5 años.

$2^{\circ}$.-Ganará el interés anual del $6 \%$.

$3^{\circ}$.-Se expedirán billetes al portador y nunca se cancelarán con los vales de consolidación.

$4^{\circ}$.-Serán admitidos los billetes como dinero en pago de la quinta parte de toda clase de contribuciones o responsabilidades fiscales.

$5^{\circ}$.-Se anticipará por el Gobierno en cuenta de pago, los montos que los propietarios calculen necesario para impulsar, bajo la administración de ellos mismos una inmigración europea capaz de reanimar la agricultura de la costa. 
$6^{\circ}$.- Queda garantizado el derecho de estos acreedores con la quinta parte de la Renta Nacional, inclusive en éstos los sobrantes de la venta del Guano.

$7^{\circ}$.- Está expedita la acción de los propietarios para convenir en mejores términos con el Gobierno, acerca del pago de esta deuda, consultándose el monto de las rentas públicas, la protección a la agricultura y el respeto al derecho de propiedad.

Dado en la casa del Supremo Gobierno en Huancayo a 3 de Diciembre de 1854.

RAMÓN CASTILLA.

IMPRENTA DEL EJERCITO LIBERTADOR ADMINISTRADA POR TADEO PÉREZ. Fuente: Antonio Quispe Rivadeneyra. Presidente de APEIDO. Boletín de Cimarrones.

http://www.concytec.gob.pe/foroafroperuano/decreto2.htm

(Nota 71) Pagos por la manumisión de los Esclavos. Algunos ejemplos. Noticias publicadas en el diario El Comercio de Lima en 1855:

17 de enero. Como aviso o bando de la policía de Lima se ordena que "...las personas que mantengan en su servicio a individuos que han obtenido su libertad... se presentarán con ellas en la Intendencia desde las 10 de mañana el día de mañana (jueves 18 de enero) para tomar razón de sus nombres y demás circunstancias en el libro que a este respecto se ha abierto en esta fecha conforme a la orden que se ha recibido".

(El Comercio, 22 de enero de 1855) 
23 de enero. En esta fecha se hace público por periódicos el decreto del 3 de diciembre de 1854, no en su versión inicial hecho en campaña, sino otra muy amplia, por eso es más que un decreto, incluye indicaciones de cómo debería hacerse el proceso para la puesta en marcha de la manumisión de la esclavitud. Según las precisiones añadidas se debían crear juntas de inscripción en distritos donde hubiera habido esclavos y siervos; en cada uno de ellos el gobernador, el cura y un vecino notable debían formarlas. De esta manera se harían los registros en los que se debía consignar datos tales como: nombre, edad (años y meses), estado civil, oficio, hacienda o casa de procedencia y nombre del dueño, constitución física (robusta o débil), estado de salud. Luego se hacían los envíos al gobierno.

8 de enero. Un esclavo que quiere ser libre, de esta manera firma una persona que envía una comunicación a El Comercio, en la que informa que ha ido donde el cura de su parroquia para que le diese la boleta de ser hombre libre, y el sacerdote le contestó que aún no le habían pasado el libro de registros ni nada de lo que era necesario para actuar y "que volviese dentro de dos días". Como ese retraso le infería agravio, reclamaba por lo que consideraba que era sagrado: la libertad del hombre; exigía, en última línea, que se cumpla el supremo decreto tomando las medidas del caso.

(El Comercio, jueves 8 de febrero de 1855)

10 de febrero. El síndico de la ciudad de Arequipa, Mariano Elías Medina, que había estado presente en los trabajos de instalación e iniciales de la Junta de Inscripción, sin pertenecer a ella, le escribe al prefecto una comunicación del 10 de febrero en la que le dice que constató que había varios reclamos de los libertos "...cuyos hijos fueron vendidos indebidamente...ya que eran libres por ley del Congreso de Huancayo y por los decretos del Libertador. Hay el peligro que no tengan sus respectivas boletas y que por eso queden retenidos, o los encierren y castiguen sus titulados amos". A 
esa misma autoridad le pide que ordene a la Junta que también expida boletos "aunque sea un papel común..." para los hijos de los libertos. Ese mismo día el síndico recibe la respuesta, le dicen que él ordene que la Junta dé a los hijos de los libertos una papeleta simple donde conste su condición de libre.

(El Comercio, 24 de febrero de 1855)

Fuente: Recopilación de Humberto "Tito" Rodríguez. Boletín de Cimarrones. http://www.concytec.gob.pe/foroafroperuano/tito19-20.htm

(Nota 72) En la comunicación de Los Libres, se sostiene que la abolición es una conquista de elevada significación en el orden político, moral y económico; con esta medida en absoluto se atacaba la propiedad individual (de los amos, HRP) ; los autores se hacían una inteligente y sólida pregunta; "¿quién la ha concedido al hombre sobre el hombre?" Si todos somos iguales en derecho, decían, somos por lo tanto iguales en el orden moral, es por eso que no se puede tener bajo dominio a los que Dios formó a su semejanza. Señalan que aquellos "que viven del sudor de los infelices esclavos a quienes tratan como a manadas de bestias", son , sin duda, "los que pueden lamentar la abolición de la esclavatura, se referían, no vacilaban al señalar, a los propietarios de haciendas. Estos mismos defensores de la ley de Castilla estaban contra las intenciones de que se continuara con el patronato, esa forma de mantener sujetos a los exesclavos -sobre todo criaturas, niños y jóvenes- que consistía en que los patrones los retenían hasta cierta edad (25 años), les daban educación y, a cambio, estos criados debían continuar sirviéndolos. El patronato surgió con José de San Martín y seguía vigente al instante de la Ley de la Abolición de la Esclavitud de Ramón Castilla y de Manuel Toribio Ureta.

Una argumentación contraria a la anterior sostenía que el lugar de partida a tener en cuenta era el buen o mal uso de la libertad y desde ese punto de vista inicial se tenía 
que examinar la cuestión de la esclavatura. No se debía ver el asunto como válido para cualquier país, ya que lo que era bueno para una nación no necesariamente lo era para otra. Se tiene que considerar, se argüía, "los hábitos, el grado de educación, la tendencia de los individuos, el vigor de las instituciones, etc. En una palabra: debe prepararse el terreno antes de sembrar la semilla". Quien hace este artículo (y otros que siguieron) procuraba demostrar que en el Perú la libertad de los esclavos no era humanitaria; todo lo contrario, era inmoral, perjudicaría a los esclavos, además de ser contraria a las leyes vigentes, y, por supuesto, se arruinaría la agricultura, por eso la libertad engendraría un semillero de pleitos lo que haría necesario tener una policía particular que aún no existía.

En el sustento de la propuesta mencionada se añadía que "nuestros esclavos no están aún preparados para obtener su libertad, carecen de educación, son viciosos, propensos a la bebida (¿No es en Lima una vieja y muy conocida costumbre la santificación del lunes por la gente de color?), además de crueles con sus hijos y esposas. Muchos de estos males se evitaban porque había la vigilancia y moral de los amos; de ellos los esclavos recibían el texto doctrinal que inspiraban continuamente sus sentimientos religiosos así como los amos daban "lecciones prácticas de moral de la manera más eficaz". Lo que mostraban como hechos, estos opositores a la manumisión, era que esos esclavos habían pasado a engrosar los grupos de montoneros en los alrededores de Lima y Callao, de esta manera robaban, flagelaban, mataban y quemaban a los hombre "por puro placer" y lo hacían en las barbas de las autoridades y de la fuerza armada.

(EC, 19 de enero de 1855).

Toda esa discusión, en El Comercio y en otros diarios, que la presentamos sólo en sus momentos iniciales, ocurría al mismo tiempo en que se producían movilizaciones callejeras de parte de los exesclavos manumitidos o liberados. 
Una persona llamada Eugenio Larrabure escribe un comunicado dirigido al Intendente de Policía que publica El Comercio (del lunes 22 de enero de 1855) donde muestra su ira por los sucesos que ha visto y que le han tocado vivir: "Es llegada la vez, le dice al Intendente, (que) dicte las medidas más enérgicas para poner coto a las demasías, y para contener la tendencia (de la soez plebe de Lima) a aprovechar del más leve pretexto para con los gritos de: ¡viva Castilla!, ¡viva la libertad!, allanar y saquear las casas. En la noche del (sábado) 20 (de enero) a las ocho y media una turba de bandidos, la mayor parte de la raza africana... ha entrado en mi casa (calle Lechugal $\mathrm{N}^{\mathrm{O}}$ 124), ha roto a palos el reverbero del zaguán de la casa, e intentaba ingresar (para saquear) al interior de ella..., (no ocurrió nada de esto, pues) ...mis hijos se apresuraron a cerrar las puertas interiores..." Una información posterior del mismo diario (EC, 30 de enero de 1855) indica que una vez que fue conocido el decreto (del 5 de diciembre) de Huancayo, los esclavos se sintieron en completo ejercicio de la libertad. Abandonaron las haciendas, las saquearon, se llevaron a Lima los frutos que había en los campos y en los almacenes. De su parte, la policía añadió lo suyo, pues en vez de reprimir a esa gente les daba un documento de seguridad en que les confirmaba el uso de su libertad. A pesar de las quejas de algunas personas, la policía resolvía todo a favor de los libertados. En sus casas los amos o patrones de improviso se vieron abandonados. "Los libertos y los hijos de éstos, menores de edad, fueron arrebatados de sus casas (las de los amos, HRP) por los padres o parientes (exesclavos en libertad, HRP) ...para llevarlos en su compañía".

Fuente: Discusiones y movilizaciones inmediatas luego de la Ley de libertad de los esclavos. Recopilación de Humberto "Tito" Rodríguez. Boletín de Cimarrones. http:/ / www.concytec.gob.pe/foroafroperuano/tito10.htm

(Nota 73) Cuadro: 2. Población negra en América entre 1860 y 1872. http:/ / www.arbil.org/(42)irab.htm 
(Nota 74) Fuente: Cronología: Esclavitud y trata del negro en América. Antología del Ensayo Hispánico - Emilio Cautelar.

http://www.ensayistas.org/antologia/XIXE/castelar/esclavitud/c-esclavitud.htm

(Nota 75) Cronología: Esclavitud y trata del negro en América. Antología del Ensayo Hispánico - Emilio Castelar.

http://www.ensayistas.org/antologia/XIXE/castelar/esclavitud/c-esclavitud.htm

(Nota 76) La misma fuente añade también que la esclavitud fue declarada ilegal en América Latina en un lapso de 85 años, siendo Haití el primer país donde fue abolida, siguiendo Chile (1823), la Federación Centroamericana (1824), Méjico (1829), las posesiones británicas y Canadá (1833), Uruguay (1846), las posesiones francesas del Caribe (1848), Colombia y Panamá (1850), Ecuador (1852), Argentina (1853), Venezuela (1854), Perú (1855), Bolivia (1861), Surinam y las posesiones holandesas del Caribe (1863), los Estados Unidos (1865), Paraguay (1870), Puerto Rico (1878) y Cuba (1886).

En el caso de Ecuador y Perú, el trabajo indica también que La abolición de la esclavitud en el Ecuador, lo mismo que en el Perú y en otras naciones andinas, llevó décadas para completarse después de la independencia. En el Ecuador y en el Perú comenzó en 1821 con declaraciones de abolición de los líderes independentistas, notablemente del general Simón Bolívar y de José de San Martín. Los afroperuanos y afroecuatorianos aprovecharon la guerra -de la misma manera en que lo harían los afroamericanos del sur de los Estados Unidos cuarenta años después- para avanzar la emancipación. Como Lincoln en la década de 1860, los generales San Martín y Bolívar hicieron un llamado a la abolición como una táctica militar. Los hombres negros se unieron a las filas de los movimientos independentistas para avanzar la emancipación general. 
Fuente: Abolicionismo en América: Hacia un Estudio Comparativo de Historia Mundial. Omar H. Ali, Ph.D. Departamento de Historia.

http://pages.towson.edu/oali/CASO.htm

(Nota 77) Referencia: Cronología: Esclavitud y trata del negro en América. Antología del Ensayo Hispánico - Emilio Castelar.

http://www.ensayistas.org/antologia/XIXE/castelar/esclavitud/c-esclavitud.htm

(Nota 78) Referencia: Cronología: Esclavitud y trata del negro en América. Antología del Ensayo Hispánico - Emilio Castelar.

http://www.ensayistas.org/antologia/XIXE/castelar/esclavitud/c-esclavitud.htm

(Nota 79) Referencia: Cronología: Esclavitud y trata del negro en América. Antología del Ensayo Hispánico - Emilio Castelar.

http:/ / www.ensayistas.org/antologia/XIXE/castelar/esclavitud/c-esclavitud.htm

(Nota 80) El portal China.org.cn, cuyas reseñas históricas no cuentan con el crédito de su autor, rememora estos luctuosos sucesos: En el plazo del contrato, los chinos no tenían libertad personal y sufrían la inhumana explotación de los finqueros. En una palabra, eran esclavos verdaderos, aunque no en nombre. De día trabajaban vigilados por los capataces y de noche dormían en galpones bajo candados. El historiador peruano Sagarra describió así la miserable situación de los trabajadores chinos: "Para el chino el inicio de un día nuevo significa solamente trabajo. Todo el día piensa que el trabajo no le hace ningún beneficio. El telón de la noche se aploma sobre sus pesadillas. Luego llega un día igual. Cuando enferma, no está su madre. Si muere no puede esperar que alguien rece por él, ni que las lágrimas de sus seres queridos mojen el ataúd". 
La mayoría de los chinos aguantaban mudos los ultrajes y el trabajo típico de los esclavos. Pero rebasada la paciencia por la opresión, ponían resistencia. La mayor insurrección de chinos ocurrió el 4 de septiembre de 1870. Ese día se levantaron en una finca, a $200 \mathrm{~km}$ al norte de Lima, y su acción cundió rápido a otras fincas. En total se sumaron al motín 1.200 trabajadores chinos. Indignados, dieron muerte al mayordomo y destruyeron la finca. En seguida aparecieron 300 policías, despachados de Lima, quienes reprimieron en pocas horas la así llamada "rebelión de los cariamarillos". No obstante, el levantamiento conmovió a todo el Perú.

Fuente: "Rebelión de los cariamarillos" por la opresión insoportable. Portal Chinos Residentes en Latinoamérica.

http://www.china.org.cn/xi-xinwen/ peru1-5.htm

(Nota 81) Referencia: Los chinos trabajaban como esclavos, excavando guano, construyendo ferrocarriles y cultivando caña de azúcar. Portal Chinos Residentes en Latino América.

http://www.china.org.cn/xi-xinwen/peru1-3.htm

(Nota 82) Compra de culíes chinos, comercio por "la ruta de la muerte". Portal Chinos Residentes en Latino América.

http://www.china.org.cn/xi-xinwen/ peru1-2.htm

(Nota 83) La misma fuente citada amplía detalles sobre dicho tratado en el artículo: "Amistad y comercio" en reemplazo del "comercio de trabajadores" de triste fama. Los principales contenidos del tratado son: Los chinos y los peruanos gozan de igual libertad de comercio, turismo, contrata de trabajadores y residencia en uno y el otro país; se prohíbe llevar de Macao y otros lugares a trabajadores chinos al Perú por medio de engaños; China y el Perú establecen consulados recíprocamente; los chinos 
en el Perú gozan de derechos de igualdad y beneficio mutuo y son protegidos por la ley; los peruanos residentes en China que violen la ley serán juzgados por funcionarios peruanos; y el Gobierno peruano abroga todo lo reglamentado injustificable contra los trabajadores chinos. Desde entonces, la situación de los trabajadores chinos en el Perú mejoró en cierto modo.

Referencia: Portal Chinos Residentes en Latino América.

http://www.china.org.cn/xi-xinwen/ peru1-6.htm

(Nota 84)

Figura 75

Perú - Censo General de 1876

Costa

Lima

15.404

Piura

5.380
Sierra

Selva

Cajamarca 1.051

Loreto

110

Junín

472

Amazonas 108
Arequipa $\quad 3.854$
Lambayeque 2.683
Callao $\quad 2.646$
Callao $\quad 2.646$
Libertad $\quad 2.467$
Cuzco
417
Huancayo 343
Ayacucho
311
Puno
224 
$\begin{array}{llll}\text { Ancash } & 2.453 & \text { Huancavelica } & 161 \\ & & & \\ \text { Tacna } & 1.299 & \text { Apurimac } & 96\end{array}$

Moquegua 621

Tarapacá 564

$\begin{array}{llll}\text { Total } & 37.371 & 3.075 & 218\end{array}$

Nota: Según el censo de aquel año, la República Peruana tenía un total de 2.699.945 habitantes. La población negra correspondía al 10\% de la población total, aproximadamente.

Fuente: Los Afroperuanos. Historia y situación actual. Centro de Desarrollo Étnico. (CEDET)

http:/ / afrolatino.org/forum/view topic.php?p=5611\&sid=47960a9f6b68d22df2d4b6e b57c44bb5

(Nota 85) Artículo 4. Nadie estará sometido a esclavitud ni a servidumbre, la esclavitud y la trata de esclavos están prohibidas en todas sus formas. Asimismo, los artículos $1^{\circ}, 2^{\circ}$ y $3^{\circ}$ de dicha declaración refuerzan esta posición unánime.

http://www.un.org/spanish/aboutun/hrights.htm

(Nota 86) Fuente: "Amistad y comercio" en reemplazo del "comercio de trabajadores" de triste fama. Portal Chinos Residentes en Latino América.

http://www.noticiaspyme.com/sec/sec.actu/noti_int.asp?idn=90605\&pon=1\&ids= 26 
(Nota 87) Este revelador informe titulado Niños de obras, escrito por Gastón Agurto, dice lo siguiente: Silba el viento y se forman pequeños remolinos de polvo y bolsas de golosinas sobre la cancha de fulbito del Asentamiento Humano Nueva Jerusalén, de 600 familias, en el distrito de Carabayllo. En cambio, se escuchan gritos, risotadas y tosidos infantiles en un botadero de basura vecino. i¿Qué hacen los niños en medio del basural, disputándose los desperdicios con las moscas y los perros sarnosos?!

Diariamente acuden a ese relleno sanitario clausurado hace dos décadas, un promedio de cuarenta niños entre 4 y 12 años. Son los hijos de los habitantes más pobres de la zona. Descalzos y con ropas sucias, excavan galerías, cual topos, en las que se internan a extraer todo tipo de desechos: desde aluminio y cobre (que venden a 4 soles el kilo) hasta vidrios y huesos (10 céntimos/kilo). ¿Huesos?, ¿para qué?, se le pregunta a Andrea, una recolectora de 12 años. "Los señores que lo compran lo utilizan para fabricar alimento para aves", dice, pero eso más bien parece mitología de basural. ¿Te molesta estar aquí? "En el colegio nadie sabe que hago esto, me daría vergüenza que se enteren. Los chicos del barrio, que sí saben, dicen que soy una cochina, que me gusta revolcarme en la basura".

En marzo del 2001 la ONG Proceso Social examinó a los 40 niños trabajadores del basural. El $60 \%$ de ellos presentaba enfermedades gastrointestinales, el $45 \%$ enfermedades respiratorias, el $55 \%$ enfermedades de la piel y el 4,5\% enfermedades oftalmológicas. Además de malnutrición, cortes con vidrios, jeringas, picaduras de insectos, mordeduras de perro, etcétera. El diagnóstico está dado; la cura aún no llega.

Es un hecho que en épocas de crisis el trabajo infantil, en el Perú, aumenta en cantidad y disminuye en calidad. Según la Encuesta Nacional de Niveles de Vida 1997, de los casi 10 millones de habitantes peruanos menores de 18 años, 1.932 .000 
entre 6 y 17 años pertenecen a la población económicamente activa. "El problema es que el $70 \%$ de niños y adolescentes que comparten el estudio con el trabajo, se atrasan o abandonan la escuela", señala Eliseo Cuadrao, coordinador de la Organización Internacional del Trabajo (OIT). "Además de dañar su presente, los niños también comprometen su futuro como ciudadanos, ya que, según la CEPAL, por cada dos años menos de educación, ellos perderán alrededor del $20 \%$ de los ingresos mensuales durante su vida adulta". El Convenio 138 de la OIT considera estas labores dentro de "las peores formas de trabajo infantil". Basta ver a los niños picapedreros de Carabayllo para entender que no se trata de ningún juego de niños.

Allí está Erlita, de 8 años, metiendo la cara en el humo del fuego que atiza para calentar y ablandar una roca más grande que ella. O Roy, de 6 años, blandiendo un pesado martillo de acero. Está encorvado sobre una piedra, pica que pica con el martillo, levantando un polvillo que afecta su vista. Sus brazos y sus piernas están llenos de cortes, magulladuras y quemaduras.

El padre de ambos niños, Marco Ramírez, viudo de 34 años, explica la dureza de su vida y la de sus hijos. "A uno de mis hijos le han pedido en el colegio el libro 'Coquito Integrado 2001', que cuesta treinta soles. Esa suma es lo que nos pagan por llenar de piedras la tolva de un volquete, cosa que nos demora de cuatro a cinco días". Entre comprar el libro o alimentar a sus hijos, obviamente Ramírez va a optar por lo segundo. ¿Y qué hace usted para mejorar esta situación? "Antes de dormir, por mis hijos, rezo para que una piedra no me caiga encima".

Los olvidados. Paralela a la "erradicación del trabajo infantil" promovida por la OIT, existe una segunda corriente que asegura ser más acorde con la realidad peruana. Para ésta, el trabajo infantil y adolescente "es una fuente de dignidad, formación y sustento" de economías familiares de supervivencia, que el Estado debe proteger y 
regular. En contraposición, Rocío Valencia de la Riva, especialista de la OIT, opina que, lejos de ser un paliativo, el empleo infantil es un reproductor de la pobreza. "Por trabajar, los niños se quedan sin educación y, por lo tanto, sin armas para ingresar en el mercado laboral adulto. Esos niños que no terminan el colegio, son los pobres del futuro".

Por ahora eso parece no preocupar a los comerciantes del terminal pesquero de Ventanilla, donde decenas de menores de 14 años cumplen jornadas de trabajo de cinco de la mañana a una de la tarde. Gerardo Cancino, de 11 años, trabaja seis horas diarias pelando almejas. Con un cuchillo abre la concha para sacar de su interior la carne, muy apreciada en el mercado. A diario pela un aproximado de medio millar de almejas. A cambio, su abuela le da cinco soles. La palma de sus manos presenta escoriaciones y hongos debido al constante contacto con el agua y con un líquido morado que despide el molusco como autodefensa. En 1990 el Perú ratificó la Convención Internacional sobre los Derechos del Niño, de la UNICEF, un texto hermoso y justiciero que se estrella brutalmente contra la realidad. Faltan ratificar dos convenios de la OIT. El Convenio 138 sobre la edad mínima legal para trabajar; que en el Perú es de 12 años, cuando el promedio en Sudamérica es de 14 y 15. Y el Convenio 182 sobre la prohibición de "las peores formas de trabajo infantil", que data de 1999, y que ni siquiera figura en la agenda del Congreso de la República.

Mientras tanto, niños como Francisco, de 10 años, seguirán robándole horas al estudio y al juego para trabajar seis horas diarias inmerso en las diez toneladas de hielo que carga el camión frigorífico de sus empleadores. O como José, también de 10 años, que trabaja para su padre en una estación informal de servicio mecánico y que, como él dice con orgullo e inocencia, "jatiende las 24 horas del día!" Es hora de que los niños dejen de cargar sobre sus hombros las responsabilidades de los adultos. Fuente: Revista Caretas. Edición \# 1668 (3/5/2001)Fuente: Revista Caretas. Edición \# 
1668

$(3$

de

mayo

de

2001)

http://www.caretas.com.pe/2001/1668/articulos/ninos.phtml

(Nota 88) Monstruo de mil cabezas: esclavitud. Especiales BBC Mundo.

http://www.bbc.co.uk/spanish/especiales/monstruo/7.stm

(Nota 89) Cifras de la esclavitud. BBC MUNDO

http://news.bbc.co.uk/hi/spanish/news/newsid_1525000/1525099.st()m

(Nota 90) Algunos datos sobre la esclavitud infantil (ADITAL)

http://www.adital.com.br/site/noticia.asp?lang=ES\&cod=6653

(Nota 91) Latinoamérica tiene más de 1 millón de esclavos.

Prensa Libre. Internacional.

http://www.prensalibre.com/pl/2006/marzo/11/136608.html

(Nota 92) Ya no zarpan los barcos de África con esclavos... BBC Mundo.

http://news.bbc.co.uk/hi/spanish/international/newsid_4066000/4066337.stm

(Nota 93) Fuente: Los Afroperuanos. Historia y situación actual. Centro de Desarrollo Étnico. (CEDET)

http:/ / afrolatino.org/forum/viewtopic.php?p=5611\&sid=47960a9f6b68d22df2d4b6e b57c44bb5 
Figura 76. Infografía de la esclavitud negra y china en el Perú.

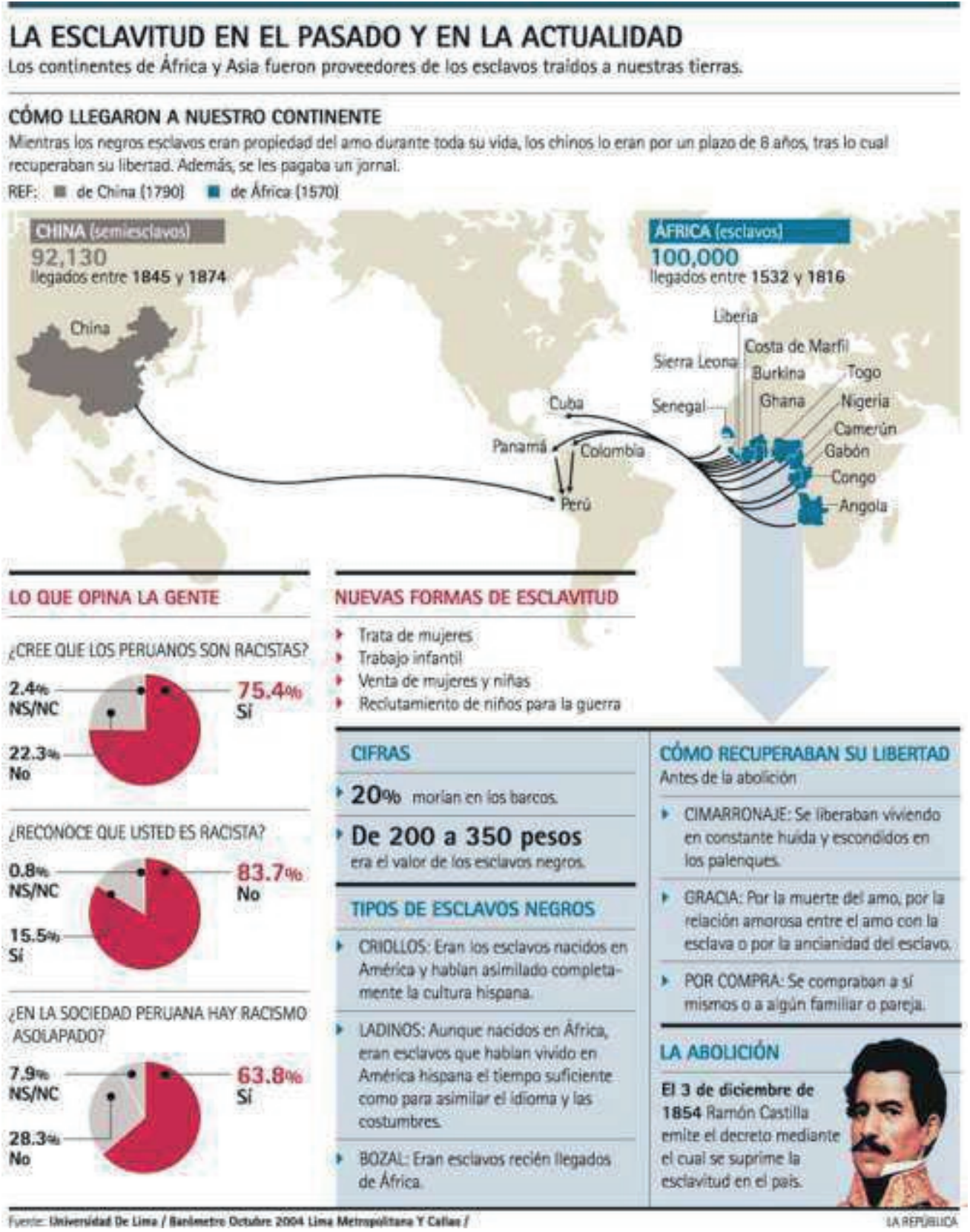

Fuente: Universidad de Lima - Diario La República. Octubre de 2004.

(Nota 94) Brasil: "25.000 esclavos" BBC Mundo.

http://news.bbc.co.uk/hi/spanish/latin_america/newsid_3909000/3909969.stm 
(Nota 95) PERÚ: Dos millones de niños esclavizados. (ADITAL) http://www.solidaridad.net/articulo3401_enesp.htm

(Nota 96) Para complicar el panorama, UNICEF informó también que cerca de 70\% (171 millones) de los niños y niñas trabajan en condiciones peligrosas, que incluyen la minería, labores agrícolas con productos sometidos a químicos y pesticidas o el manejo de maquinaria peligrosa. Estos niños y niñas se encuentran en todas partes, pero son invisibles; trabajan como sirvientes domésticos en casas, están ocultos tras las paredes de talleres o se encuentran fuera de la vista del público en plantaciones.

Datos del UNICEF exponen que millones de niños y niñas trabajan bajo circunstancias terribles. Pueden ser víctimas de la trata (1,2 millones), víctimas de la servidumbre por deuda u otras formas de esclavitud (5,7 millones), víctimas de la prostitución y/o la pornografía (1,8 millones) o reclutados como niños soldados en los conflictos armados (300.000).

Para erradicar la esclavitud infantil, la organización UNICEF recomienda a los países: construir un entorno protector para la infancia; asegurar que todos los niños y las niñas tengan acceso a una educación obligatoria; cambiar las actitudes y las prácticas; poner en práctica leyes que prohíban el trabajo infantil; calcular cuantos niños están sometidos; retirar a los niños de las formas más graves de trabajo infantil; tener en cuenta los puntos de vista de los niños y niñas y aumentar la asistencia que asignan a los servicios sociales básicos.

Fuente: PERU: Dos millones de niños esclavizados. Sixto Eleuteria. (ADITAL) http://www.solidaridad.net/noticias.php?not=3401 
(Nota 97) Fuente: Perú: el madereo ilegal, fuente del trabajo forzado en la Amazonía. Boletín \# 39 de WRM.

http://www.wrm.org.uy/boletin/99/Peru.html

(Nota 98) Trata de mujeres: Esclavitud en el siglo XXI.

http:/ / www.cimacnoticias.com/noticias/06mar/06032901.html

(Nota 99) Cuadro: Definiciones de trabajo forzado según la OIT y países donde se ha reportado que la práctica de la esclavitud todavía existe.

http:/ / www.hrea.net/learn/guides/ esclavitud.html

(Nota 100) Fragmento La Esclavitud del Siglo XXI, de un editorial del portal católico Mensajero de San Antonio.

http://www.mensajerodesanantonio.com/messaggero/pagina_articolo.asp?IDX=77 IDRX $=36$

(Nota 101) Versos extraídos de las referencias literarias sobre la Esclavitud y Nicolás Guillén. Enciclopedia Universal en español.

http://enciclopedia.us.es/index.php/Esclavitud

\section{Origen de las ilustraciones}

(Advertencia al amable lector: Los hipervínculos que siguen a continuación estaban operativos en la fecha de cierre de este trabajo: 1 de octubre de 2006)

40. (a y b) Dos litografías de diversas etnias de esclavos negros en Brasil, tomadas por el viajero francés Jean-Baptiste Dubret...

http://www.si.umich.edu/CHICO/Schomburg/text/who2.html 
41. Vendedora ambulante negra en el primer tercio del siglo XIX.

http://www.educared.edu.pe/estudiantes/historia6/fenomeno2.htm\#

42. Las islas Chincha. Vikipedia.

http://es.wikipedia.org/wiki/Guano

43. En la tierra de las montañas de estiércol. Portal Antehistoria.com.

http://www.artehistoria.com/frames.htm

http://www.artehistoria.com/historia/obras/12455.htm

44. La vida a golpes.

http://www.andrew.cmu.edu/course/79-104/Readings/Gallery/4.html

45. Esclavo sobre un burro... Early Cities of the America.

http:/ / www.common-place.org/vol-03/no-04/lima/

46. Don Ramón Castilla y Marquesado.

http:/ / www.educared.edu.pe/estudiantes/historia6/ prosperidad3.htm\#

47. Cuadro: 2. Población negra en América entre 1860 y 1872

http:/ / www.arbil.org/ (42)irab.htm

48a. (lado a) Modelo de contrato suscrito en Macao...

http:/ / www.rree.gob.pe/portal/archivos.nsf/ce380461d66f6d0205256d490080f2ae/ b595d874787149e60525717000579d1f?OpenDocument

48b. (lado b) El mismo documento en su versión en chino.

http://www.rree.gob.pe/portal/archivos.nsf/ce380461d66f6d0205256d490080f2ae/ 
b595d874787149e60525717000579d1f?OpenDocument

49. Trabajador chino coolie en una plantación de caña de azúcar. Chicamita, Perú. http:// www.skidmore.edu/ jdym/hi228/

50. Inmigrantes chinos cortando caña.

http:/ / www.rree.gob.pe/portal/archivos.nsf/ce380461d66f6d0205256d490080f2ae/ b595d874787149e60525717000579d1f?OpenDocument

51. Mapa de Lima y Callao en 1888.

http://es.wikipedia.org/wiki/Lima

52. Malcolm X. Vikipedia, la enciclopedia Libre.

http://es.wikipedia.org/wiki/Esclavitud

53. Martin Luther King.

http://es.wikipedia.org/wiki/Martin_Luther_King\#.C2.BFC.C3.B3mo_muri.C3.B3.3 $\mathrm{F}$

54 (a y b) Niños de obras. Revista Caretas \# 1668, 3 de mayo de 2001

http://www.caretas.com.pe/2001/1668/articulos/ninos.phtml

54 (c y d) Niños de obras. Revista Caretas \# 1668, 3 de mayo de 2001

http://www.caretas.com.pe/2001/1668/articulos/ninos.phtml

55. Cuadro. Cifras de la esclavitud.

http://news.bbc.co.uk/hi/spanish/news/newsid_1525000/1525099.stm 
56. La esclavitud permanece camuflada. BBC Mundo.

http://news.bbc.co.uk/hi/spanish/international/newsid_4066000/4066337.stm

57. Perú Negro pa' todo el mundo. Danza peruana en Toronto.

http://www.thelivemusicreport.com/dance/royThomson/peruNegro.html

58. "Brasil: 25.000 esclavos". BBC MUNDO.

http://news.bbc.co.uk/hi/spanish/latin_america/newsid_3909000/3909969.stm

59. Las ocho modalidades actuales del trabajo según la OIT.

http://www.hrea.net/learn/guides/esclavitud.html

(Figuras correlativas -60 a 71b- en la primera parte)

Siguen...

72. Litografía de Jean Baptiste Debret en su obra Voyage Pittoresque et Historique au Brasil.

http://slavery2003.tripod.com/fromafricatoslavery/id6.html

73. Abolición de la esclavitud. Texto de la placa conmemorativa de la plaza Constitución de Huancayo. 3 de diciembre de 1854.

http://www.concytec.gob.pe/foroafroperuano/placa_castilla.htm

74. Decreto de la abolición de la esclavitud. Norma del 3 de enero de 1855.

http://www.concytec.gob.pe/foroafroperuano/decreto2.htm

75. Perú - Censo General de 1876. 
http:/ / afrolatino.org/forum/viewtopic.php?p=5611\&sid=47960a9f6b68d22df2d4b6e b57c44bb5

76. Cuadro. Infografía de la esclavitud negra y china en el Perú. http://www.larepublica.com.pe/news/images/EP_2004111_20061_L.gif

77. Cuadro. Epílogo. Consecuencias del tráfico (de esclavos) para África. Historia / Canarias / Navegación.

http://www.mgar.net/var/por_escl.htm 